STONE CENTER ON SOCIO-ECONOMIC INEQUALITY

WORKING PAPER SERIES

No. 29

The Geography of Intergenerational Mobility

in Latin America and the Caribbean

Ercio Muñoz

March 2021

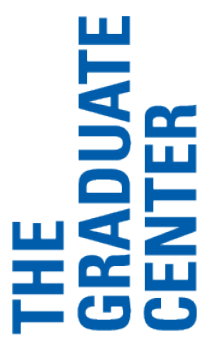

CITY UNIVERSITY

OF NEW YORK 


\title{
The Geography of Intergenerational Mobility in Latin America and the Caribbean*
}

\author{
Ercio Muñoz \\ The Graduate Center, CUNY
}

This draft: March 2021

\begin{abstract}
In this paper, I estimate intergenerational mobility (IGM) in education using crosssectional data from 91 censuses that span 24 countries in Latin America and the Caribbean (LAC) over half a century. I measure upward mobility as the likelihood of obtaining at least a primary education for individuals whose parents did not finish primary school, whereas downward mobility as the likelihood of failing to complete primary education for individuals whose parents completed at least primary school. In addition, I explore the geography of educational IGM using nearly 400 "provinces" (coarse administrative units similar to states in the U.S.) and more than 6,000 "districts" (fine administrative units similar to counties in the U.S.). I document wide cross-country and within-country heterogeneity. In LAC, the distance between the most and least upwardly mobile country is close to what has been recently documented in Africa, although the least mobile countries in Africa are less mobile than the least mobile in LAC. I document a declining trend in the mobility gap between urban and rural populations, but I do not find important differences by gender. Within countries, the level of mobility is highly correlated to the share of primary completion of the previous generation, which suggests a high level of inertia. In addition, upward (downward) mobility is negatively (positively) correlated to distance to the capital and the share of employment in agriculture, but positively (negatively) correlated to the share of employment in industry.
\end{abstract}

JEL-Codes: D63, I24, J62.

Keywords: Socioeconomic mobility, Education, Latin America and the Caribbean.

*I thank Bennett Callaghan, Miles Corak, Marco Ranaldi, Nuria Rodriguez-Planas, Roy van der Weide, and Wim Vijverberg, and several seminar/conference participants for helpful comments; Pablo Vargas and Joaquin Prieto provided outstanding research assistance. The usual caveats apply. First version: November 2020 .

${ }^{\dagger}$ Email: emunozsaavedra@gc.cuny.edu. 


\section{Introduction}

Intergenerational mobility (IGM) has gained interest in the economic literature among other things thanks to its importance for equity, social cohesion, and economic growth. Its observed correlation with income inequality, commonly named "the Great Gatsby Curve", has contributed to the desire for understanding IGM given the documented rise of inequality over the last decades in rich countries (see Corak, 2013).

In the case of the developing economies, the Latin America and the Caribbean (LAC) is of particular interest because of its historically documented high levels of income inequality relative to other regions of the world. ${ }^{1}$ However, the scarcity of high-quality data (e.g. long panel data sets or tax records with linked generations) has limited the study of IGM in income. These constraints are also common in other regions, so the efforts to document IGM on a global scale has taken an alternative path given by the measurement of mobility in education. These measures are of interest in and of themselves, but they are also a proxy for economic status given the close relationship between education and income.

Recent studies have used household and public opinion surveys with retrospective information about parents' education to document the levels of intergenerational mobility in education in LAC countries. They have found that the intergenerational persistence of education is high (in other words, IGM is low) relative to other regions of the world (for an example, see Hertz et al., 2007; Narayan et al., 2018; Neidhöfer, Serrano, \& Gasparini, 2018).

Previous literature has focused on country-level analysis, however, analyzing IGM at a more geographically disaggregated level, as argued in Narayan et al. (2018), is valuable because it can help researchers understand the importance of localized patterns and drivers of IGM, as shown for the case of developed countries. Along these lines, Chetty, Hendren, Kline, and Saez (2014) state that the United States can be better described as a collection of societies, some of which are "lands of opportunity" with high rates of mobility across generations, and others in which only a few children escape poverty. Thus far, this type

\footnotetext{
${ }^{1}$ See for example Messina and Silva (2019) for an analysis of wage inequality over the last two decades.
} 
of analysis has not been conducted in LAC countries as a whole due to the inadequacy of most survey data for this purpose. This paper fills that gap in the literature by generating estimates of IGM in education at smaller geographical levels.

In this paper, I estimate intergenerational mobility in education for LAC countries at a disaggregated regional level using data from 91 censuses. The analysis covers 24 countries spanning more than half a century (between 1960 and 2012). I rely on samples of co-residents (i.e., children living with their parents or older relatives). To minimize the impact of coresidence, I investigate mobility in education at the bottom of the educational attainment distribution by focusing on primary education, which can be measured with a high degree of confidence between ages 14 and 18. Furthermore, an important share of the population does not attain more than primary education in the period analyzed.

The estimates of upward (and downward) mobility measured as the likelihood of finishing (or failing to finish) primary education, conditional on having parents who failed to finish (or who were able to finish) primary school, show wide cross-country and within-country heterogeneity. In LAC, the distance between the most and least upwardly mobile country is similar to what has been recently documented in Africa, although the least mobile countries in Africa are less mobile than the least mobile country in LAC. I do not find significant differences by gender, but I do document a declining trend in the mobility gap between urban and rural populations. At the sub-national level, there is heterogeneity in mobility across districts/provinces, and some countries show lower levels of mobility in the northern regions (e.g., Brazil), whereas the opposite is true for Mexico. However, the variability is much lower in countries with lower number of regions and less population. The level of mobility at the sub-national level is highly positively correlated to the share of primary completion of the previous generation, which suggests a high level of inertia. In addition, geographical correlates do not appear to be highly correlated to mobility except for distance to the capital. Similarly, some proxies of economic development like the share of employment in industry and agriculture at the beginning of the sample period seem to be associated to 
the levels of mobility at the district-level.

This paper is related to two strands of the economic literature. First, it adds to the literature about intergenerational mobility in general (see Black \& Devereux, 2011, for a suvey) but specifically to the literature focusing on the geography of socioeconomic mobility that recently received more attention in part because of the work of Chetty et al. (2014), which shows important variation across commuting zones in the US. Furthermore, it adds to the recent wave of research that looks at intergenerational mobility in education (see Torche, 2019, for a survey). This set of papers include on one hand those that use household survey data. For example, Hertz et al. (2007), Narayan et al. (2018), and Van der Weide, Lakner, Gerszon Mahler, Narayan, and Ramasubbaiah (2021) that document IGM for a very large set of countries, and Neidhöfer et al. (2018) that focus only on Latin America. On the other hand and more closely related to this paper, there are recent studies that use administrative data or census data. For instance, Asher, Novosad, and Rafkin (2018) study mobility among different marginalized groups and analyzes geographic differences in India; Card, Domnisoru, and Taylor (2018) use 1940 census data to study the role of school quality in mediating upward mobility in the US; Van der Weide, Ferreira de Souza, and Barbosa (2020) study mobility at sub-national level in Brazil; and most closely related to this paper, Alesina, Hohmann, Michalopoulos, and Papaioannou (2021) document patterns of IGM in Africa using census data and estimate whether regions have a causal effect on mobility.

Second, this paper is also related at the conceptual level to the theoretical literature about the intergenerational transmission of socioeconomic status. Seminal papers in this area of focus include Becker and Tomes (1979), Becker and Tomes (1986), Loury (1981); and, more recently, they also include contributions from Solon (2004), Solon (2014), and Becker (2018).

The paper is organized as follows. Section II describes data and methodology. Section III reports the main descriptive results at country level and the geography of mobility. Section IV looks at correlates of intergenerational mobility. Finally, section V concludes with final 
remarks.

\section{Data and Methodology}

Three sources of data have been typically used to estimate intergenerational mobility. 1) cross-sectional samples of adult populations with retrospective questions about parental education. For example, Narayan et al. (2018) use household survey data that covers the $96 \%$ of the world population; 2) panel data long enough in its time dimension to include the socioeconomic or educational attainment of two generations. For example, Celhay, Sanhueza, and Zubizarreta (2010) use the Chilean CASEN to estimate mobility in schooling and income; and 3) administrative/registry data with linked information for parents and adult children. For example, Chetty et al. (2014) use tax records in the U.S. to estimate income mobility.

In the case of Latin America, most of the literature has used household survey data or public opinion surveys (see for example, Hertz et al., 2007; Narayan et al., 2018; Neidhöfer et al., 2018). Long panel data as well as administrative/registry data that allow the researcher to link generations are rare.

In this paper, I use census data obtained from IPUMS International (Integrated Public Use Microdata Series, IPUMS, 2019), hosted at the University of Minnesota Population Center, which reports harmonized representative samples (typically 10\%) of full census micro data sets for a large number of countries. In particular, I use 91 samples of population and housing censuses, which are run to compute the total population and contain an educational attainment question in their questionnaire. ${ }^{2}$ The key advantage of this data set is that it contains the entire population (or at least a large share of it publicly available) at a point in time, allowing me to analyze mobility at a very dis-aggregated geographical level. However, the main disadvantage of this data is that does not link all the individuals with their parents, so I need to rely on samples of co-residents as it is explained below.

\footnotetext{
${ }^{2}$ Because the individuals are not organized into households, I do not use Chile 1960, Colombia 1964, Costa Rica 1963, Dominican Republic 1960 and 1970, Ecuador 1962, Honduras 1961 and Mexico 1960. I also omit the 1995, 2005 and 2015 inter decennial Census counts of Mexico.
} 
Figure 1: Coverage over time

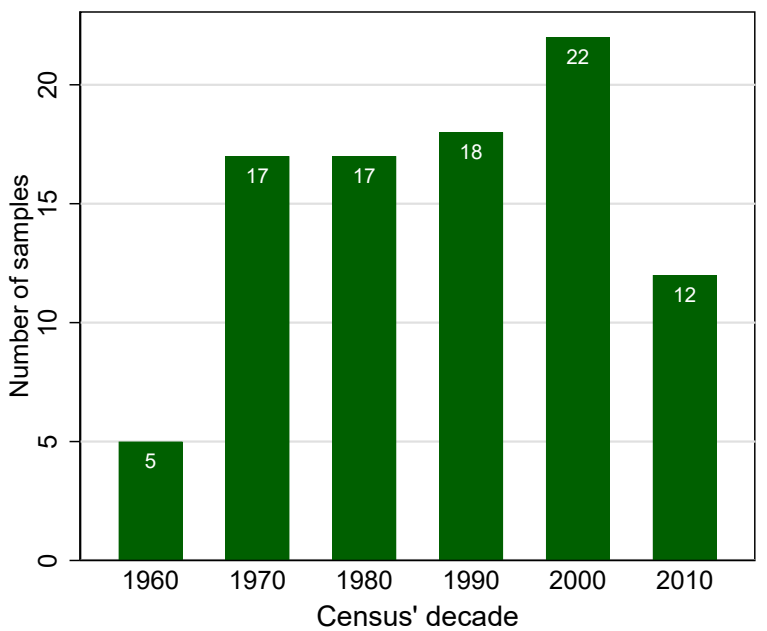

(a) Number of samples by decade

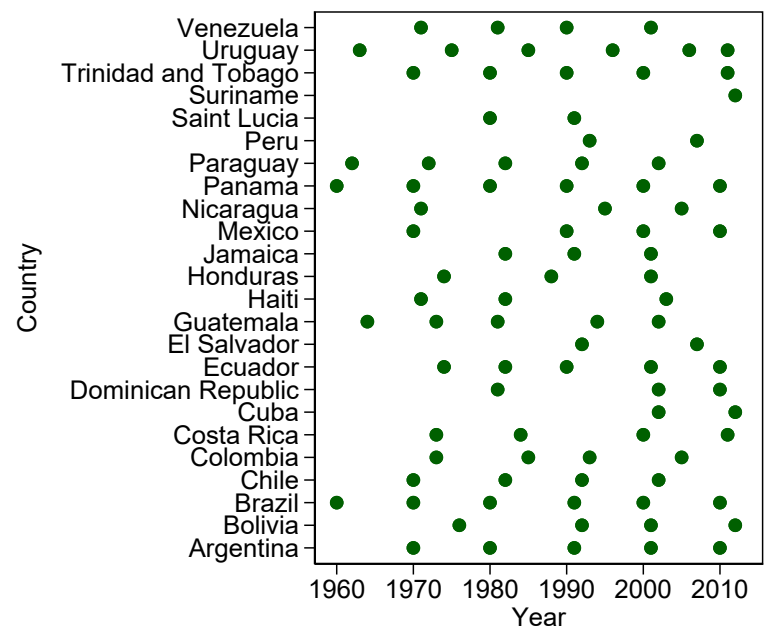

(b) Samples by country

\section{Countries and smaller administrative units}

I use individual records, retrieved from 91 national censuses from 24 countries: Argentina, Bolivia, Brazil, Chile, Colombia, Costa Rica, Cuba, Dominican Republic, Ecuador, El Salvador, Guatemala, Haiti, Honduras, Jamaica, Trinidad and Tobago, Mexico, Nicaragua, Panama, Paraguay, Peru, Uruguay, Saint Lucia, Suriname, and Venezuela (see Table A1 in the Appendix for the details about the fraction of the data available by census).

These 91 samples span approximately half a century going from 1960 to 2012 in an unbalanced fashion. Figure 1a shows the number of samples by decade, highlighting that they are concentrated between the 1970s and 2000s. Figure 1b shows the coverage by country and year highlighting some heterogeneity in coverage. In terms of frequency and time span, there are countries such as Brazil, Panama, and Uruguay with the highest availability of data (i.e. roughly one census per decade between 1960 and 2010). On the other extreme, Suriname has only one Census in 2012 while Cuba, El Salvador, Peru, and Saint Lucia have only two censuses in different decades.

In terms of geography, IPUMS reports residence at the time of the interview for at most 
two levels of administrative units in which the households were enumerated. These variables contain the geographies for every country harmonized spatio-temporally to provide spatially consistent boundaries across samples in each country. This allows me to assign individuals to "coarse" (roughly similar to states in the U.S.) and "fine" administrative units (roughly similar to counties in the U.S.). The sample spans 400 provinces (admin-1 units) and 6,684 districts (admin-2 units). The baseline estimates will make use of the former to avoid issues derived from having a reduced number of observations per administrative unit but estimates using the latter are also reported in the Appendix.

\section{Linking generations and coresidence}

The data collection is organized at the household level, so it is only possible to link individuals who live in the same household at the time of the interview. The data set includes a variable that by means of 62 different values details the relationship between the individual and the head of the household. Based on this variable, I classify individuals into five different generations where the head corresponds to generation zero (see Table 1), and based on the generation number I use individuals who live with at least one member of the immediately previous generation, where these old generation members are considered as "pseudo-parents". 3 Table 1 provides the details of the assignment.

Figure 2 shows the unweighted average rate of co-residence by age in the sample pooling all the countries and years. There are rates above $90 \%$ for individuals before reaching 18 years old that then start decreasing more rapidly getting close to $40 \%$ for people who are 25 years old. When the coresidence rate is computed with samples that distinguish urban/rural or gender, I find negligible differences in the former and a steeper fall in the rate of coresidence by age for women relative to men (see Figure A1 in the Appendix).

Figure 3 disaggregates the coresidence rate by country displaying some variability in the

\footnotetext{
${ }^{3}$ I closely follow Alesina et al. (2021) that uses a similar method to assign individuals with Census data for Africa.
} 
Table 1: Relationship to household head and identification of different generations

\begin{tabular}{llll}
\hline \hline Relationship to the head & Generation & Relationship to the head & Generation \\
\hline Grandparent & -2 & Sibling of sibling-in-law & 0 \\
Great grandparent & -2 & Ex-spouse & 0 \\
Parent/parent-in-law & -1 & Child & 1 \\
Parent & -1 & Biological child & 1 \\
Stepparent & -1 & Adopted child & 1 \\
Parent-in-law & -1 & Stepchild & 1 \\
Aunt/uncle & -1 & Child-in-law & 1 \\
Head & 0 & Spouse/partner of child & 1 \\
Spouse/partner & 0 & Unmarried partner of child & 1 \\
Spouse & 0 & Nephew/niece & 1 \\
Unmarried partner & 0 & Foster child & 1 \\
Same-sex spouse/partner & 0 & Tutored/foster child & 1 \\
Sibling/sibling-in-law & 0 & Tutored child & 1 \\
Sibling & 0 & Grandchild & 2 \\
Stepsibling & 0 & Grandchild or great grandchild & 2 \\
Sibling-in-law & 0 & Great grandchild & 2 \\
Cousin & 0 & Great-great grandchild & 2 \\
\hline
\end{tabular}

Categories not classified are: Other relative, not elsewhere classified; other relative with different family name; non-relative; friend; housemate/roommate; visitor; godparent; godchild; domestic employee; relative of employee; spouse of servant; child of servant; other relative of servant; roomer/boarder/lodger/foster child; boarder; boarder or guest; lodger; employee, boarder or guest; other specified non-relative; agregado; temporary resident, guest; group quarters; group quarters, non-inmates; institutional inmates; non-relative, n.e.c.; other relative or non-relative; unknown.

magnitude of the fall of it with age. This figure also suggest that the fall in coresidence around age 25 is driven by Brazil, which is the most populated country in Latin America. Table A3 in the Appendix provides co-residence rates by country for different age groups.

\section{Education}

Why is education a suitable variable by which to measure IGM? Education as a measure of socioeconomic status relative to income in the context of developing countries has three key advantages: 1) it contains less measurement error, reducing potential attenuation bias (see Solon, 1992); 2) it is fixed early in the life cycle, which avoids the life-cycle bias found in studies that use income (see Haider \& Solon, 2006). In addition, education is closely linked to income and it is important by itself in terms of human development; 3) it can 
Figure 2: Coresidence rate by age

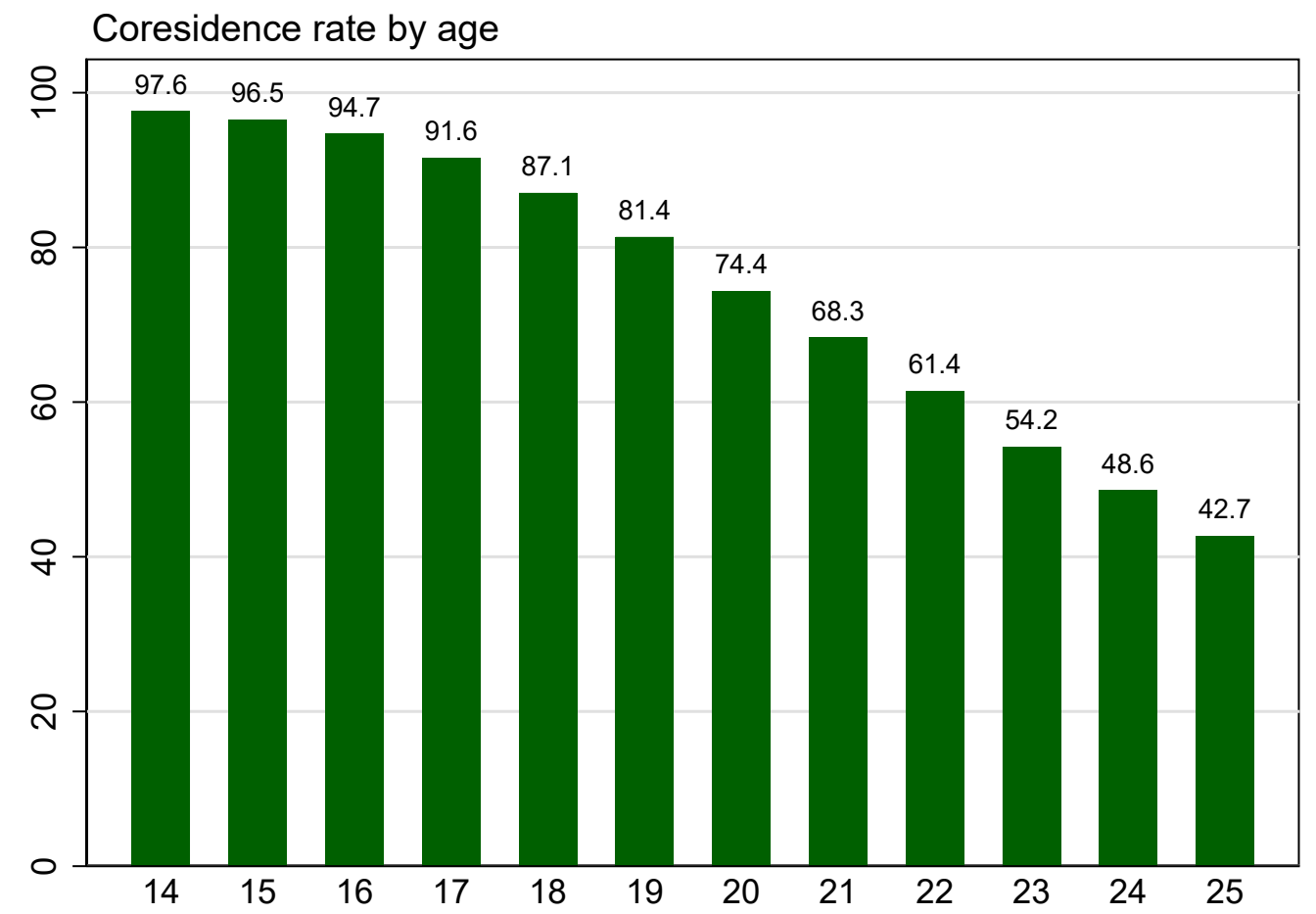

Notes: Coresidence is defined as living with at least one relative of the immediately previous generation. The data in the graph is unweighted.

be completely attributed to a specific individual, while income sometimes is hard to assign within a household (e.g., a household with multiple persons and home production, which may be specially relevant in the case of rural populations in poor countries).

There are two questions about educational attainment in the data set. The first one reports the total years of schooling completed by each individual (formal schooling regardless of the track or kind of study), and the second one is re-coded by IPUMS to capture educational attainment in terms of the level of schooling completed ${ }^{4}$ and contains four categories: 1) Less than primary completed, 2) primary completed, 3) secondary completed, 4) university completed. In the main analysis of the paper I use the latter variable, which has a lower number of missing values and it is available for more countries than the former. ${ }^{5}$ This

\footnotetext{
${ }^{4}$ It does not necessarily reflect any particular country's definition of the various levels of schooling in terms of terminology or number of years of schooling.

${ }^{5}$ Years of schooling is not available for Brazil 2010, Cuba 2002, Saint Lucia 1991, Suriname 2012, Trinidad and Tobago 1970, and Uruguay 2011.
} 
Figure 3: Coresidence rate by age and country

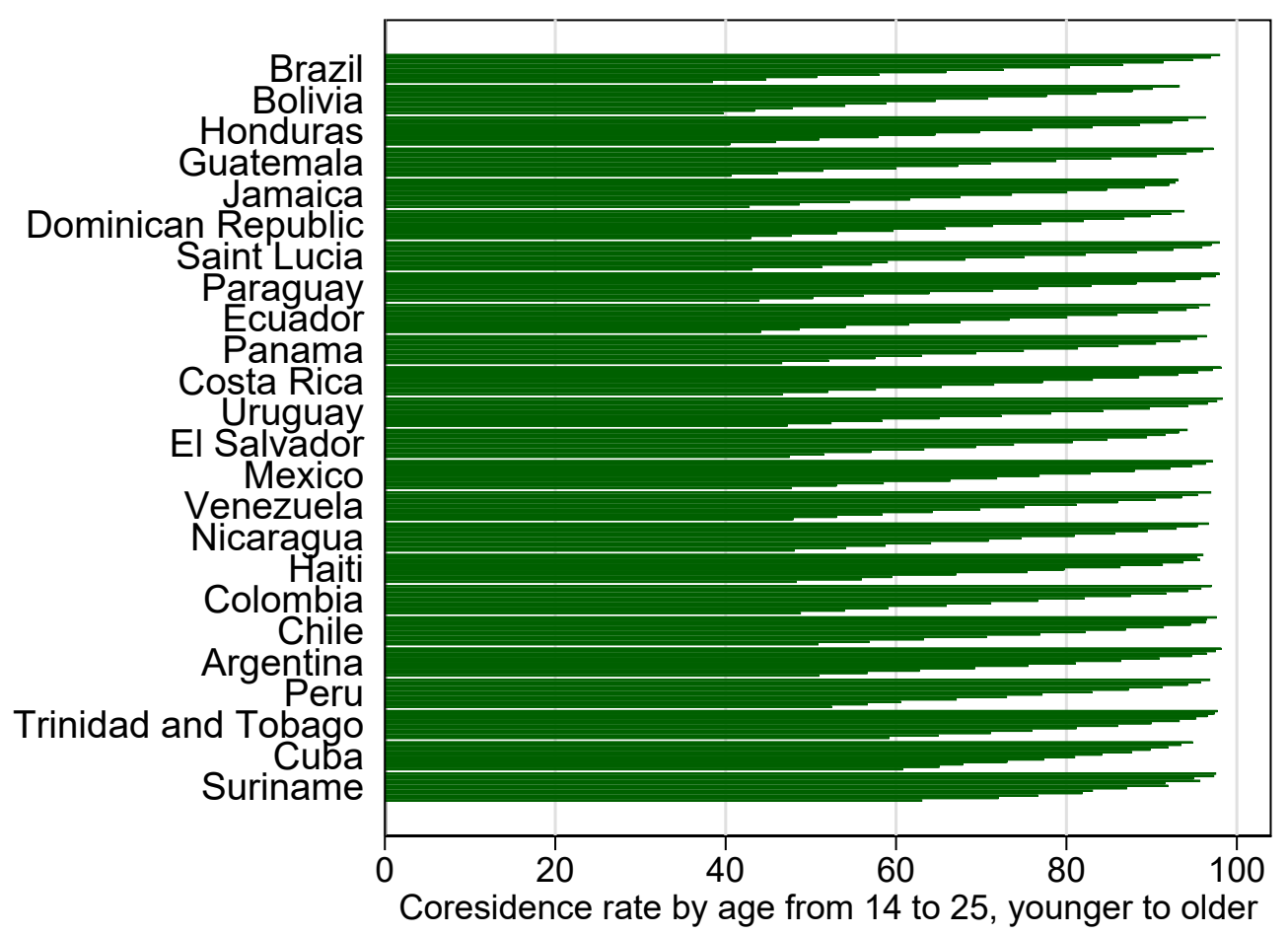

Notes: Coresidence is defined as living with at least one relative of the immediately previous generation. The data in the graph is unweighted.

variable applies, to the extent possible, the United Nations standard of six years of primary schooling, three years of lower secondary schooling, and three years of higher secondary schooling.

In the sample, a majority of individuals show levels of education that correspond to less than completed secondary (see Figure 4a), which supports the focus on primary completion that I will detail later as most of the action happens at lower levels of completion. In addition, although the level of education in Latin America and the Caribbean has been increasing across cohorts (see Figure 4b), the continent still shows a share of around sixty percent with at most nine years of schooling in the most recent cohort (those born in the 1980s), which roughly corresponds to the completion of lower secondary education.

Figure 5 shows the transition matrix for individuals older than 25 to get a rough idea of the patterns of intergenerational education mobility present in the data set. This plot 
Figure 4: Educational Attainment

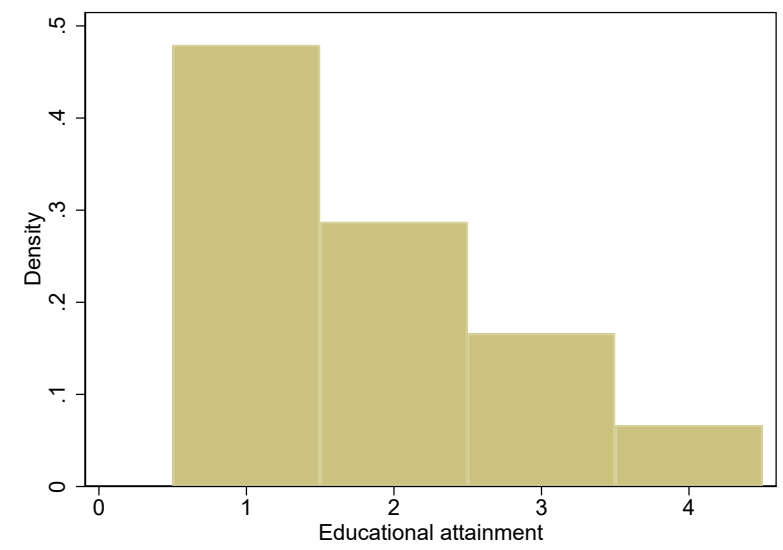

(a) Histogram of attainment

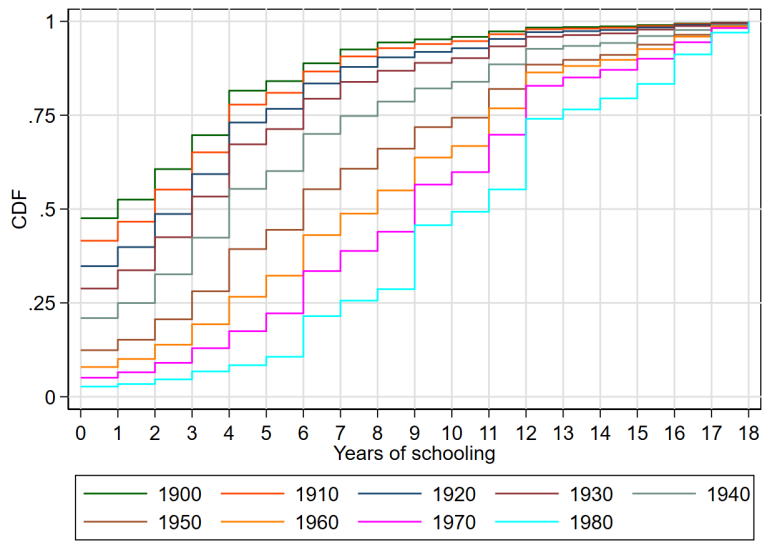

(b) CDF of years of schooling

Notes: The graphs use different samples as years of schooling is not available in six country-year samples. The graph includes only individuals older than 25 from decade cohorts 1900 to 1980.

highlights that the action is terms of mobility happens in the lower two levels of educational attainment, qualitatively similar to what can be seen in Alesina et al. (2021) for the African continent. The same mosaic plot can be found by country in the Appendix. Two countries that stand out in terms of low and high levels of parental attainment of primary education are Jamaica and Guatemala ${ }^{6}$ (see Figure 6).

\section{Methodology}

For each individual in the sample, I analyze the relationship between its own educational attainment against the average attainment of individuals one generation older living in the same household, rounded to the nearest integer. For this I consider a measure of absolute intergenerational mobility that reflects the likelihood that a children complete a strictly higher or lower education level than the members of the immediately previous generation in the household (parents and/or extended family members, such as aunts and uncles).

Upward mobility at the country level. To estimate upward IGM, I estimate the

\footnotetext{
${ }^{6}$ Saint Lucia shows similar patterns but contains a much smaller population.
} 
Figure 5: Educational Attainment Transition Matrix

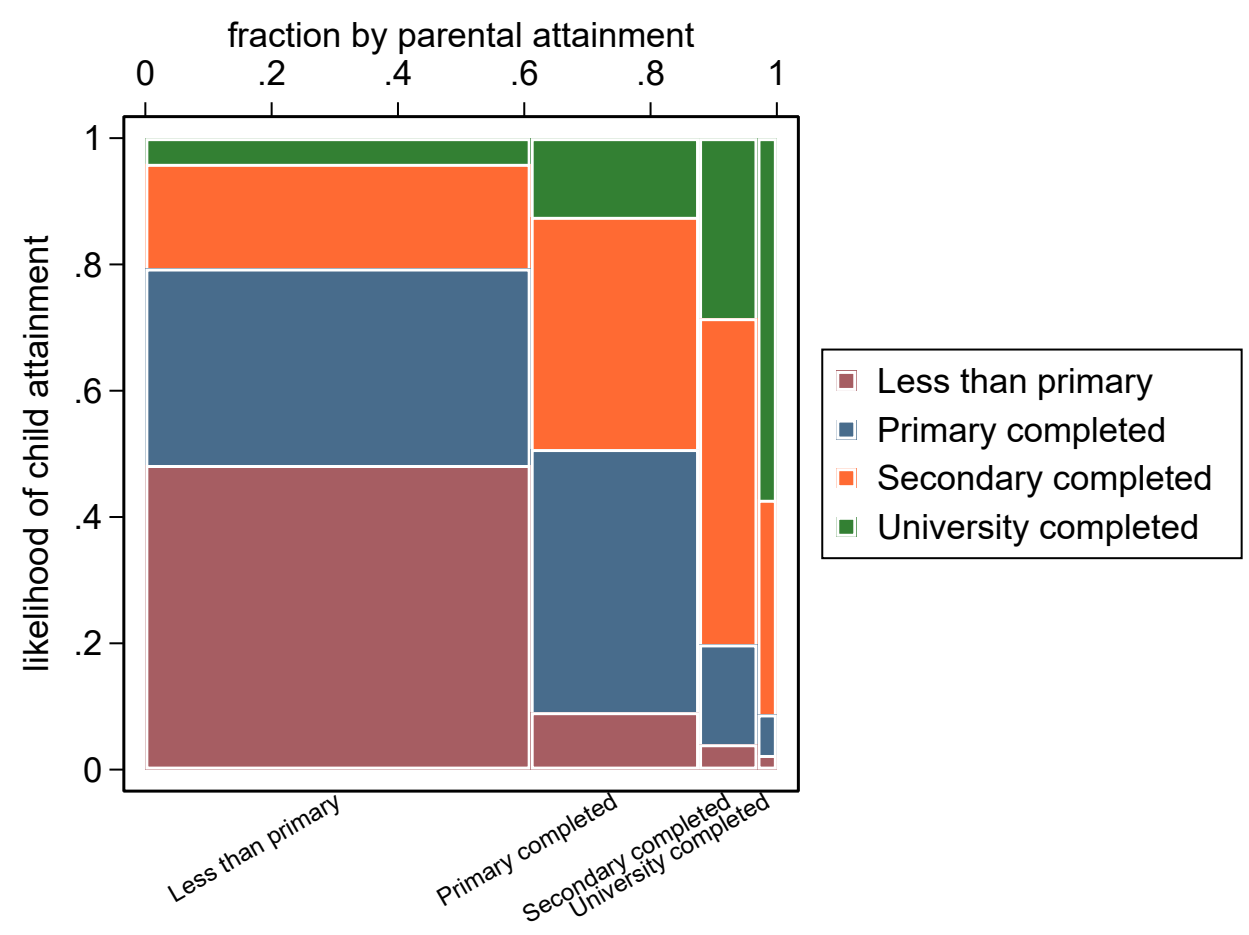

Notes: The sample is constructed with individuals older than 25 .

following econometric specification, pooling observations from all the censuses and countries:

$$
y_{i c o y t}^{u p}=\alpha_{c}^{u p}+\gamma_{o}^{b}+\gamma_{y}^{b}+\theta_{t}+\epsilon_{i c o y t}
$$

where $y_{i c o y t}^{u p}$ is a dummy variable that takes a value equal to one when individual $i$ completes at least primary education and zero otherwise. The parameters $\gamma_{o}^{b}, \gamma_{y}^{b}, \theta_{t}$ refer respectively to fixed effects by decade-cohort of the individual $i$, decade-cohort of the generation above that co-resides with individual $i$, and census year. This regression uses a sample of individuals with ages between 14 and 18 (or 14 to 25), for whom the generation above (parents or older relatives) have on average less than primary education. Hence, $\alpha_{c}^{u p}$ is the parameter of interest and measures the likelihood of completing primary for children whose "parents" did not complete primary net of cohort and census year effects.

This empirical approach has been used in Alesina et al. (2021) with data from Africa and 
Figure 6: Transition matrix for selected countries

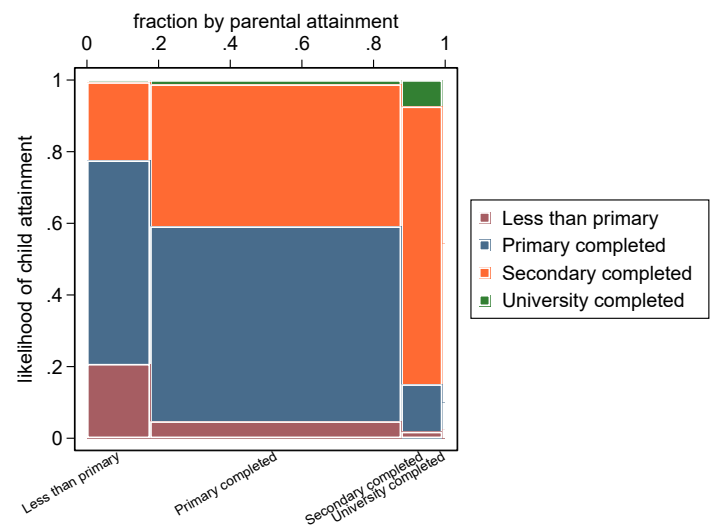

(a) Jamaica

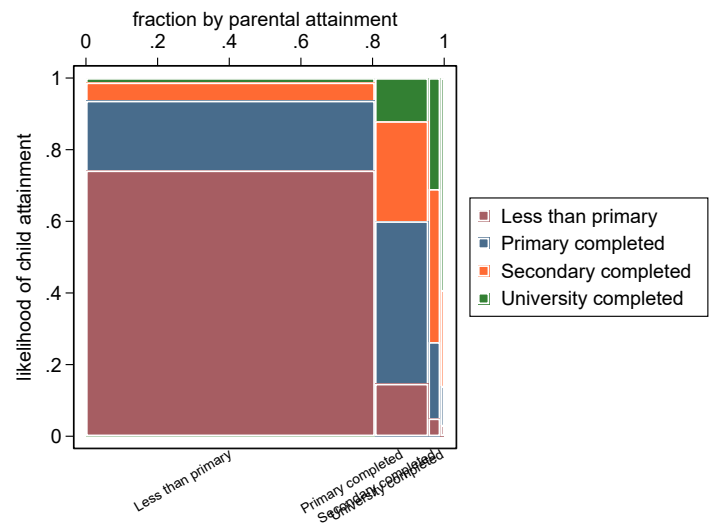

(b) Guatemala

Notes: The sample is constructed with individuals older than 25.

delivers a measure of mobility comparable between countries that captures some long-term patterns over half a decade by netting out common (across countries) birth cohorts and census year effects.

Downward mobility at the country level. To estimate downward IGM, I use a similar econometric specification, pooling observations from all the censuses and countries:

$$
y_{\text {icoyt }}^{\text {down }}=\alpha_{c}^{\text {down }}+\gamma_{o}^{b}+\gamma_{y}^{b}+\theta_{t}+\epsilon_{i c o y t}
$$

where $y_{\text {icoyt }}^{\text {down }}$ is a dummy variable that takes a value equal to one when individual $i$ do not complete primary education and zero otherwise. The parameters $\gamma_{o}^{b}, \gamma_{y}^{b}, \theta_{t}$ again refer respectively to fixed effects by decade-cohort of the individual $i$, decade-cohort of the generation above that co-resides with individual $i$, and census year. This regression uses a sample of individuals with ages between 14 and 18 (or 14 to 25), for whom the generation above (parents or older relatives) have on average completed at least primary education. Hence, $\alpha_{c}^{\text {down }}$ is the parameter of interest and measures the likelihood of failing to complete primary for children whose "parents" completed at least primary school net of cohort and census year effects. 
Upward and downward mobility at finer geographical level. To estimate IGM at a more disaggregated level (i.e., provinces or districts), I use the following econometric specifications run country by country:

$$
\begin{array}{r}
y_{\text {icroyt }}^{u p}=\alpha_{c r}^{u p}+\gamma_{o}^{b}+\gamma_{y}^{b}+\theta_{t}+\epsilon_{\text {icroyt }} \\
y_{\text {icroyt }}^{\text {down }}=\alpha_{c r}^{\text {down }}+\gamma_{o}^{b}+\gamma_{y}^{b}+\theta_{t}+\epsilon_{\text {icroyt }}
\end{array}
$$

where the variables and subscripts in common have similar interpretation as in Equation 1 and 2 , and the additional subscript $r$ refers to the district or province according to the level of geographical dis-aggregation used in the analysis (provinces as the baseline estimates and districts as an additional exercise reported in the Appendix).

\section{Why is primary education a suitable variable by which to measure IGM?} The focus on primary education is based on the fact that a non-negligible share of the population in Latin America and the Caribbean has an educational attainment of less than primary as shown in the previous subsection. Furthermore, this focus makes the analysis directly comparable to the recent work of Alesina et al. (2021) in Africa and allows me to minimize the potential bias that comes from using samples of co-residents. Nonetheless, the focus on the lowest level of education can also be justified from a conceptual point of view. Development policy discussions often claim that the poorest should not be left behind and this focus is related to the school of moral philosophy exemplified by the principle of justice proposed by Rawls (1971). ${ }^{7}$

Robustness. As a robustness check, I compute upward and downward mobility using some alternative options in terms of data construction. First, I use the maximum attainment of the generation above instead of average. This change produces estimates with differences that are negligible (for example, Pearson correlation coefficient between the measures using average versus maximum at the country, province, and district level are approximately 1). Second, I estimate mobility using a sample of individuals linked to (probable) parents as

\footnotetext{
${ }^{7}$ See Ravallion (2016) as an example of the focus on the poorest in the context of poverty measurement.
} 
done by IPUMS (2019). This change produces estimates that are also highly correlated (for example, Pearson correlation coefficient between the measures using average versus maximum at the country, province, and district level are 0.98, 0.97 and 0.93, respectively).

Alternative measures of IGM. I estimate a set of additional measures of intergenerational mobility, which are less focused on the bottom of the educational attainment distribution. In contrast to the estimates that focus on primary education, these measures are computed using individuals with ages between 19 and 25. First, I estimate upward and downward mobility considering secondary education instead of primary. Second, I estimate upward mobility as the likelihood of finishing at least secondary education for those whose generation above were not able to complete primary school.

\section{Intergenerational Mobility in Latin America and the Caribbean}

\section{Country-level estimates}

Table 2 summarizes the estimates of mobility at the country-level. On average, close to fifty percent of children with parents that did not finish primary education (from now on, illiterate parents) are able to complete primary. On the other hand, downward mobility is close to ten percent, as one out of ten children with parents that finished primary education (from now on, literate parents) do not complete primary.

There is substantial heterogeneity within LAC countries. The probability of completing primary for children of illiterate parents ranges from 18\% in Guatemala to $87 \%$ in Jamaica. In the case of downward mobility, the estimated probability of not completing primary for children of literate parents ranges from being null in Jamaica to $23 \%$ in Haiti. The heterogeneity found in upward mobility in Latin America (e.g., the 69 percentage points between Jamaica and Guatemala) is relatively similar to the one documented for African 
Table 2: Country-Level Estimates of Educational Intergenerational Mobility

\begin{tabular}{|c|c|c|c|c|c|c|c|}
\hline & & $(1)$ & $(2)$ & $(3)$ & $(4)$ & 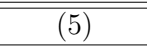 & $(6)$ \\
\hline mobility / N & census years & upward & upward & downward & downward & $\mathrm{N}$ & $\mathrm{N}$ \\
\hline age range & & $14-18$ & $14-25$ & $14-18$ & $14-25$ & $14-18$ & $14-25$ \\
\hline Jamaica & $1982,1991,2001$ & .868 & .864 & -.004 & .003 & 43,404 & 77,227 \\
\hline Trinidad and Tobago & $1970,1980,1990,2000,2011$ & .839 & .833 & .023 & .023 & 41,253 & 81,100 \\
\hline Argentina & $1970,1980,1991,2001,2010$ & .762 & .789 & .035 & .034 & $1,068,471$ & $2,017,618$ \\
\hline Chile & $1970,1982,1992,2002$ & .682 & .709 & .05 & .044 & 344,149 & 651,737 \\
\hline Uruguay & $1963,1975,1985,1996,2006,2011$ & .668 & .685 & .064 & .052 & 108,528 & 199,653 \\
\hline Cuba & 2002,2012 & .662 & .688 & .027 & .024 & 101,268 & 214,486 \\
\hline Panama & $1960,1970,1980,1990,2000,2010$ & .635 & .665 & .049 & .04 & 86,527 & 157,906 \\
\hline Costa Rica & $1973,1984,2000,2011$ & .634 & .643 & .086 & .068 & 107,088 & 197,018 \\
\hline Bolivia & $1976,1992,2001,2012$ & .609 & .634 & .068 & .057 & 206,745 & 358,013 \\
\hline Mexico & $1970,1990,2000,2010$ & .602 & .622 & .048 & .042 & $2,811,581$ & $4,961,471$ \\
\hline Ecuador & $1974,1982,1990,2001,2010$ & .543 & .572 & .089 & .074 & 373,130 & 667,055 \\
\hline Suriname & 2012 & .535 & .563 & .042 & .031 & 2,999 & 6,141 \\
\hline Venezuela & $1971,1981,1990,2001$ & .533 & .587 & .096 & .08 & 517,834 & 940,766 \\
\hline Saint Lucia & 1980,1991 & .523 & .492 & .126 & .142 & 2,089 & 3,679 \\
\hline Peru & 1993,2007 & .48 & .524 & .115 & .088 & 357,472 & 668,806 \\
\hline Paraguay & $1962,1972,1982,1992,2002$ & .432 & .463 & .116 & .096 & 118,082 & 207,766 \\
\hline Colombia & $1973,1985,1993,2005$ & .402 & .437 & .142 & .114 & 886,765 & $1,605,718$ \\
\hline Honduras & $1974,1988,2001$ & .398 & .433 & .151 & .133 & 109,458 & 182,786 \\
\hline Dominican Republic & $1981,2002,2010$ & .376 & .442 & .15 & .124 & 173,340 & 312,654 \\
\hline Brazil & $1960,1970,1980,1991,2000,2010$ & .367 & .422 & .171 & .128 & $10,755,296$ & $18,713,402$ \\
\hline El Salvador & 1992,2007 & .342 & .374 & .164 & .138 & 85,402 & 150,582 \\
\hline Haiti & $1971,1982,2003$ & .212 & .266 & .226 & .178 & 104,465 & 183,588 \\
\hline Nicaragua & $1971,1995,2005$ & .194 & .238 & .223 & .18 & 93,635 & 167,740 \\
\hline Guatemala & $1964,1973,1981,1994,2002$ & .181 & .212 & .159 & .129 & 238,047 & 402,133 \\
\hline mean / total & & .52 & .548 & .101 & .084 & $18,737,028$ & $33,129,045$ \\
\hline
\end{tabular}

Notes: Columns (1) and (2) give upward-IGM estimates. They reflect the likelihood that children, aged 14-18 and 14-25, whose parents have not completed primary schooling will manage to complete at least primary education. Columns (3) and (4) give downward-IGM estimates. They reflect the likelihood that children, aged 14-18 and 14-25, whose parents have completed primary schooling or higher will not manage to complete primary education. Columns (5) and (6) give the number of observations used to estimate the country-specific IGM statistics (children whose parental education is reported in the censuses). Countries are sorted from the highest to the lowest level of upward IGM in the 14-18 sample (column (1)). "mean" gives the unweighted average of the 24 country-estimates.

countries (e.g., the 75 percentage points between South Africa and South Sudan) by Alesina et al. (2021), although with higher minimum and maximum values. Furthermore, the level of upward mobility among countries in LAC shows substantial overlap with that of Africa. Countries such as Haiti, Guatemala, and Nicaragua with the lowest levels of upward mobility in LAC are more upwardly mobile than five (Malawi, Ethiopia, Sudan, Mozambique, and South Sudan) out of the 27 countries for which Alesina et al. (2021) provide estimates.

Figure 7 maps the country-level estimates of upward and downward mobility in education. They highlight the heterogeneity found across the continent, show that the patterns of 
Figure 7: Intergenerational Educational Mobility in LAC

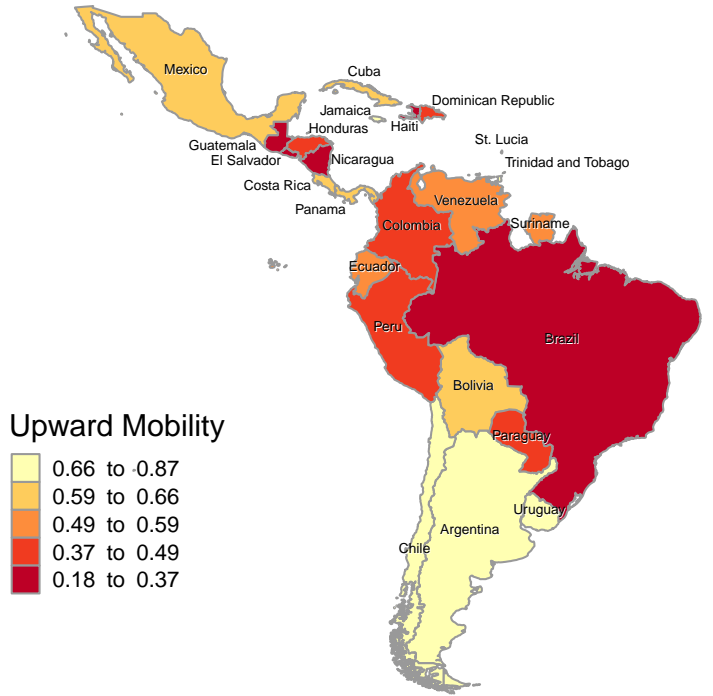

(a) Upward Mobility

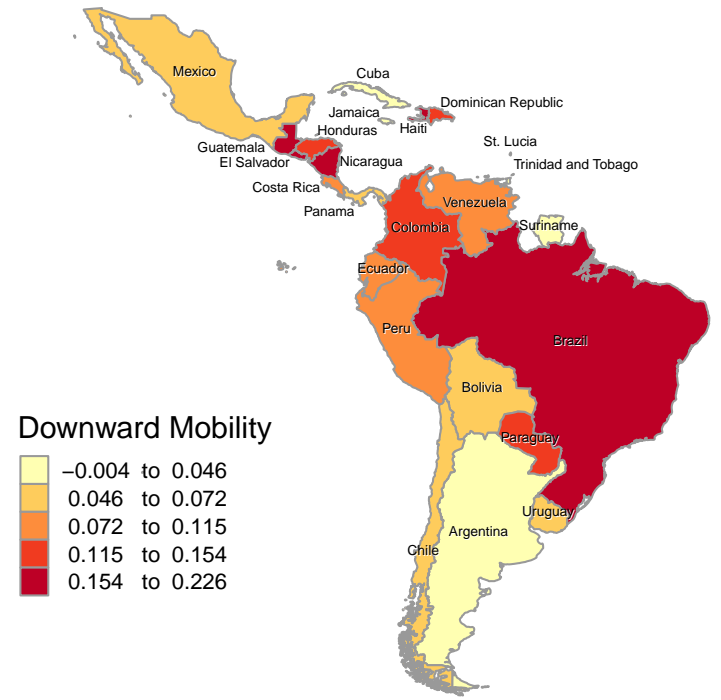

(b) Downward mobility

Notes: Upward mobility reflects the likelihood that children, aged 14-18, whose parents have not completed primary schooling will manage to complete at least primary education. Downward mobility reflects the likelihood that children, aged 14-18, whose parents have completed primary schooling or higher will not manage to complete primary education. Both estimates are net of cohort and census year effects.

upward mobility are inversely related to downward mobility and that there are combinations of low and high mobility countries in South America, as well as in Central America and the Caribbean. The estimates of upward and downward mobility at the level of country are significantly negatively correlated (see Figure A10 in the Appendix).

Country-level estimates of intergenerational mobility focused on secondary education can be found in Table A7 of the Appendix. The level of upward (downward) mobility is considerable lower (higher) and the samples smaller. Similar to the estimates using primary education, we observed significant variation across countries. In the case of upward mobility measured as the likelihood that children complete at least secondary education when their parents were not able to complete primary, we see even lower levels of mobility at the country-level (see Table A10). 
Figure 8: Intergenerational Educational Mobility in LAC - Urban/rural

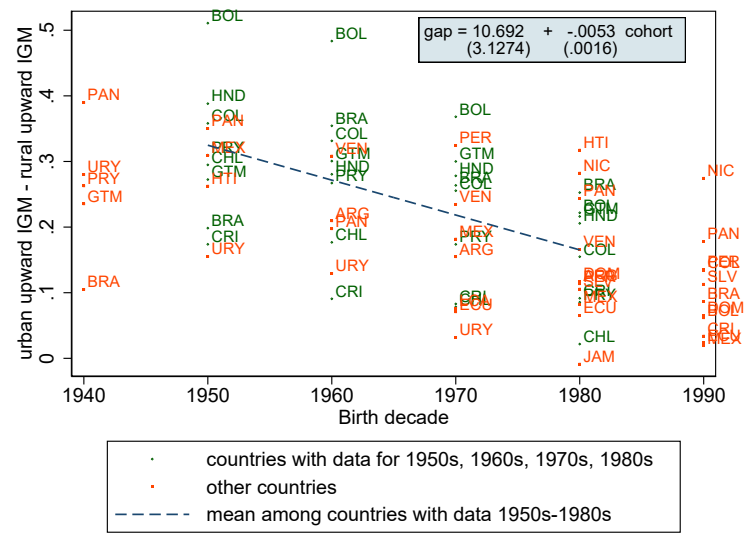

(a) Upward mobility

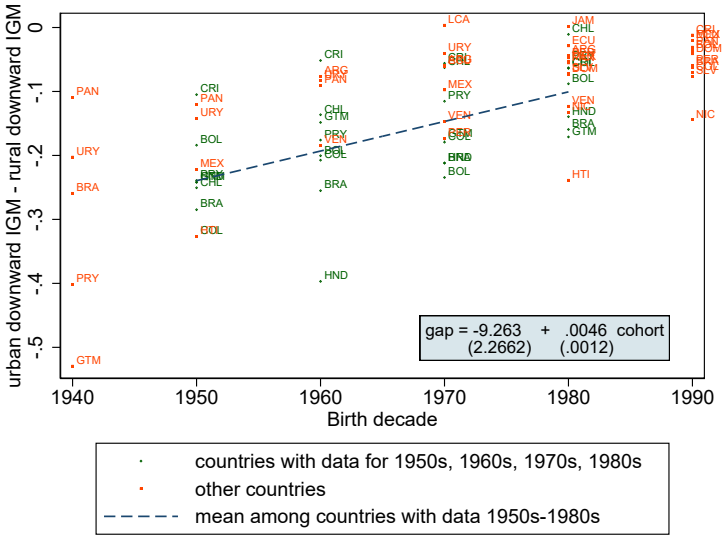

(b) Downward mobility

Notes: The estimates are done by birth decade cohort of the children.

\section{I.1 Urban-rural}

Within countries there may be some level of heterogeneity between the mobility of populations living in urban areas versus rural areas. To explore this, I estimate mobility by birth-decade cohort of the children and country. ${ }^{8}$ Figure 8 reports the gap between the upward/downward mobility in urban-rural areas over birth cohort. I find a positive gap that has been declining as one moves towards older birth cohorts.

\section{I.2 Gender}

Similar to the gaps between urban and rural populations, there may exist heterogeneous levels of mobility by gender. To explore this possibility I estimate mobility by gender and birth-decade cohort. ${ }^{9}$ I do not find systematic differences by gender although it appears that there is a trend towards higher upward mobility for women (see Figure 9) while downward mobility appears flat.

\footnotetext{
${ }^{8}$ This analysis is done by estimating a modified version of equations 1 and 2 that measure mobility at the country-cohort, i.e. $y_{i c o y t}^{u p}=\alpha_{c y}^{u p}+\epsilon_{i c o y t}$ and $y_{i c o y t}^{d o w n}=\alpha_{c y}^{d o w n}+\epsilon_{i c o y t}$ using samples restricted to urban or rural population.

${ }^{9}$ This analysis is done by estimating a modified version of equations 1 and 2 that measure mobility at the country-cohort, i.e. $y_{i c o y t}^{u p}=\alpha_{c y}^{u p}+\epsilon_{i c o y t}$ and $y_{i \text { coyt }}^{\text {down }}=\alpha_{c y}^{\text {down }}+\epsilon_{i c o y t}$ using samples restricted to male or
} 
Figure 9: Intergenerational Educational Mobility in LAC - Gender

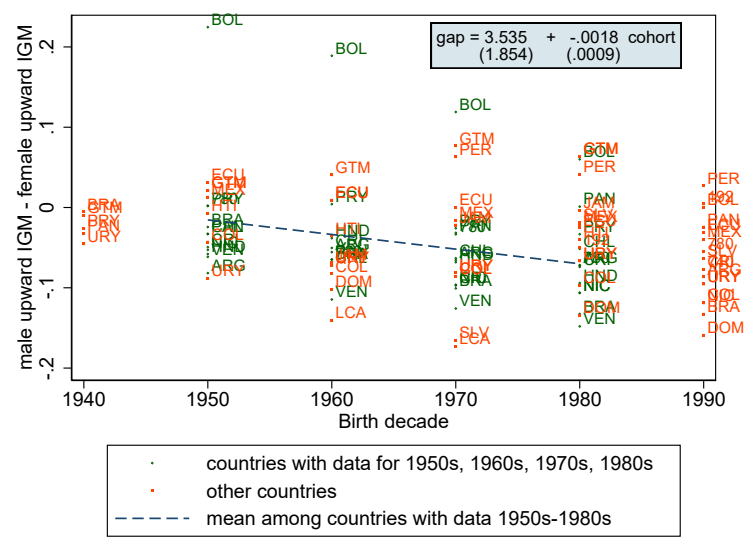

(a) Upward mobility

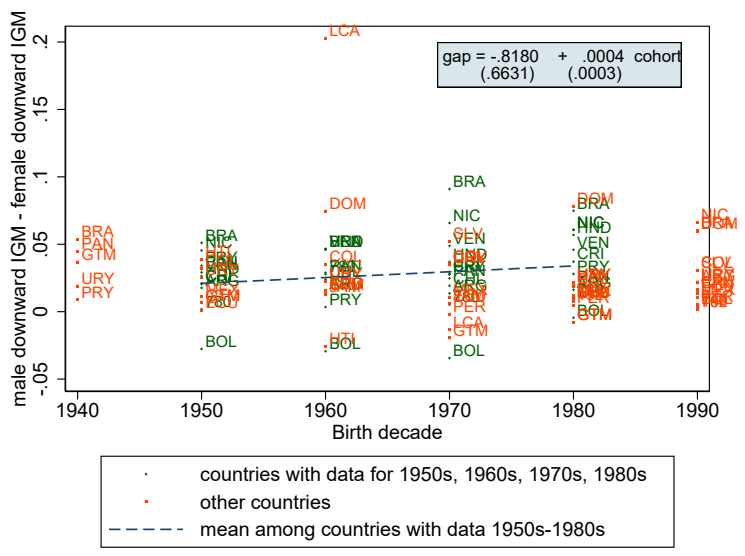

(b) Downward mobility

Notes: These estimates are computed by birth decade cohort of the children.

\section{I.3 Evolution over time}

As Figure $1 \mathrm{~b}$ made clear, the coverage over time is unbalanced with some countries spanning more years than others. This limits the analysis of trends over time and the conclusions that can be derived from comparisons between them at given points in time or for a given cohort. Nevertheless, I document estimates of mobility by country for the different birth cohorts that are available. Figure 10 reports these estimates. It is clear how the level of upward mobility has been increasing at the same time that downward mobility has been falling. This is not surprising given the fact that educational attainment has increased in the region over the last decades.

\section{Spatial variation of intergenerational mobility in LAC}

Table 3 summarizes the estimates of mobility at the province-level. These results show that there are countries with substantial variance in mobility levels across provinces. This is for example the case of Paraguay, Mexico, Guatemala, Bolivia, and Peru, where the difference in upward mobility between the most upwardly mobile to the least upwardly mobile is more 
Figure 10: Intergenerational Educational Mobility in LAC across cohorts

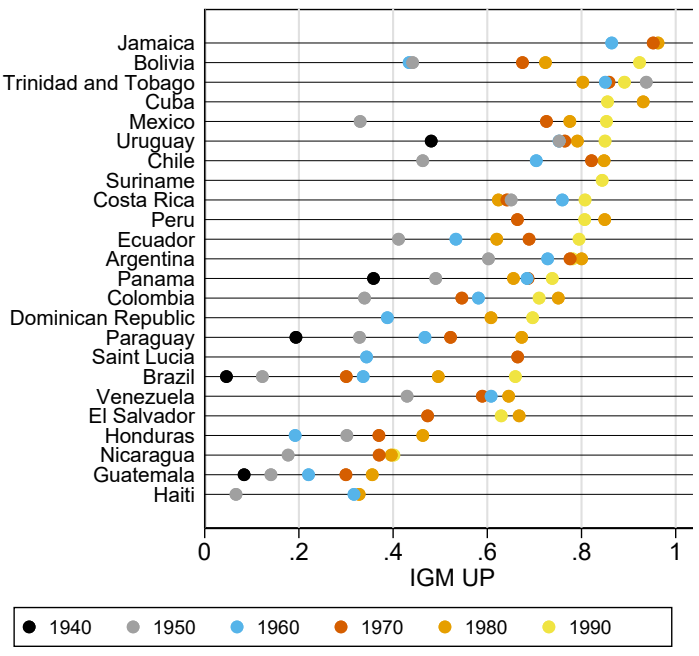

(a) Upward mobility

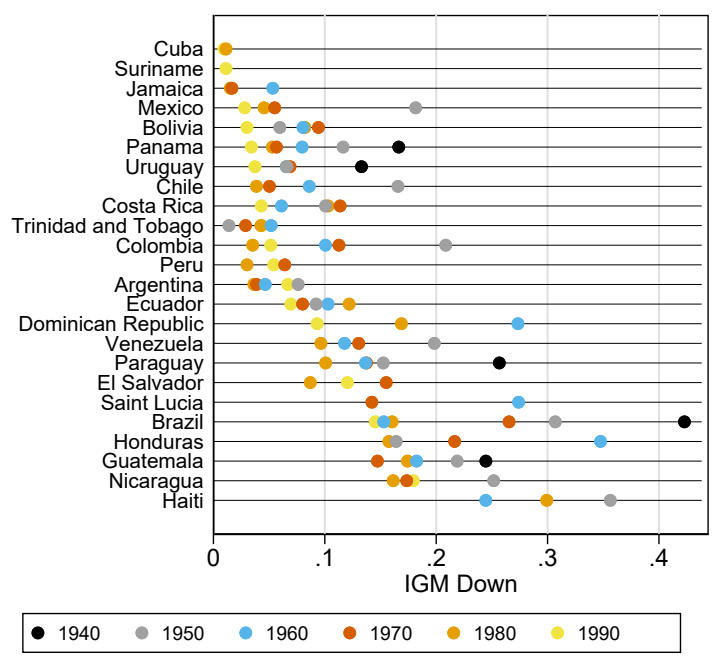

(b) Downward mobility

Notes: These estimates are computed by birth decade cohort of the children.

than half the range found in the case of countries in Latin America. However, there are also particular cases with either high or low upward mobility at the country level and a very small variation within country, such as Jamaica and Haiti, although somewhat expected as they correspond to countries with small number of administrative units and population.

In the case of downward mobility, the variability is much smaller in level with Paraguay that stands out in terms of the range between the province with the minimum and the maximum level of downward mobility.

Figure 11 and 12 maps the same estimates that are summarized in Table 3. We can see some interesting patterns in some countries. For example, Mexico shows a somewhat lower level of upward mobility in the south and you can identify a lighter spot in the middle of the country that corresponds to the region of the capital. In contrast, Brazil shows much lower level of mobility in the northern regions and higher mobility in the East coast near the states of Sao Paulo and Rio de Janeiro. Overall, the continent shows higher levels in the south, especially in the Pacific coast and some heterogeneous level in the case of Islands of the Caribbean region with important contrasts between Cuba and Haiti. 
In the Appendix, I report similar estimates (see Table A6) and maps (see Figure A2 and A3) at the district-level, which corresponds to the finest administrative unit available in the data set. The patterns are qualitatively similar, however, given the level of dis-aggregation there are some districts with just few observations used for the estimation that produces estimates that end up outside the unitary range.

Similarly, summary statistics of alternative estimates of intergenerational mobility that consider secondary education at the province and district levels can be found in the Appendix (see Table A8, A9, A11, and A12). They are consistent with the country-level estimates, in the sense that relative to my baseline estimates using primary education, they show lower levels of upward mobility, higher levels of downward mobility, smaller samples, and significant within country variation.

Table 3: Summary Statistics: Province-Level Estimates of Educational IGM

\begin{tabular}{|c|c|c|c|c|c|c|c|c|c|c|c|c|c|c|c|}
\hline \multirow[b]{2}{*}{ country } & \multirow[b]{2}{*}{ provinces } & \multicolumn{7}{|c|}{ upward } & \multicolumn{7}{|c|}{ downward } \\
\hline & & mean & median & stdev & $\min$ & $\max$ & Nmin & Nmean & mean & median & stdev & $\min$ & $\max$ & Nmin & Nmean \\
\hline Cuba & 14 & .917 & .932 & .056 & .757 & .972 & 63 & 146 & .011 & .011 & .003 & .006 & .017 & 889 & 7104 \\
\hline Suriname & 7 & .897 & .897 & .095 & .83 & .965 & 56 & 73 & .012 & .013 & .005 & .005 & .021 & 72 & 395 \\
\hline Jamaica & 14 & .888 & .893 & .029 & .84 & .936 & 106 & 322 & .029 & .028 & .006 & .018 & .042 & 1193 & 2779 \\
\hline Trinidad and Tobago & 4 & .872 & .871 & .043 & .822 & .923 & 66 & 1763 & .033 & .034 & .005 & .027 & .037 & 1272 & 8550 \\
\hline Chile & 44 & .773 & .767 & .066 & .655 & .915 & 93 & 1523 & .064 & .065 & .019 & .027 & .113 & 256 & 4804 \\
\hline Peru & 25 & .749 & .702 & .115 & .555 & .93 & 298 & 5728 & .07 & .072 & .028 & .03 & .139 & 699 & 8571 \\
\hline Argentina & 24 & .702 & .691 & .087 & .545 & .874 & 204 & 9763 & .061 & .058 & .02 & .021 & .099 & 2329 & 34757 \\
\hline Costa Rica & 7 & .693 & .693 & .054 & .623 & .753 & 2261 & 4929 & .083 & .071 & .023 & .058 & .112 & 5091 & 10369 \\
\hline Uruguay & 19 & .679 & .677 & .048 & .598 & .781 & 281 & 1418 & .064 & .065 & .012 & .04 & .086 & 734 & 4294 \\
\hline Mexico & 32 & .674 & .67 & .079 & .498 & .899 & 2265 & 38282 & .053 & .052 & .016 & .015 & .1 & 6269 & 49580 \\
\hline Bolivia & 9 & .651 & .641 & .097 & .504 & .814 & 534 & 9900 & .071 & .062 & .025 & .04 & .125 & 968 & 13072 \\
\hline Ecuador & 14 & .622 & .602 & .057 & .561 & .718 & 1371 & 10618 & .091 & .082 & .031 & .06 & .179 & 1322 & 16034 \\
\hline Panama & 7 & .596 & .629 & .108 & .401 & .744 & 802 & 3829 & .084 & .068 & .051 & .046 & .197 & 481 & 8532 \\
\hline Venezuela & 22 & .545 & .526 & .079 & .402 & .708 & 801 & 10079 & .131 & .133 & .025 & .097 & .193 & 707 & 13459 \\
\hline El Salvador & 14 & .538 & .541 & .062 & .436 & .669 & 1740 & 3346 & .16 & .158 & .033 & .098 & .218 & 479 & 2754 \\
\hline Colombia & 22 & .519 & .526 & .094 & .373 & .724 & 164 & 19078 & .118 & .118 & .033 & .052 & .179 & 897 & 21230 \\
\hline Saint Lucia & 4 & .474 & .475 & .049 & .429 & .516 & 325 & 446 & .155 & .155 & .01 & .148 & .162 & 79 & 111 \\
\hline Paraguay & 14 & .458 & .412 & .118 & .33 & .777 & 1740 & 5381 & .147 & .138 & .046 & .04 & .207 & 953 & 3701 \\
\hline Dominican Republic & 23 & .451 & .469 & .071 & .302 & .584 & 688 & 2176 & .149 & .149 & .023 & .109 & .206 & 340 & 2693 \\
\hline Honduras & 18 & .381 & .377 & .094 & .22 & .575 & 211 & 4291 & .219 & .217 & .066 & .12 & .397 & 255 & 1790 \\
\hline Nicaragua & 12 & .349 & .366 & .109 & .205 & .529 & 1211 & 5000 & .211 & .198 & .063 & .137 & .35 & 246 & 2803 \\
\hline Brazil & 25 & .285 & .249 & .103 & .144 & .493 & 7290 & 332632 & .21 & .23 & .052 & .123 & .299 & 5407 & 97580 \\
\hline Guatemala & 22 & .256 & .256 & .085 & .099 & .479 & 2399 & 8340 & .229 & .239 & .037 & .12 & .282 & 548 & 2480 \\
\hline Haiti & 4 & .223 & .218 & .032 & .191 & .266 & 5399 & 20467 & .341 & .363 & .052 & .262 & .375 & 832 & 5649 \\
\hline total & 400 & .587 & .604 & .203 & .099 & .972 & 56 & 29432 & .112 & .087 & .076 & .005 & .397 & 72 & 17814 \\
\hline
\end{tabular}

Notes: This table shows summary statistics for province level estimates of IGM. Upward reflects the likelihood that children, aged 14-18, whose parents have not completed primary schooling will manage to complete at least primary education. Downward reflects the likelihood that children, aged 14-18, whose parents have completed primary schooling or higher will not manage to complete primary education. "Total" shows the unweighted summary statistics across all provinces. The columns "Nmin" and "Nmean" report respectively the smallest and average sample size across provinces. Countries are sorted from the highest to the lowest average level of upward IGM across provinces (column "mean"). Provinces with less than 50 observations are omitted. 
Figure 11: Upward Mobility in LAC

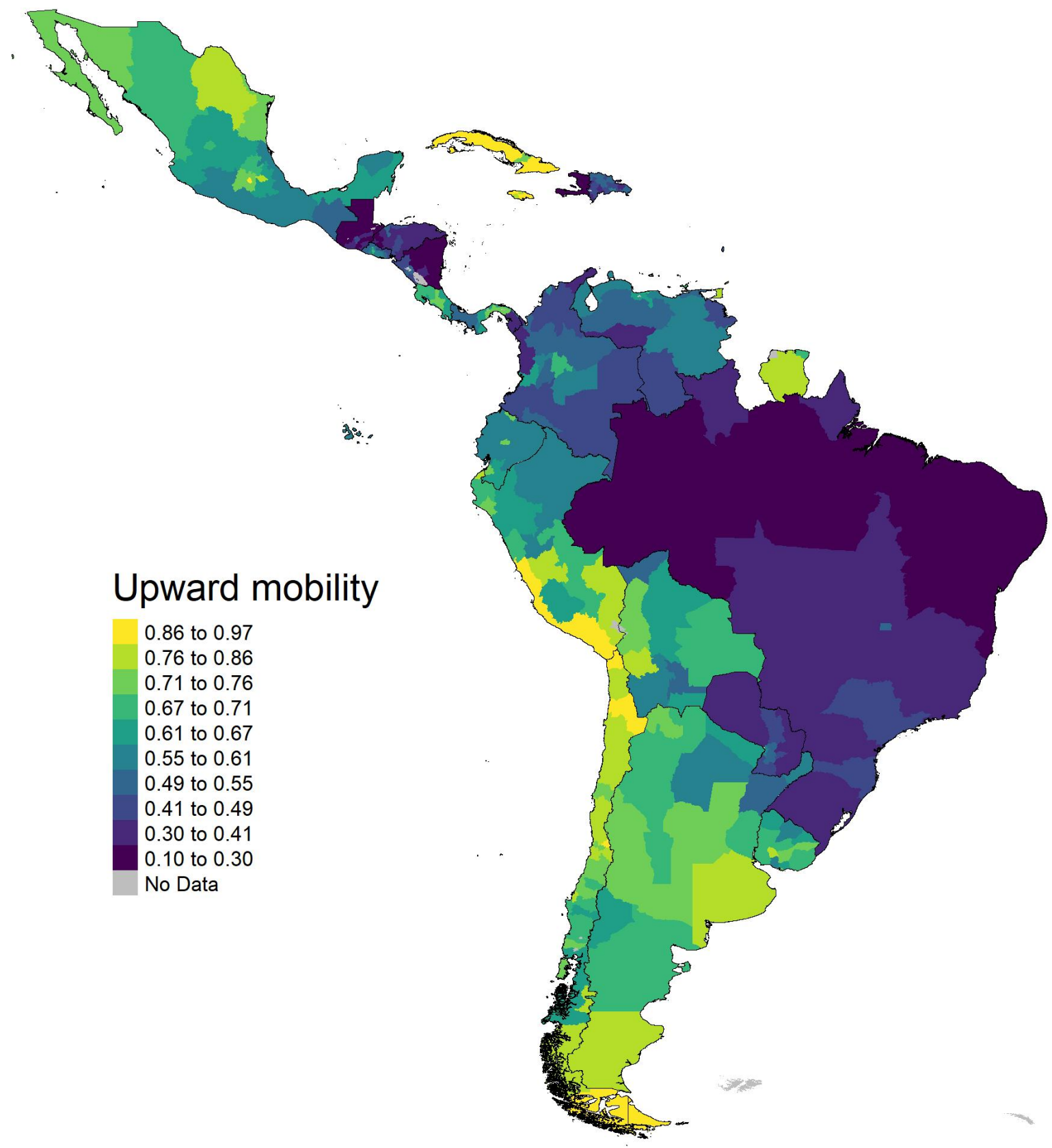

Notes: Upward mobility reflects the likelihood that children, aged 14-18, whose parents have not completed primary schooling will manage to complete at least primary education. 
Figure 12: Downward Mobility in LAC

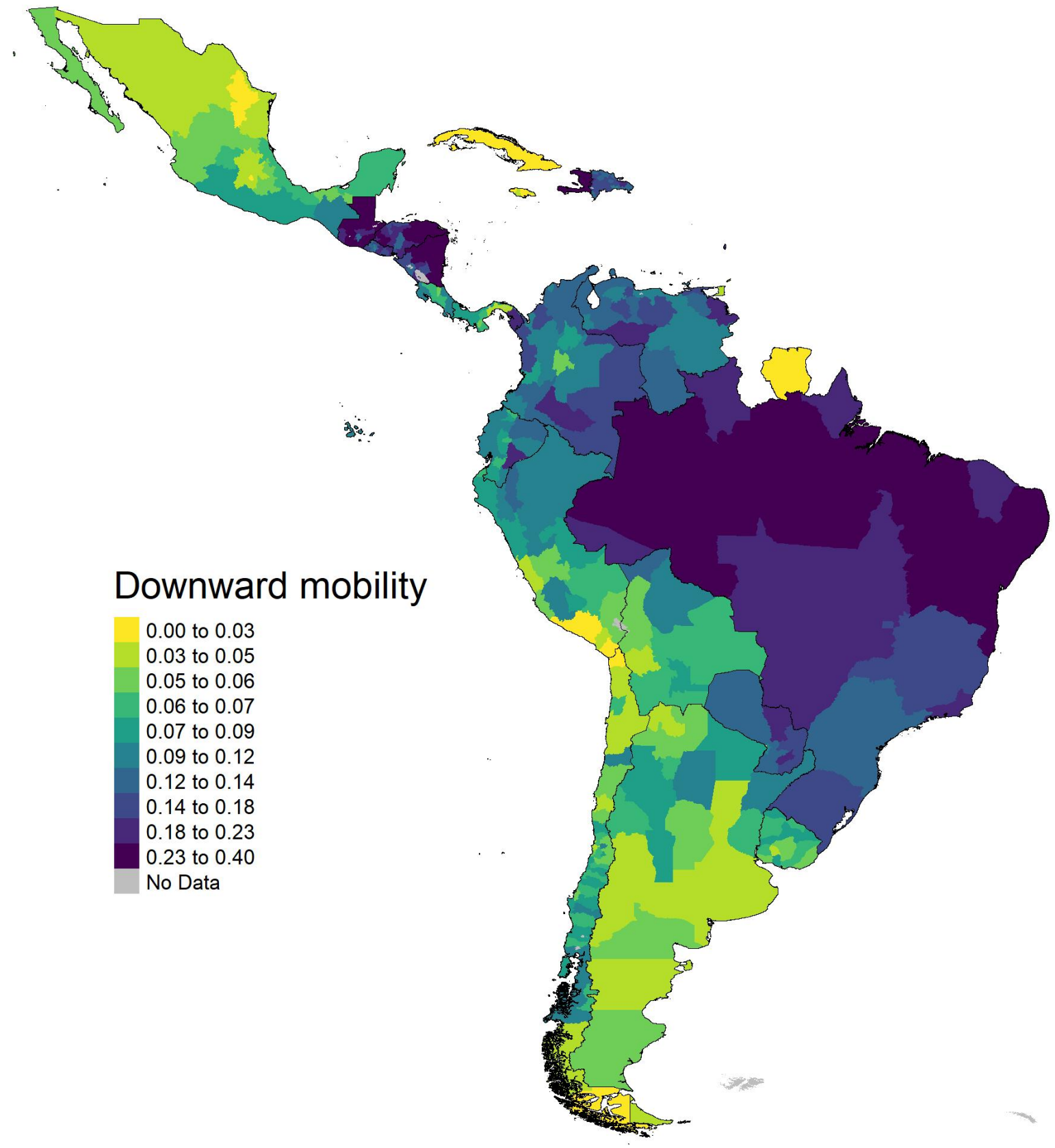

Notes: Downward mobility reflects the likelihood that children, aged 14-18, whose parents completed primary schooling will not manage to complete at least primary education. 


\section{Correlates of Intergenerational Mobility}

In this section, I explore a set of correlates of regional IGM with the aim of uncovering a set of stylized facts that help characterize its geography. A necessary caveat is that the set is relative small given the difficulty of collecting data that is comparable for all the administrative units. An additional and perhaps more important caveat is that the analysis does not provide any causal interpretation and it is solely descriptive.

I run univariate regressions pooling all the countries linking IGM to geographical and initial conditions that have been discussed in previous studies on intergenerational mobility outside the continent (for example, see Alesina et al., 2021). This is done estimating the following econometric specification:

$$
\alpha_{c r}^{u p / d o w n}=\eta_{c}+\beta Z_{c r}+\epsilon_{c r}
$$

where the dependent variable corresponds to the measure of upward or downward intergenerational mobility previously estimated for province/district $r$ in country $\mathrm{c}, \eta_{c}$ denote country fixed effects, $Z_{c r}$ and $\beta$ are respectively the covariate and the coefficient of interest. The latter summarizing the linear association between intergenerational mobility and the covariate.

\section{Education of the old generation}

First I analyze the share of the old generation that was able to complete primary education. Alesina et al. (2021) finds this measure to be strongly associated with mobility in Africa. This correlate in part reflects the initial outcomes at the province/district-level for parents. I compute this variable using an econometric specification similar to the one used to compute mobility at regional level (see Equation 3) run country by country:

$$
e_{\text {icroyt }}=\delta_{c r}+\gamma_{o}^{b}+\gamma_{y}^{b}+\theta_{t}+\epsilon_{i c r o y t}
$$


Figure 13: Intergenerational Mobility and Literacy of the Old Generation

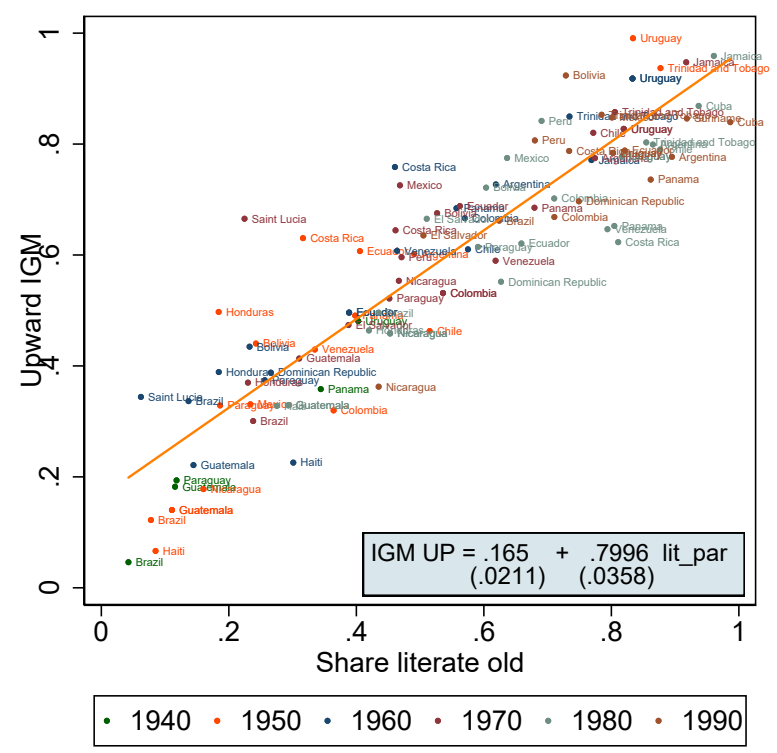

(a) Upward mobility

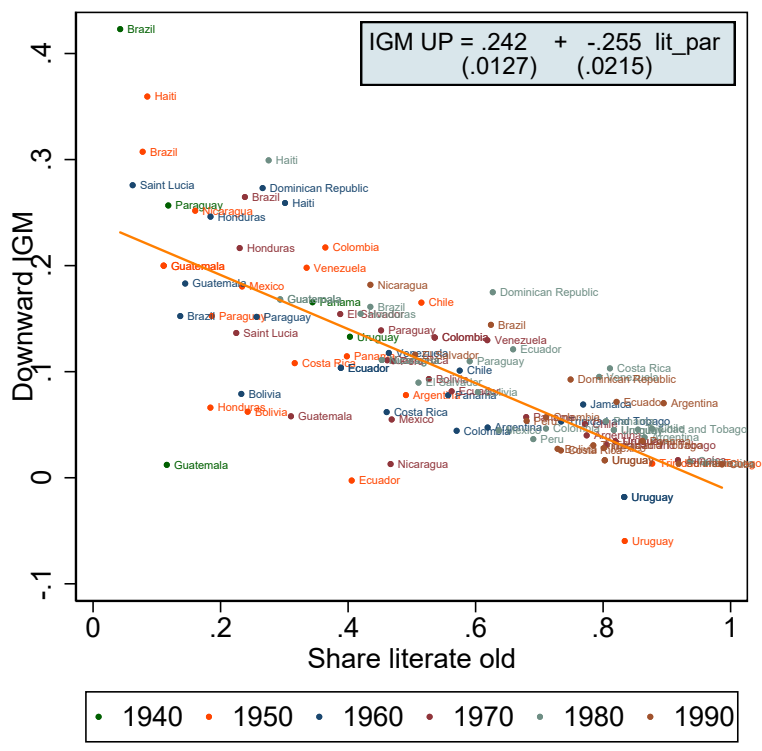

(b) Downward mobility

Notes: These estimates are computed by birth decade cohort of the children.

where $e_{\text {icroyt }}$ is a dummy variable equal to 1 if the completed educational level of the old generation observed for individual $i$ from country $c$ region $\mathrm{r}$ is at least primary. Similar to before, $\gamma_{o}^{b}$ and $\gamma_{y}^{b}$ are birth-decade fixed effects for parents and children, and $\theta_{t}$ a census year fixed effect. In other words, $\delta_{c r}$ estimates the share of "parents" who complete primary by region netting out cohort and census year effects.

I find a strong positive (negative) correlation between upward (downward) mobility and literacy of the old generation (see Figure A11). This suggests the existence of a high level of inertia, confirming the findings of Alesina et al. (2021). Similar patterns are found at the country-birth cohort (see Figure 13).

\section{Other covariates}

Given the high level of inertia, the correlation analysis of the remaining correlates is performed one by one and also partialling out the effect of the educational attainment of the 
old generation. The idea is to test whether any potential relationship with the covariate of interest remains after removing the effect of the covariate on "initial conditions". This is done estimating the following specification (in addition to equation 4):

$$
\alpha_{c r}^{u p / d o w n}=\eta_{c}+\beta Z_{c r}+\gamma W_{c r}+\epsilon_{c r}
$$

where $m_{c r}^{u p / d o w n}$ corresponds to the measure of upward or downward IGM for province/district $r$ in country c, $\eta_{c}$ denote country fixed effects, $W_{c r}$ is the share of literacy of the parents in region $r$, and $Z_{c r}$ and $\beta$ are respectively the covariate and the coefficient of interest.

Alesina et al. (2021) has shown that some geographical characteristics are also correlated to the level of intergenerational mobility. In this paper I consider distance to the capital, distance to the border, and distance to the coast. I also consider other characteristics of the districts that are proxies of the level of development at the beginning of the period of study. These are the urban share of the population, the share of employment in agriculture, the share of employment in industry, and the share of employment in service. These last four covariates are computed restricting the sample to only individuals born before 1960 .

The results are reported in Figure 14 for upward and downward mobility respectively. Although upward mobility seems to be correlated with most of the proxies of development, the correlations become insignificant at the $5 \%$ when controlling by education of the old generation in all the cases. Only the share of employment in industry, which is positively associated with upward mobility, is statistically significant at the $10 \%$. In the case of downward mobility, I find a significant correlation at the standard level, even conditioning on education of the old generation, with the share of employment in industry and agriculture, although with opposite signs. Higher share of employment in agriculture is associated with higher downward mobility while higher share of employment in industry is associated with lower downward mobility.

In the case of geographical correlates, distance to the border and coast are not significantly 
Figure 14: IGM and Correlates

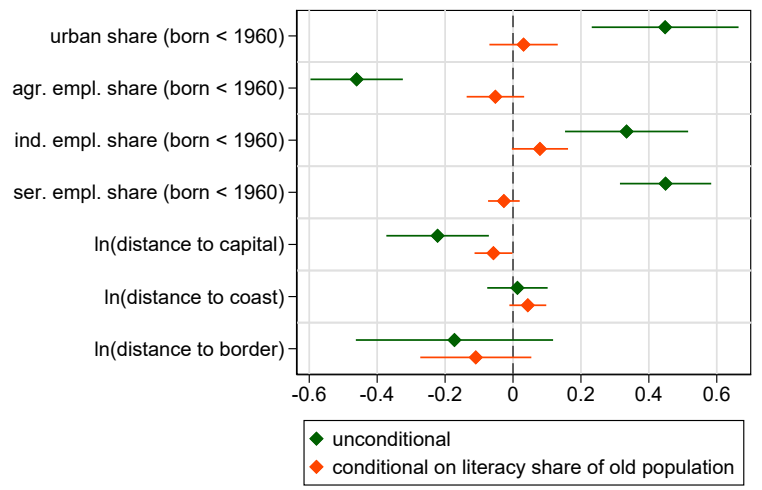

(a) Upward mobility

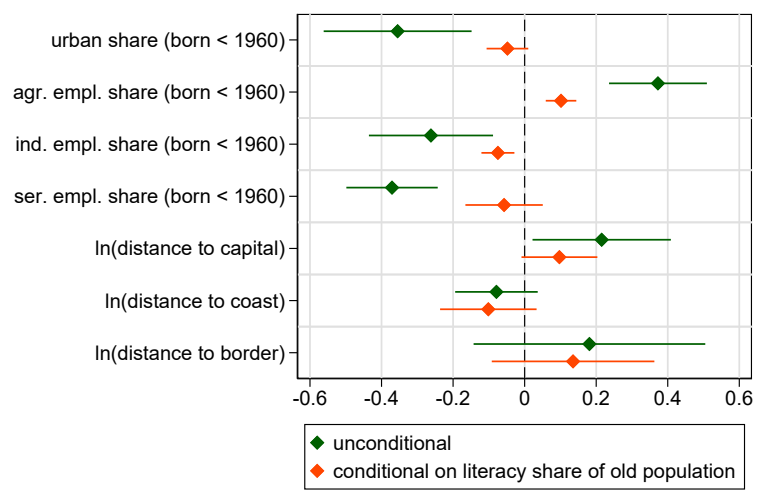

(b) Downward mobility

Notes: The graph plots the estimated coefficients and 95\% confidence intervals computed clustering standard errors by country. The analysis is done at district-level running regressions by covariate as in equation 4 and 6 . The coefficients are standarized.

correlated to either measure of mobility. This is in line with Alesina et al. (2021) in the case of the border but differ relative to their results for the coast. However, distance to the capital is negatively (positively) correlated to upward (downward) mobility although weakly (statistically significant at the $5 \%$ for upward and at $10 \%$ for downward mobility).

\section{Final Remarks}

This paper examines intergenerational educational mobility for Latin American and the Caribbean countries at a disaggregated regional level using census data spanning more than half a century. I investigate mobility in education at the bottom of the educational attainment distribution by focusing on the likelihood of completion of primary education for those whose parents did not complete the level, which can be measured with a high degree of confidence between ages 14 and 18. Similarly, I measure downward mobility as the likelihood of not completing primary for those whose parents were able to complete at least primary school. 
I find wide cross-country and within-country heterogeneity. In LAC, the distance between the most and least upwardly mobile country is relative close to what has been recently documented in Africa, although the least mobile countries in Africa are less mobile than any country in LAC. Similarly, the median country in LAC shows higher upward mobility than the median country in Africa. I do not find significant differences by gender but I do document a declining trend in the mobility gap between urban and rural populations.

Within country mobility shows a variety of patterns, with countries having higher mobility in the northern regions (e.g., Mexico), whereas others show higher mobility in the southern regions (e.g., Brazil). The level of heterogeneity within country also varies country by country with the lowest levels found in the smallest and less populated ones.

In terms of correlates within countries, the level of mobility is highly correlated to the share of primary completion of the previous generation, which suggests a high level of inertia. In addition, upward mobility appears weakly positively correlated to the share of employment in industry and distance to the capital, whereas downward mobility is significantly correlated to the shares of employment in industry and agriculture, and only weakly correlated to distance to the capital.

Given the unbalanced nature of the data set in terms of coverage over time and across countries, further research could shed more light on potential determinants of mobility in Latin America by focusing on the analysis of particular countries with a relatively high coverage such as Chile, Mexico, or Brazil, which makes the collection of correlates by administrative unit easier. This paper contributes to this goal by creating the estimates of mobility at a disaggregated geographical level and making them available in an online data appendix for future research. 


\section{References}

Alesina, A., Hohmann, S., Michalopoulos, S., \& Papaioannou, E. (2021). Intergenerational Mobility in Africa. Econometrica, 89(1), 1-35.

Asher, S., Novosad, P., \& Rafkin, C. (2018). Intergenerational Mobility in India: Estimates from New Methods and Administrative Data. mimeo.

Becker, G. S. (2018). A Theory of Intergenerational Mobility. Journal of Political Economy, $126(\mathrm{~S} 1), \mathrm{S} 7-\mathrm{S} 25$.

Becker, G. S., \& Tomes, N. (1979). An Equilibrium Theory of the Distribution of Income and Intergenerational Mobility. Journal of Political Economy, 87(6), 1153-1189.

Becker, G. S., \& Tomes, N. (1986). Human Capital and the Rise and Fall of Families. Journal of Labor Economics, 4(3), S1-S39.

Black, S. E., \& Devereux, P. J. (2011). Recent Developments in Intergenerational Mobility (Vol. 4b).

Card, D., Domnisoru, C., \& Taylor, L. (2018). The Intergenerational Transmission of Human Capital: Evidence from the Golden Age of Upward Mobility. NBER Working Paper(25000), 1-69.

Celhay, P., Sanhueza, C., \& Zubizarreta, J. (2010). Intergenerational Mobility of Income and Schooling: Chile 1996-2006. Revista de Analisis Economico, 25(2), 43-63.

Chetty, R., Hendren, N., Kline, P., \& Saez, E. (2014). Where is the Land of Opportunity? The Geography of Intergenerational Mobility in the United States. The Quarterly Journal of Economics, 129(4), 1553-1623.

Corak, M. (2013). Income Inequality, Equality of Opportunity, and Intergenerational Mobility. Journal of Economic Perspectives, 27(3), 79-102.

Haider, S., \& Solon, G. (2006). Life-Cycle Variation in the Association between Current and Lifetime Earnings. American Economic Review, 96(4), 1308-1320.

Hertz, T., Jayasundera, T., Piraino, P., Selcuk, S., Smith, N., \& Verashchagina, A. (2007). The Inheritance of Educational Inequality: International Comparisons and Fifty-Year Trends. The B.E. Journal of Economic Analysis \& Policy, 7(2).

IPUMS. (2019). Integrated Public Use Microdata Series, International: Version 7.2 [dataset]. Minneapolis, MN: IPUMS: Minnesota Population Center.

Loury, G. (1981). Intergenerational Transfers and the Distribution of Earnings. Econometrica, $49(4), 843-867$. 
Messina, J., \& Silva, J. (2019). Twenty Years of Wage Inequality in Latin America. Policy Research Working Paper(8995).

Narayan, A., Van der Weide, R., Cojocaru, A., Lakner, C., Redaelli, S., Gerszon Mahler, D., ... Thewissen, S. (2018). Fair Progress?: Economic Mobility Across Generations Around the World. The World Bank.

Neidhöfer, G., Serrano, J., \& Gasparini, L. (2018). Educational Inequality and Intergenerational Mobility in Latin America: A New Database. Journal of Development Economics, 134, 329-349.

Ravallion, M. (2016). Are the World's Poorest being Left Behind? Journal of Economic Growth, 21, 139-164.

Rawls, J. (1971). A Theory of Justice. Cambridge, MA: Harvard University Press.

Solon, G. (1992). Intergenerational Income Mobility in the United States. The American Economic Review, 82(3), 393-408.

Solon, G. (2004). A Model of Intergenerational Mobility Variation over Time and Place. In Generational income mobility in north america and europe (chap. 2). Cambridge University Press.

Solon, G. (2014). Theoretical Models of Inequality Transmission across Multiple Generations. Research in Social Stratification and Mobility, 35, 13-18.

Torche, F. (2019). Educational Mobility in Developing Countries. WIDER Working Pa$\operatorname{per}(88), 1-31$.

Van der Weide, R., Ferreira de Souza, P., \& Barbosa, R. (2020). Intergenerational Mobility in Education in Brazil. mimeo.

Van der Weide, R., Lakner, C., Gerszon Mahler, D., Narayan, A., \& Ramasubbaiah, R. (2021). Intergenerational Mobility Around the World. mimeo. 


\section{Appendices}

In this Appendix I provide details on the sample construction and some additional tables and graphs.

Table A1 list the Census' samples obtained from IPUMS-International and the size of the extract.

Table A2 reports sample size from raw data to samples restricted by age and by availability of information on education.

Table A3 reports the rates of co-residency by country for different ages.

Table A4 reports the rates of co-residency by country-sample for different ages.

Figure A1 displays rates of coresidence by urban/rural population and by gender.

Table A5 summarizes the education level by cohort using data on individuals at least 25 years old.

Table A6 reports district-level estimates of intergenerational mobility.

Figure A2 and A3 displays maps of mobility at the district-level for LAC.

Figure A4 and A5 displays maps of mobility at the district-level for LAC using secondary education.

Table A7, A8, and A9 report estimates of IGM that consider secondary education.

Table A10, A11, and A12 report estimates of IGM that consider the likelihood of completing secondary education when parents completed less than primary.

Figure A10 displays the negative relationship between upward and downward mobility.

Figure A11 shows scatter plots between IGM and share of the old generation that completes at least primary education by district. 


\section{A Sample coverage and construction}

Table A1: Census' samples

\begin{tabular}{|c|c|c|c|c|c|c|c|c|c|c|c|}
\hline$\overline{\mathrm{N}}$ & Country & Year & $\begin{array}{l}\text { Fraction } \\
(\%)\end{array}$ & "Households & Persons & $\overline{\mathrm{N}}$ & Country & Y Year & $\begin{array}{l}\text { Fraction } \\
(\%)\end{array}$ & "Households & Persons \\
\hline 1 & Argentina & 1970 & 2 & 129,728 & 466,892 & 47 & Haiti & 2003 & 10 & 219,633 & 838,045 \\
\hline 2 & Argentina & 1980 & 10 & 672,062 & $2,667,714$ & 48 & Honduras & 1974 & 10 & 49,064 & 278,348 \\
\hline 3 & Argentina & 1991 & 10 & $1,199,651$ & $4,286,447$ & 49 & Honduras & 1988 & 10 & 77,406 & 423,971 \\
\hline 4 & Argentina & 2001 & 10 & $1,040,852$ & $3,626,103$ & 50 & Honduras & 2001 & 10 & 123,584 & 608,620 \\
\hline 5 & Argentina & 2010 & 10 & $1,217,166$ & $3,966,245$ & 51 & Jamaica & 1982 & 10 & 54,526 & 223,667 \\
\hline 6 & Bolivia & 1976 & 10 & 121,378 & 461,699 & 52 & Jamaica & 1991 & 10 & 62,291 & 232,625 \\
\hline 7 & Bolivia & 1992 & 10 & 177,926 & 642,368 & 53 & Jamaica & 2001 & 10 & 64,317 & 205,179 \\
\hline 8 & Bolivia & 2001 & 10 & 239,475 & 827,692 & 54 & Mexico & 1970 & 1 & 82,856 & 483,405 \\
\hline 9 & Bolivia & 2012 & 10 & 292,117 & $1,003,516$ & 55 & Mexico & 1990 & 10 & $1,648,280$ & $8,118,242$ \\
\hline 10 & Brazil & 1960 & 20 & $3,066,365$ & $14,983,769$ & 56 & Mexico & 2000 & 10.6 & $2,312,035$ & $10,099,182$ \\
\hline 11 & Brazil & 1970 & 25 & $5,111,039$ & $24,789,716$ & 57 & Mexico & 2010 & 10 & $2,903,640$ & $11,938,402$ \\
\hline 12 & Brazil & 1980 & 25 & $6,716,885$ & $29,378,753$ & 58 & Nicaragua & 1971 & 10 & 36,063 & 189,469 \\
\hline 13 & Brazil & 1991 & 10 & $4,024,553$ & $17,045,712$ & 59 & Nicaragua & 1995 & 10 & 82,815 & 435,728 \\
\hline 14 & Brazil & 2000 & 10 & $5,304,711$ & $20,274,412$ & 60 & Nicaragua & 2005 & 10 & 119,339 & 515,485 \\
\hline 15 & Brazil & 2010 & 10 & $6,192,502$ & $20,635,472$ & 61 & Panama & 1960 & 5 & 11,869 & 53,553 \\
\hline 16 & Chile & 1970 & 10 & 199,041 & 890,481 & 62 & Panama & 1970 & 10 & 31,755 & 150,473 \\
\hline 17 & Chile & 1982 & 10 & 282,356 & $1,133,062$ & 63 & Panama & 1980 & 10 & 47,726 & 195,577 \\
\hline 18 & Chile & 1992 & 10 & 373,964 & $1,335,055$ & 64 & Panama & 1990 & 10 & 61,458 & 232,737 \\
\hline 19 & Chile & 2002 & 10 & 486,115 & $1,513,914$ & 65 & Panama & 2000 & 10 & 84,346 & 284,081 \\
\hline 20 & Colombia & 1973 & 10 & 349,853 & $1,988,831$ & 66 & Panama & 2010 & 10 & 95,579 & 341,118 \\
\hline 21 & Colombia & 1985 & 10 & 571,046 & $2,643,125$ & 67 & Paraguay & 1962 & 5 & 18,307 & 90,236 \\
\hline 22 & Colombia & 1993 & 10 & 774,321 & $3,213,657$ & 68 & Paraguay & 1972 & 10 & 43,883 & 233,669 \\
\hline 23 & Colombia & 2005 & 10 & $1,054,812$ & $4,006,168$ & 69 & Paraguay & 1982 & 10 & 60,465 & 301,582 \\
\hline 24 & Costa Rica & 1973 & 10 & 36,323 & 186,762 & 70 & Paraguay & 1992 & 10 & 100,704 & 415,401 \\
\hline 25 & Costa Rica & 1984 & 10 & 56,186 & 241,220 & 71 & Paraguay & 2002 & 10 & 113,039 & 516,083 \\
\hline 26 & Costa Rica & 2000 & 10 & 106,973 & 381,500 & 72 & Peru & 1993 & 10 & 564,765 & $2,206,424$ \\
\hline 27 & Costa Rica & 2011 & 10 & 124,693 & 430,082 & 73 & Peru & 2007 & 10 & 821,675 & $2,745,895$ \\
\hline 28 & Cuba & 2002 & 10 & 371,878 & $1,118,767$ & 74 & Saint Lucia & 1980 & 10 & 2,674 & 11,451 \\
\hline 29 & Cuba & 2012 & 10 & 416,577 & $1,115,643$ & 75 & Saint Lucia & 1991 & 10 & 3,394 & 13,382 \\
\hline 30 & Dominican Rep & 1981 & 8.5 & 103,904 & 475,829 & 76 & Suriname & 2012 & 10 & 14,037 & 53,636 \\
\hline 31 & Dominican Rep & 2002 & 10 & 247,375 & 857,606 & 77 & Trinidad and Tobago & 1970 & 10 & 15,871 & 69,349 \\
\hline 32 & Dominican Rep & 2010 & 10 & 309,624 & 943,784 & 78 & Trinidad and Tobago & 1980 & 10 & 23,870 & 105,464 \\
\hline 33 & Ecuador & 1974 & 10 & 145,902 & 648,678 & 79 & Trinidad and Tobago & 1990 & 10 & 27,561 & 113,104 \\
\hline 34 & Ecuador & 1982 & 10 & 195,401 & 806,834 & 80 & Trinidad and Tobago & 2000 & 10 & 35,715 & 111,833 \\
\hline 35 & Ecuador & 1990 & 10 & 243,898 & 966,234 & 81 & Trinidad and Tobago & 2011 & 8.8 & 41,606 & 116,917 \\
\hline 36 & Ecuador & 2001 & 10 & 354,222 & $1,213,725$ & 82 & Uruguay & 1963 & 10 & 79,403 & 256,171 \\
\hline 37 & Ecuador & 2010 & 10 & 386,944 & $1,448,233$ & 83 & Uruguay & 1975 & 10 & 95,935 & 279,994 \\
\hline 38 & El Salvador & 1992 & 10 & 125,695 & 510,760 & 84 & Uruguay & 1985 & 10 & 105,761 & 295,915 \\
\hline 39 & El Salvador & 2007 & 10 & 172,012 & 574,364 & 85 & Uruguay & 1996 & 10 & 118,067 & 315,920 \\
\hline 40 & Guatemala & 1964 & 5 & 40,220 & 210,411 & 86 & Uruguay & 2006 & 8.4 & 85,316 & 256,866 \\
\hline 41 & Guatemala & 1973 & 5.5 & 59,622 & 289,458 & 87 & Uruguay & 2011 & 10 & 118,498 & 328,425 \\
\hline 42 & Guatemala & 1981 & 5 & 65,555 & 302,106 & 88 & Venezuela & 1971 & 2 & 284,336 & $1,158,527$ \\
\hline 43 & Guatemala & 1994 & 10 & 160,603 & 833,139 & 89 & Venezuela & 1981 & 10 & 323,321 & $1,441,266$ \\
\hline 44 & Guatemala & 2002 & 10 & 222,770 & $1,121,946$ & 90 & Venezuela & 1990 & 10 & 468,808 & $1,803,953$ \\
\hline 45 & Haiti & 1971 & 10 & 95,145 & 434,869 & 91 & Venezuela & 2001 & 10 & 646,080 & $2,306,489$ \\
\hline 46 & Haiti & 1982 & 2.5 & 28,698 & 128,770 & & & & & & \\
\hline
\end{tabular}


Table A2: Sample sizes

\begin{tabular}{|c|c|c|c|c|c|c|c|c|c|c|c|c|c|}
\hline \multirow[b]{2}{*}{ Country } & \multirow[b]{2}{*}{ Year } & \multirow[b]{2}{*}{ age: All } & \multicolumn{2}{|c|}{ All observations } & \multicolumn{2}{|c|}{ Obs. with education } & \multirow[b]{2}{*}{ Country } & \multirow[b]{2}{*}{ Year } & \multirow[b]{2}{*}{ age: All } & \multicolumn{2}{|c|}{ PAll observations } & \multicolumn{2}{|c|}{ Obs. with education } \\
\hline & & & age: $14-18$ & age: $14-25$ & age: $14-18$ & age: $14-25$ & & & & age: $14-18$ & age: $14-25$ & age: $14-18$ & age: $14-25$ \\
\hline Argentina & 1970 & 466,892 & 42,317 & 96,744 & 31,411 & 59,124 & Haiti & 2003 & 838,045 & 103,088 & 218,016 & 72,705 & 130,436 \\
\hline Argentina & 1980 & $2,700,000$ & 241,353 & 532,289 & 193,448 & 348,232 & Honduras & 1974 & 278,348 & 32,262 & 64,660 & 24,018 & 37,966 \\
\hline Argentina & 1991 & $4,300,000$ & 392,977 & 844,871 & 347,074 & 611,881 & Honduras & 1988 & 423,971 & 47,258 & 95,944 & 37,642 & 62,769 \\
\hline Argentina & 2001 & $3,600,000$ & 321,380 & 764,630 & 295,621 & 596,468 & Honduras & 2001 & 608,620 & 73,272 & 154,339 & 62,008 & 105,745 \\
\hline Argentina & 2010 & $4,000,000$ & 354,910 & 813,073 & 323,256 & 621,385 & Jamaica & 1982 & 223,668 & 27,612 & 58,456 & 17,270 & 28,729 \\
\hline Bolivia & 1976 & 461,699 & 51,674 & 109,380 & 35,230 & 57,307 & Jamaica & 1991 & 232,625 & 25,145 & 56,810 & 17,326 & 32,498 \\
\hline Bolivia & 1992 & 642,368 & 69,992 & 147,085 & 46,235 & 75,965 & Jamaica & 2001 & 205,179 & 21,357 & 47,770 & 14,349 & 25,241 \\
\hline Bolivia & 2001 & 827,692 & 90,786 & 199,275 & 63,080 & 111,001 & Mexico & 1970 & 483,405 & 54,069 & 111,210 & 41,915 & 64,605 \\
\hline Brazil & 1960 & $15,000,000$ & $1,600,000$ & $3,500,000$ & $1,300,000$ & $2,200,000$ & Mexico & 1990 & $8,100,000$ & $1,000,000$ & $2,100,000$ & 900,739 & $1,500,000$ \\
\hline Brazil & 1970 & $25,000,000$ & $2,800,000$ & $6,000,000$ & $2,300,000$ & $3,700,000$ & Mexico & 2000 & $10,000,000$ & $1,100,000$ & $2,400,000$ & 963,638 & $1,700,000$ \\
\hline Brazil & 1980 & $29,000,000$ & $3,300,000$ & $7,400,000$ & $2,700,000$ & $4,600,000$ & Mexico & 2010 & $12,000,000$ & $1,300,000$ & $2,700,000$ & $1,200,000$ & $2,200,000$ \\
\hline Brazil & 1991 & $17,000,000$ & $1,800,000$ & $4,000,000$ & $1,600,000$ & $2,800,000$ & Nicaragua & 1971 & 189,469 & 22,601 & 44,957 & 16,771 & 26,368 \\
\hline Brazil & 2000 & $20,000,000$ & $2,200,000$ & $4,800,000$ & $1,900,000$ & $3,400,000$ & Nicaragua & 1995 & 435,728 & 51,956 & 107,402 & 42,619 & 74,447 \\
\hline Brazil & 2010 & $21,000,000$ & $1,900,000$ & $4,500,000$ & $1,700,000$ & $3,200,000$ & Nicaragua & 2005 & 515,485 & 60,691 & 136,084 & 50,811 & 95,961 \\
\hline Chile & 1970 & 890,481 & 96,432 & 203,625 & 73,392 & 123,911 & Panama & 1960 & 53,553 & 5,481 & 11,869 & 3,368 & 5,498 \\
\hline Chile & 1982 & $1,100,000$ & 130,958 & 293,439 & 106,794 & 197,946 & Panama & 1970 & 150,473 & 15,817 & 34,219 & 11,310 & 18,797 \\
\hline Chile & 1992 & $1,300,000$ & 121,069 & 290,349 & 100,838 & 199,734 & Panama & 1980 & 195,577 & 22,673 & 47,420 & 17,725 & 30,333 \\
\hline Chile & 2002 & $1,500,000$ & 130,506 & 297,907 & 110,343 & 214,019 & Panama & 1990 & 232,737 & 25,536 & 57,471 & 19,537 & 36,604 \\
\hline Colombia & 1973 & $2,000,000$ & 245,355 & 493,144 & 172,222 & 281,047 & Panama & 2000 & 284,081 & 27,438 & 62,585 & 21,924 & 41,171 \\
\hline Colombia & 1985 & $2,600,000$ & 312,063 & 705,404 & 245,920 & 466,142 & Panama & 2010 & 341,118 & 30,266 & 70,017 & 26,170 & 49,837 \\
\hline Colombia & 1993 & $3,200,000$ & 336,233 & 758,037 & 263,014 & 485,909 & Paraguay & 1962 & 90,236 & 10,003 & 20,431 & 6,011 & 10,224 \\
\hline Colombia & 2005 & $4,000,000$ & 399,870 & 860,151 & 325,438 & 579,432 & Paraguay & 1972 & 233,669 & 27,630 & 54,005 & 18,806 & 31,105 \\
\hline Costa Rica & 1973 & 186,762 & 23,539 & 46,832 & 18,809 & 30,070 & Paraguay & 1982 & 301,582 & 34,248 & 74,515 & 25,177 & 45,971 \\
\hline Costa Rica & 1984 & 241,220 & 28,005 & 64,067 & 23,982 & 44,198 & Paraguay & 1992 & 415,401 & 41,705 & 89,839 & 30,061 & 52,473 \\
\hline Costa Rica & 2000 & 381,500 & 40,582 & 88,091 & 36,085 & 63,624 & Paraguay & 2002 & 516,083 & 59,365 & 125,811 & 48,042 & 85,609 \\
\hline Costa Rica & 2011 & 430,082 & 40,703 & 98,328 & 36,805 & 74,880 & Peru & 1993 & $2,200,000$ & 245,196 & 539,320 & 183,244 & 335,766 \\
\hline Cuba & 2002 & $1,100,000$ & 82,556 & 180,787 & 69,378 & 132,152 & Peru & 2007 & $2,700,000$ & 280,035 & 636,955 & 222,254 & 419,885 \\
\hline Dominican Republic & 1981 & 475,829 & 62,387 & 126,838 & 49,358 & 84,310 & Saint Lucia & 1980 & 11,451 & 1,516 & 2,985 & 1,076 & 1,754 \\
\hline Dominican Republic & 2002 & 857,606 & 85,616 & 194,479 & 69,843 & 128,140 & Saint Lucia & 1991 & 13,382 & 1,455 & 3,406 & 1,138 & 2,154 \\
\hline Dominican Republic & 2010 & 943,784 & 98,661 & 221,932 & 78,426 & 142,857 & Trinidad and Tobago & 1970 & 69,349 & 8,259 & 16,684 & 6,398 & 10,873 \\
\hline Ecuador & 1974 & 648,678 & 72,812 & 162,826 & 49,142 & 82,561 & Trinidad and Tobago & 1980 & 105,464 & 13,096 & 28,713 & 11,078 & 20,578 \\
\hline Ecuador & 1982 & 806,834 & 89,627 & 194,868 & 64,889 & 112,394 & Trinidad and Tobago & 1990 & 113,104 & 10,646 & 24,520 & 9,232 & 18,279 \\
\hline Ecuador & 1990 & 966,234 & 108,806 & 237,150 & 83,171 & 146,856 & Trinidad and Tobago & 2000 & 111,833 & 12,444 & 26,458 & 10,890 & 20,515 \\
\hline Ecuador & 2001 & $1,200,000$ & 126,354 & 287,034 & 100,955 & 186,327 & Trinidad and Tobago & 2011 & 116,917 & 8,325 & 22,630 & 7,288 & 17,595 \\
\hline Ecuador & 2010 & $1,400,000$ & 145,454 & 326,549 & 117,218 & 212,597 & Uruguay & 1963 & 256,171 & 20,618 & 47,079 & 15,749 & 28,722 \\
\hline El Salvador & 1992 & 510,760 & 62,794 & 129,373 & 44,508 & 74,325 & Uruguay & 1975 & 279,994 & 24,213 & 53,152 & 18,704 & 33,222 \\
\hline El Salvador & 2007 & 574,364 & 62,912 & 131,762 & 55,338 & 100,318 & Uruguay & 1985 & 295,915 & 23,728 & 55,355 & 18,881 & 35,368 \\
\hline Guatemala & 1964 & 210,079 & 22,674 & 46,804 & 17,177 & 27,249 & Uruguay & 1996 & 315,920 & 26,188 & 60,440 & 21,870 & 41,399 \\
\hline Guatemala & 1973 & 289,446 & 33,148 & 71,814 & 24,569 & 39,263 & Uruguay & 2006 & 256,866 & 21,943 & 45,451 & 20,277 & 36,604 \\
\hline Guatemala & 1981 & 302,106 & 33,771 & 72,879 & 26,958 & 45,277 & Uruguay & 2011 & 328,425 & 26,825 & 60,496 & 23,925 & 43,382 \\
\hline Guatemala & 1994 & 833,137 & 97,480 & 196,310 & 82,505 & 135,877 & Venezuela & 1971 & $1,200,000$ & 133,044 & 282,119 & 87,971 & 144,465 \\
\hline Guatemala & 2002 & $1,100,000$ & 127,311 & 269,696 & 114,181 & 200,981 & Venezuela & 1981 & $1,400,000$ & 166,729 & 367,032 & 133,566 & 238,340 \\
\hline Haiti & 1971 & 434,869 & 51,096 & 101,984 & 35,014 & 58,427 & Venezuela & 1990 & $1,800,000$ & 199,055 & 445,482 & 149,752 & 269,185 \\
\hline Haiti & 1982 & 128,770 & 15,471 & 36,494 & 8,349 & 15,840 & Venezuela & 2001 & $2,300,000$ & 234,403 & 534,204 & 204,784 & 394,511 \\
\hline
\end{tabular}

Notes: This table reports the total sample size by country-year Census, and for restricted population by age and keeping only observations with information of education for children and parents. 


\section{B Rates of co-residence}

This table shows the co-residency rate by country for different ages. The co-residence rate is the total number of individuals that co-reside with at least one member of an immediately older generation in the household divided by the total number of individuals in the age group. The sample considers only individuals for whom their own educational attainment and the relationship to household head are observed.

Table A3: Co-residence rates

\begin{tabular}{|c|c|c|c|c|c|c|c|c|}
\hline & \multicolumn{4}{|c|}{ Rate } & \multicolumn{4}{|c|}{ Observations (thousands) } \\
\hline & $14-18$ & $18-25$ & $21-25$ & $20-23$ & $14-18$ & $18-25$ & $21-25$ & $20-23$ \\
\hline Argentina & 95.7 & 72.1 & 63.1 & 72.2 & 1246 & 1746 & 1067 & 870 \\
\hline Bolivia & 86.7 & 57.6 & 48.8 & 56.4 & 263 & 358 & 218 & 180 \\
\hline Brazil & 93.7 & 63.0 & 51.7 & 62.0 & 12292 & 16695 & 10015 & 8312 \\
\hline Chile & 95.4 & 72.7 & 63.8 & 73.3 & 410 & 570 & 351 & 285 \\
\hline Colombia & 93.4 & 68.4 & 59.6 & 68.2 & 1086 & 1451 & 888 & 717 \\
\hline Costa Rica & 94.5 & 68.3 & 58.8 & 68.0 & 122 & 173 & 105 & 87 \\
\hline Cuba & 91.6 & 74.6 & 68.7 & 74.8 & 141 & 217 & 136 & 107 \\
\hline Dominican Republic & 89.0 & 63.4 & 54.1 & 62.7 & 222 & 307 & 182 & 153 \\
\hline Ecuador & 92.8 & 64.8 & 55.2 & 64.2 & 451 & 621 & 378 & 311 \\
\hline El Salvador & 90.8 & 66.8 & 57.8 & 66.1 & 110 & 138 & 82 & 68 \\
\hline Guatemala & 92.8 & 63.4 & 52.8 & 62.6 & 286 & 363 & 214 & 180 \\
\hline Haiti & 94.4 & 71.6 & 60.3 & 71.1 & 123 & 158 & 88 & 76 \\
\hline Honduras & 91.1 & 62.3 & 52.1 & 60.9 & 136 & 168 & 98 & 83 \\
\hline Jamaica & 90.5 & 65.2 & 55.2 & 64.7 & 58 & 76 & 45 & 37 \\
\hline Mexico & 93.8 & 69.1 & 59.4 & 68.5 & 3363 & 4318 & 2536 & 2112 \\
\hline Nicaragua & 92.4 & 67.7 & 59.1 & 67.2 & 120 & 156 & 93 & 78 \\
\hline Panama & 92.5 & 66.8 & 57.7 & 66.3 & 108 & 150 & 91 & 74 \\
\hline Paraguay & 94.7 & 67.4 & 57.4 & 67.2 & 136 & 177 & 107 & 89 \\
\hline Peru & 93.3 & 69.8 & 61.8 & 69.4 & 436 & 604 & 371 & 301 \\
\hline Saint Lucia & 94.7 & 66.3 & 55.7 & 65.2 & 2 & 3 & 2 & 2 \\
\hline Suriname & 95.7 & 81.2 & 75.6 & 82.2 & 4 & 5 & 3 & 3 \\
\hline Trinidad and Tobago & 96.1 & 78.1 & 70.4 & 78.8 & 47 & 66 & 40 & 32 \\
\hline Uruguay & 95.4 & 68.9 & 59.2 & 68.6 & 125 & 175 & 107 & 87 \\
\hline Venezuela & 92.6 & 67.7 & 59.0 & 67.1 & 630 & 858 & 518 & 428 \\
\hline
\end{tabular}


Figure A1: Coresidence rate by age for subgroups

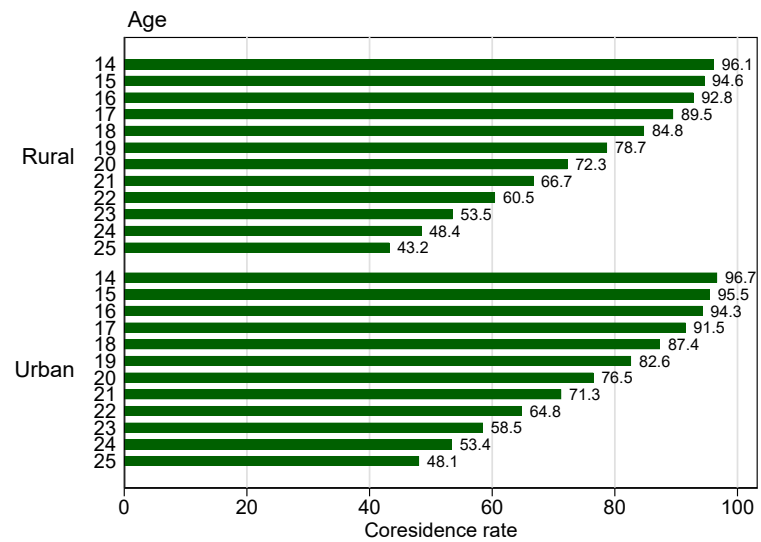

(a) Coresidence rates by urban-rural status

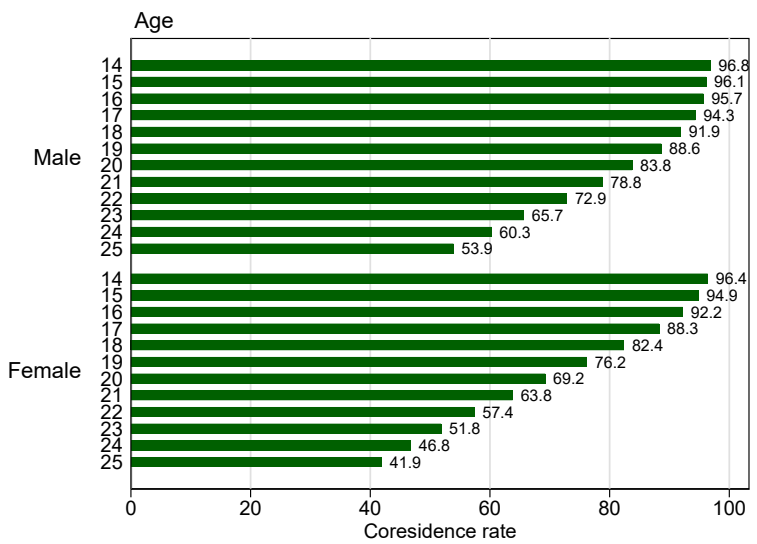

(b) Coresidence rate by gender

Notes: Coresidence is defined as living with at least one individual of the immediately previous generation.

The data in the graph is unweighted.

Table A4: Co-residence rate by sample

\begin{tabular}{llllllllll}
\hline & & \multicolumn{4}{c}{ Rate } & \multicolumn{4}{c}{ Observations (thousands) } \\
& Year & $14-18$ & $18-25$ & $21-25$ & $20-23$ & $14-18$ & $18-25$ & $21-25$ & $20-23$ \\
\hline Argentina & 1970 & 95.0 & 69.7 & 59.3 & 69.8 & 33 & 48 & 29 & 24 \\
Argentina & 1980 & 94.6 & 68.2 & 58.8 & 68.6 & 204 & 276 & 174 & 138 \\
Argentina & 1991 & 95.6 & 69.4 & 59.1 & 69.3 & 364 & 468 & 281 & 231 \\
Argentina & 2001 & 96.7 & 76.4 & 68.7 & 76.8 & 306 & 464 & 288 & 238 \\
Argentina & 2010 & 95.5 & 73.1 & 64.5 & 72.9 & 338 & 490 & 295 & 240 \\
Bolivia & 1976 & 90.8 & 54.8 & 43.0 & 52.8 & 39 & 52 & 31 & 26 \\
Bolivia & 1992 & 93.1 & 58.1 & 46.7 & 56.9 & 52 & 68 & 42 & 34 \\
Bolivia & 2001 & 85.9 & 57.5 & 49.3 & 56.6 & 74 & 102 & 62 & 52 \\
Bolivia & 2012 & 82.3 & 58.4 & 51.6 & 57.4 & 98 & 137 & 83 & 68 \\
Brazil & 1960 & 94.9 & 61.3 & 48.5 & 60.1 & 1386 & 1824 & 1069 & 905 \\
Brazil & 1970 & 95.7 & 62.9 & 49.4 & 61.4 & 2383 & 2963 & 1714 & 1474 \\
Brazil & 1980 & 94.4 & 59.6 & 47.1 & 58.2 & 2907 & 3972 & 2407 & 1987 \\
Brazil & 1991 & 92.3 & 63.5 & 53.3 & 62.8 & 1710 & 2347 & 1433 & 1166 \\
Brazil & 2000 & 92.6 & 65.5 & 54.8 & 64.6 & 2064 & 2837 & 1665 & 1404 \\
Brazil & 2010 & 91.6 & 66.2 & 58.0 & 66.1 & 1842 & 2753 & 1727 & 1377 \\
Chile & 1970 & 95.8 & 68.8 & 58.0 & 69.1 & 77 & 91 & 55 & 45 \\
Chile & 1982 & 96.2 & 74.0 & 64.5 & 74.5 & 111 & 150 & 91 & 75 \\
Chile & 1992 & 94.5 & 71.2 & 62.5 & 72.2 & 107 & 166 & 105 & 82 \\
Chile & 2002 & 95.1 & 75.1 & 67.8 & 75.6 & 116 & 163 & 101 & 83 \\
Colombia & 1973 & 93.8 & 66.2 & 54.8 & 64.8 & 185 & 212 & 122 & 103 \\
Colombia & 1985 & 95.4 & 73.1 & 64.5 & 73.8 & 260 & 370 & 225 & 183 \\
Colombia & 1993 & 94.3 & 68.7 & 60.1 & 68.6 & 282 & 398 & 251 & 197 \\
Colombia & 2005 & 91.1 & 65.5 & 57.4 & 64.9 & 360 & 472 & 290 & 233 \\
\hline & & & & & & Continued & on next page \\
\hline
\end{tabular}


Table A4 - continued from previous page

\begin{tabular}{|c|c|c|c|c|c|c|c|c|c|}
\hline & Year & $14-18$ & $18-25$ & $21-25$ & $20-23$ & $14-18$ & $18-25$ & $21-25$ & $20-23$ \\
\hline Costa Rica & 1973 & 95.5 & 64.4 & 50.9 & 62.4 & 20 & 23 & 13 & 11 \\
\hline Costa Rica & 1984 & 95.0 & 66.2 & 55.3 & 65.8 & 25 & 38 & 23 & 19 \\
\hline Costa Rica & 2000 & 94.5 & 67.5 & 57.5 & 66.7 & 38 & 50 & 30 & 25 \\
\hline Costa Rica & 2011 & 93.7 & 71.7 & 64.4 & 72.3 & 39 & 63 & 40 & 32 \\
\hline Cuba & 2002 & 91.3 & 73.5 & 66.7 & 73.3 & 76 & 103 & 62 & 48 \\
\hline Cuba & 2012 & 92.0 & 75.5 & 70.4 & 75.9 & 65 & 113 & 74 & 59 \\
\hline Dominican Republic & 1981 & 91.7 & 67.1 & 56.9 & 65.7 & 54 & 67 & 38 & 33 \\
\hline Dominican Republic & 2002 & 90.0 & 63.8 & 54.9 & 63.6 & 78 & 111 & 68 & 56 \\
\hline Dominican Republic & 2010 & 86.6 & 61.2 & 52.0 & 60.4 & 91 & 129 & 76 & 64 \\
\hline Ecuador & 1974 & 92.8 & 62.0 & 51.2 & 60.7 & 53 & 68 & 40 & 33 \\
\hline Ecuador & 1982 & 93.8 & 64.4 & 54.1 & 63.6 & 71 & 94 & 57 & 48 \\
\hline Ecuador & 1990 & 93.1 & 65.1 & 54.8 & 64.8 & 90 & 122 & 74 & 60 \\
\hline Ecuador & 2001 & 92.3 & 65.3 & 56.2 & 64.8 & 110 & 159 & 98 & 82 \\
\hline Ecuador & 2010 & 92.4 & 65.5 & 56.6 & 64.8 & 128 & 178 & 109 & 88 \\
\hline El Salvador & 1992 & 91.3 & 61.8 & 51.0 & 61.0 & 49 & 61 & 37 & 30 \\
\hline El Salvador & 2007 & 90.5 & 70.7 & 63.2 & 70.1 & 61 & 77 & 46 & 38 \\
\hline Guatemala & 1964 & 91.6 & 56.1 & 44.8 & 55.6 & 19 & 23 & 14 & 11 \\
\hline Guatemala & 1973 & 88.4 & 50.4 & 39.8 & 48.9 & 28 & 38 & 22 & 19 \\
\hline Guatemala & 1981 & 92.7 & 59.4 & 47.9 & 58.3 & 29 & 40 & 23 & 20 \\
\hline Guatemala & 1994 & 93.5 & 64.5 & 53.5 & 63.5 & 88 & 104 & 61 & 51 \\
\hline Guatemala & 2002 & 93.5 & 67.8 & 57.8 & 67.2 & 122 & 159 & 93 & 80 \\
\hline Haiti & 1971 & 94.9 & 66.9 & 52.8 & 66.8 & 37 & 45 & 25 & 21 \\
\hline Haiti & 1982 & 93.8 & 67.7 & 56.3 & 67.9 & 9 & 14 & 8 & 7 \\
\hline Haiti & 2003 & 94.3 & 74.3 & 64.3 & 73.6 & 77 & 99 & 55 & 47 \\
\hline Honduras & 1974 & 92.0 & 59.4 & 48.2 & 58.2 & 26 & 31 & 18 & 15 \\
\hline Honduras & 1988 & 92.6 & 64.6 & 54.7 & 63.5 & 41 & 48 & 29 & 24 \\
\hline Honduras & 2001 & 89.9 & 62.0 & 52.0 & 60.5 & 69 & 89 & 51 & 45 \\
\hline Jamaica & 1982 & 90.9 & 65.0 & 53.7 & 64.2 & 20 & 25 & 14 & 12 \\
\hline Jamaica & 1991 & 91.7 & 67.5 & 57.8 & 67.6 & 20 & 28 & 17 & 14 \\
\hline Jamaica & 2001 & 88.5 & 62.5 & 53.6 & 61.6 & 17 & 23 & 14 & 11 \\
\hline Mexico & 1970 & 94.7 & 58.2 & 44.0 & 56.8 & 44 & 51 & 29 & 24 \\
\hline Mexico & 1990 & 94.0 & 66.5 & 55.3 & 65.8 & 958 & 1191 & 689 & 579 \\
\hline Mexico & 2000 & 93.0 & 66.8 & 57.4 & 66.4 & 1079 & 1442 & 869 & 708 \\
\hline Mexico & 2010 & 94.2 & 73.3 & 64.7 & 72.8 & 1282 & 1634 & 949 & 801 \\
\hline Nicaragua & 1971 & 93.1 & 61.8 & 49.6 & 60.8 & 18 & 20 & 12 & 10 \\
\hline Nicaragua & 1995 & 93.5 & 69.4 & 60.4 & 68.8 & 46 & 56 & 33 & 28 \\
\hline Nicaragua & 2005 & 91.2 & 68.1 & 60.5 & 67.6 & 56 & 80 & 49 & 40 \\
\hline Panama & 1960 & 91.3 & 52.8 & 40.6 & 52.3 & 4 & 5 & 3 & 3 \\
\hline Panama & 1970 & 91.7 & 57.8 & 46.4 & 56.5 & 12 & 16 & 10 & 8 \\
\hline Panama & 1980 & 92.7 & 65.9 & 55.1 & 65.1 & 19 & 24 & 14 & 12 \\
\hline Panama & 1990 & 93.2 & 69.9 & 61.0 & 69.6 & 21 & 30 & 18 & 15 \\
\hline Panama & 2000 & 93.3 & 68.8 & 60.4 & 68.4 & 24 & 33 & 21 & 16 \\
\hline Panama & 2010 & 91.8 & 68.6 & 61.0 & 68.5 & 29 & 41 & 25 & 20 \\
\hline Paraguay & 1962 & 95.7 & 63.1 & 51.9 & 64.3 & 6 & 8 & 5 & 4 \\
\hline Paraguay & 1972 & 96.0 & 66.5 & 55.3 & 67.1 & 20 & 23 & 14 & 11 \\
\hline & & & & & & \multicolumn{4}{|c|}{ Continued on next page } \\
\hline
\end{tabular}


Table A4 - continued from previous page

\begin{tabular}{llllllllll}
\hline & Year & $14-18$ & $18-25$ & $21-25$ & $20-23$ & $14-18$ & $18-25$ & $21-25$ & $20-23$ \\
\hline Paraguay & 1982 & 94.7 & 67.6 & 57.9 & 67.8 & 27 & 37 & 23 & 19 \\
Paraguay & 1992 & 93.2 & 61.8 & 52.0 & 60.9 & 32 & 44 & 27 & 22 \\
Paraguay & 2002 & 95.1 & 72.0 & 62.5 & 71.5 & 51 & 64 & 37 & 32 \\
Peru & 1993 & 94.0 & 69.5 & 60.9 & 69.1 & 196 & 267 & 165 & 135 \\
Peru & 2007 & 92.7 & 70.0 & 62.5 & 69.6 & 240 & 337 & 206 & 166 \\
Saint Lucia & 1980 & 95.3 & 64.5 & 51.5 & 63.2 & 1 & 1 & 1 & 1 \\
Saint Lucia & 1991 & 94.0 & 67.7 & 58.6 & 66.9 & 1 & 2 & 1 & 1 \\
Suriname & 2012 & 95.7 & 81.2 & 75.6 & 82.2 & 4 & 5 & 3 & 3 \\
Trinidad and Tobago & 1970 & 97.0 & 72.1 & 59.5 & 72.0 & 7 & 8 & 4 & 4 \\
Trinidad and Tobago & 1980 & 95.2 & 73.2 & 63.2 & 73.6 & 12 & 16 & 9 & 8 \\
Trinidad and Tobago & 1990 & 95.8 & 76.9 & 69.4 & 78.0 & 10 & 14 & 9 & 7 \\
Trinidad and Tobago & 2000 & 96.4 & 81.4 & 74.2 & 81.2 & 12 & 15 & 8 & 7 \\
Trinidad and Tobago & 2011 & 96.5 & 84.4 & 80.1 & 86.2 & 8 & 14 & 9 & 7 \\
Uruguay & 1963 & 97.1 & 70.6 & 60.0 & 70.3 & 16 & 23 & 14 & 11 \\
Uruguay & 1975 & 96.5 & 67.6 & 56.0 & 66.6 & 19 & 27 & 16 & 13 \\
Uruguay & 1985 & 96.9 & 67.1 & 57.5 & 67.6 & 19 & 29 & 19 & 15 \\
Uruguay & 1996 & 94.0 & 69.3 & 60.5 & 69.3 & 23 & 34 & 21 & 17 \\
Uruguay & 2006 & 95.0 & 74.9 & 65.7 & 74.6 & 21 & 27 & 16 & 13 \\
Uruguay & 2011 & 94.0 & 65.6 & 56.5 & 64.8 & 25 & 36 & 22 & 18 \\
Venezuela & 1971 & 93.7 & 60.5 & 48.4 & 58.8 & 97 & 121 & 71 & 60 \\
Venezuela & 1981 & 92.8 & 66.7 & 57.3 & 66.1 & 144 & 192 & 115 & 96 \\
Venezuela & 1990 & 91.7 & 66.6 & 57.9 & 65.8 & 168 & 227 & 137 & 112 \\
Venezuela & 2001 & 92.7 & 71.7 & 64.6 & 71.7 & 221 & 318 & 195 & 160 \\
\hline \hline
\end{tabular}




\section{Schooling by cohort}

In this section, I summarize the education level by country and cohort using data on individuals at least 25 years old.

Table A5: Education by cohort

\begin{tabular}{|c|c|c|c|c|c|c|}
\hline & cohort & mean years & less primary & primary & secondary & tertiary \\
\hline Argentina & 1950 & 9.1 & 17.8 & 50.6 & 24.1 & 7.5 \\
\hline Argentina & 1960 & 10.0 & 11.3 & 48.9 & 31.4 & 8.4 \\
\hline Argentina & 1970 & 10.8 & 8.1 & 45.8 & 36.1 & 9.9 \\
\hline Argentina & 1980 & 11.4 & 7.4 & 46.3 & 35.9 & 10.4 \\
\hline Bolivia & 1950 & 6.3 & 46.1 & 30.7 & 17.4 & 5.9 \\
\hline Bolivia & 1960 & 7.8 & 31.4 & 38.5 & 22.8 & 7.3 \\
\hline Bolivia & 1970 & 9.2 & 22.7 & 37.7 & 28.7 & 10.9 \\
\hline Bolivia & 1980 & 10.7 & 13.7 & 34.7 & 35.6 & 16.1 \\
\hline Brazil & 1950 & 5.7 & 58.2 & 18.0 & 15.7 & 8.2 \\
\hline Brazil & 1960 & 6.7 & 44.6 & 25.4 & 21.5 & 8.5 \\
\hline Brazil & 1970 & 7.2 & 33.8 & 28.1 & 27.9 & 10.2 \\
\hline Brazil & 1980 & & 18.9 & 28.9 & 39.0 & 13.2 \\
\hline Chile & 1950 & 9.2 & 19.0 & 47.2 & 28.7 & 5.1 \\
\hline Chile & 1960 & 10.1 & 12.0 & 45.9 & 37.3 & 4.8 \\
\hline Chile & 1970 & 11.3 & 6.8 & 39.4 & 46.2 & 7.6 \\
\hline Chile & 1980 & & & & & \\
\hline Colombia & 1950 & 6.5 & 34.9 & 39.7 & 18.9 & 6.5 \\
\hline Colombia & 1960 & 7.5 & 24.5 & 42.2 & 26.6 & 6.7 \\
\hline Colombia & 1970 & 8.8 & 18.2 & 34.6 & 34.6 & 12.6 \\
\hline Colombia & 1980 & 9.4 & 14.1 & 30.0 & 43.0 & 12.9 \\
\hline Costa Rica & 1950 & 7.9 & 23.1 & 46.9 & 18.3 & 11.7 \\
\hline Costa Rica & 1960 & 8.6 & 14.7 & 51.8 & 19.2 & 14.3 \\
\hline Costa Rica & 1970 & 8.7 & 15.1 & 50.3 & 17.2 & 17.4 \\
\hline Costa Rica & 1980 & 9.7 & 11.4 & 44.1 & 20.1 & 24.3 \\
\hline Cuba & 1950 & 10.4 & 7.6 & 46.1 & 32.6 & 13.7 \\
\hline Cuba & 1960 & 11.4 & 2.8 & 39.7 & 43.4 & 14.2 \\
\hline Cuba & 1970 & 11.7 & 1.9 & 37.6 & 46.9 & 13.6 \\
\hline Cuba & 1980 & 12.3 & 1.5 & 24.3 & 52.1 & 22.1 \\
\hline Dominican Republic & 1950 & 6.3 & 50.5 & 29.0 & 12.3 & 8.1 \\
\hline Dominican Republic & 1960 & 8.0 & 33.5 & 37.1 & 17.8 & 11.7 \\
\hline Dominican Republic & 1970 & 8.6 & 27.4 & 39.4 & 22.3 & 10.9 \\
\hline Dominican Republic & 1980 & 9.7 & 19.8 & 33.6 & 34.0 & 12.6 \\
\hline Ecuador & 1950 & 7.4 & 34.3 & 39.8 & 17.7 & 8.2 \\
\hline Ecuador & 1960 & 8.8 & 22.4 & 41.7 & 26.1 & 9.8 \\
\hline
\end{tabular}


Table A5 - continued from previous page

\begin{tabular}{lllllll}
\hline & cohort & mean years & less primary & primary & secondary & tertiary \\
\hline Ecuador & 1970 & 9.4 & 16.4 & 42.7 & 30.9 & 10.0 \\
Ecuador & 1980 & 10.2 & 11.1 & 39.5 & 37.2 & 12.1 \\
El Salvador & 1950 & 5.2 & 55.6 & 27.3 & 12.9 & 4.2 \\
El Salvador & 1960 & 6.5 & 45.0 & 31.7 & 18.3 & 5.0 \\
El Salvador & 1970 & 7.5 & 37.3 & 33.3 & 23.0 & 6.4 \\
El Salvador & 1980 & 8.1 & 31.5 & 37.2 & 25.7 & 5.6 \\
Guatemala & 1950 & 3.5 & 71.9 & 18.5 & 6.4 & 3.3 \\
Guatemala & 1960 & 4.5 & 62.3 & 24.6 & 9.1 & 3.9 \\
Guatemala & 1970 & 5.2 & 55.2 & 29.0 & 11.3 & 4.5 \\
Guatemala & 1980 & & & & & \\
Haiti & 1950 & 3.0 & 71.9 & 21.3 & 6.0 & 0.8 \\
Haiti & 1960 & 3.4 & 67.7 & 18.5 & 12.6 & 1.2 \\
Haiti & 1970 & 5.2 & 52.6 & 28.1 & 18.2 & 1.2 \\
Haiti & 1980 & & & & & \\
Honduras & 1950 & 4.5 & 61.8 & 25.8 & 9.7 & 2.7 \\
Honduras & 1960 & 5.4 & 50.7 & 33.2 & 13.0 & 3.0 \\
Honduras & 1970 & 6.0 & 41.5 & 42.2 & 13.9 & 2.5 \\
Honduras & 1980 & & & & & \\
Jamaica & 1950 & 9.7 & 7.4 & 60.5 & 29.4 & 2.7 \\
Jamaica & 1960 & 11.2 & 2.7 & 44.7 & 50.2 & 2.4 \\
Jamaica & 1970 & 12.4 & 2.1 & 20.9 & 74.5 & 2.6 \\
Jamaica & 1980 & & & & & \\
Mexico & 1950 & 6.8 & 37.4 & 41.8 & 11.4 & 9.5 \\
Mexico & 1960 & 8.3 & 23.6 & 47.8 & 17.3 & 11.4 \\
Mexico & 1970 & 9.2 & 13.8 & 54.0 & 19.9 & 12.3 \\
Mexico & 1980 & 10.1 & 9.8 & 50.3 & 24.1 & 15.8 \\
Nicaragua & 1950 & 4.9 & 59.7 & 24.4 & 9.3 & 6.5 \\
Nicaragua & 1960 & 6.0 & 48.1 & 31.6 & 13.9 & 6.5 \\
Nicaragua & 1970 & 6.4 & 42.9 & 33.2 & 16.5 & 7.4 \\
Nicaragua & 1980 & 6.8 & 39.3 & 32.7 & 20.3 & 7.7 \\
Panama & 1950 & 8.6 & 21.2 & 45.5 & 21.4 & 11.8 \\
Panama & 1960 & 9.7 & 12.4 & 45.0 & 29.0 & 13.6 \\
Panama & 1970 & 10.2 & 11.0 & 40.8 & 31.1 & 17.2 \\
Panama & 1980 & 10.7 & 8.8 & 36.7 & 36.3 & 18.2 \\
Paraguay & 1950 & 6.2 & 46.8 & 39.2 & 9.9 & 4.2 \\
Paraguay & 1960 & 7.3 & 34.1 & 43.7 & 16.9 & 5.3 \\
Paraguay & 1970 & 8.1 & 26.3 & 46.0 & 21.3 & 6.5 \\
Paraguay & 1980 & & & & & \\
Peru & 1950 & 7.5 & 38.8 & 16.8 & 32.9 & 11.6 \\
Peru & 1960 & 8.4 & 28.2 & 19.2 & 41.4 & 11.2 \\
Peru & 1970 & 9.3 & 16.9 & 20.8 & 48.3 & 14.0 \\
Peru & 1980 & 9.7 & 11.9 & 21.2 & 55.2 & 11.6 \\
\hline & & & & & Continued on next page \\
\hline
\end{tabular}


Table A5 - continued from previous page

\begin{tabular}{lllllll}
\hline & cohort & mean years & less primary & primary & secondary & tertiary \\
\hline Saint Lucia & 1950 & 9.4 & 72.3 & 3.9 & 20.8 & 3.0 \\
Saint Lucia & 1960 & & 52.7 & 8.8 & 35.6 & 2.8 \\
Saint Lucia & 1970 & & & & & \\
Saint Lucia & 1980 & & & & & \\
Suriname & 1950 & & 11.3 & 69.8 & 16.1 & 2.9 \\
Suriname & 1960 & & 7.1 & 70.9 & 18.5 & 3.5 \\
Suriname & 1970 & & 6.4 & 66.3 & 22.7 & 4.6 \\
Suriname & 1980 & & 4.9 & 57.9 & 30.8 & 6.4 \\
Trinidad and Tobago & 1950 & 9.0 & 15.8 & 44.6 & 36.4 & 3.1 \\
Trinidad and Tobago & 1960 & 10.1 & 12.1 & 31.6 & 52.9 & 3.4 \\
Trinidad and Tobago & 1970 & 11.5 & 6.7 & 20.6 & 67.8 & 4.9 \\
Trinidad and Tobago & 1980 & 12.1 & 5.4 & 15.9 & 72.0 & 6.8 \\
Uruguay & 1950 & 8.9 & 17.7 & 53.0 & 23.3 & 5.9 \\
Uruguay & 1960 & 9.2 & 12.1 & 57.5 & 22.6 & 7.8 \\
Uruguay & 1970 & 9.7 & 11.8 & 53.0 & 26.9 & 8.3 \\
Uruguay & 1980 & 10.2 & 6.6 & 54.0 & 31.9 & 7.4 \\
Venezuela & 1950 & 7.4 & 26.0 & 46.2 & 25.5 & 2.2 \\
Venezuela & 1960 & 8.1 & 18.7 & 46.3 & 34.0 & 1.1 \\
Venezuela & 1970 & 8.6 & 14.6 & 43.0 & 42.1 & 0.2 \\
Venezuela & 1980 & & & & & \\
\hline \hline
\end{tabular}




\section{District-level estimates}

Table A6: Summary Statistics: District-Level Estimates of Educational IGM

\begin{tabular}{|c|c|c|c|c|c|c|c|c|c|c|c|c|c|c|c|}
\hline \multirow[b]{2}{*}{ country } & \multirow[b]{2}{*}{ districts } & \multicolumn{7}{|c|}{ upward } & \multicolumn{7}{|c|}{ downward } \\
\hline & & mean & median & stdev & $\min$ & $\max$ & Nmin & Nmean & mean & median & stdev & $\min$ & $\max$ & Nmin & Nmean \\
\hline Cuba & 137 & .845 & .872 & .112 & .722 & .94 & 50 & 58 & .012 & .01 & .007 & 0 & .043 & 178 & 726 \\
\hline Uruguay & 67 & .798 & .793 & .056 & .684 & .94 & 50 & 151 & .046 & .043 & .022 & .003 & .098 & 238 & 737 \\
\hline Chile & 179 & .758 & .752 & .079 & .534 & .969 & 68 & 378 & .069 & .065 & .026 & .014 & .157 & 140 & 1181 \\
\hline Costa Rica & 55 & .714 & .719 & .07 & .498 & .878 & 110 & 627 & .075 & .072 & .027 & .033 & .156 & 313 & 1320 \\
\hline Argentina & 312 & .713 & .732 & .123 & .407 & .986 & 56 & 756 & .066 & .054 & .035 & .013 & .194 & 276 & 2674 \\
\hline Peru & 168 & .702 & .688 & .127 & .339 & .935 & 111 & 857 & .097 & .081 & .053 & .016 & .342 & 64 & 1275 \\
\hline Bolivia & 80 & .627 & .642 & .13 & .345 & .948 & 179 & 1114 & .111 & .104 & .059 & .027 & .317 & 80 & 1471 \\
\hline Mexico & 2,331 & .615 & .612 & .132 & .192 & 1.133 & 50 & 551 & .083 & .071 & .055 & -.052 & .504 & 50 & 702 \\
\hline Ecuador & 78 & .591 & .599 & .115 & .306 & .847 & 180 & 1930 & .109 & .095 & .047 & .054 & .291 & 244 & 2915 \\
\hline Panama & 35 & .588 & .593 & .153 & .253 & .803 & 184 & 766 & .095 & .08 & .052 & .031 & .241 & 152 & 1706 \\
\hline El Salvador & 103 & .553 & .549 & .091 & .327 & .754 & 92 & 459 & .177 & .168 & .068 & .043 & .383 & 50 & 381 \\
\hline Venezuela & 157 & .52 & .513 & .103 & .255 & .746 & 194 & 1412 & .158 & .151 & .05 & .068 & .334 & 135 & 1886 \\
\hline Colombia & 434 & .509 & .498 & .127 & -.043 & .88 & 123 & 967 & .151 & .145 & .065 & .037 & .371 & 133 & 1076 \\
\hline Paraguay & 63 & .474 & .477 & .119 & .116 & .781 & 208 & 1146 & .152 & .143 & .051 & .039 & .259 & 96 & 788 \\
\hline Dominican Republic & 66 & .462 & .463 & .082 & .301 & .667 & 73 & 770 & .154 & .147 & .036 & .082 & .273 & 94 & 953 \\
\hline Brazil & 2,040 & .386 & .387 & .15 & .019 & .827 & 366 & 2514 & .203 & .184 & .087 & .046 & .602 & 65 & 1089 \\
\hline Nicaragua & 68 & .361 & .373 & .11 & .138 & .582 & 264 & 882 & .214 & .2 & .069 & .103 & .423 & 51 & 501 \\
\hline Honduras & 96 & .355 & .346 & .109 & .112 & .576 & 211 & 805 & .24 & .224 & .08 & .109 & .44 & 52 & 359 \\
\hline Guatemala & 191 & .243 & .237 & .11 & .03 & .613 & 286 & 961 & .268 & .252 & .095 & .088 & .649 & 50 & 329 \\
\hline Haiti & 23 & .196 & .191 & .063 & .087 & .373 & 845 & 3559 & .412 & .426 & .087 & .221 & .569 & 91 & 982 \\
\hline total & 6,683 & .523 & .539 & .187 & -.043 & 1.133 & 50 & 1296 & .136 & .115 & .093 & -.052 & .649 & 50 & 1027 \\
\hline
\end{tabular}

Notes: This table shows summary statistics for district-level estimates of IGM. Upward reflects the likelihood that children, aged 14-18, whose parents have not completed primary schooling will manage to complete at least primary education. Downward reflects the likelihood that children, aged 14-18, whose parents have completed primary schooling or higher will not manage to complete primary education. "Total" shows the unweighted summary statistics across all districts. The columns "Nmin" and "Nmean" report respectively the smallest and average sample size across districts. Countries are sorted from the highest to the lowest average level of upward IGM across districts (column "mean"). Districts with less than 50 observations are omitted. 


\section{E District-level maps of mobility}

Figure A2: Upward Mobility in LAC

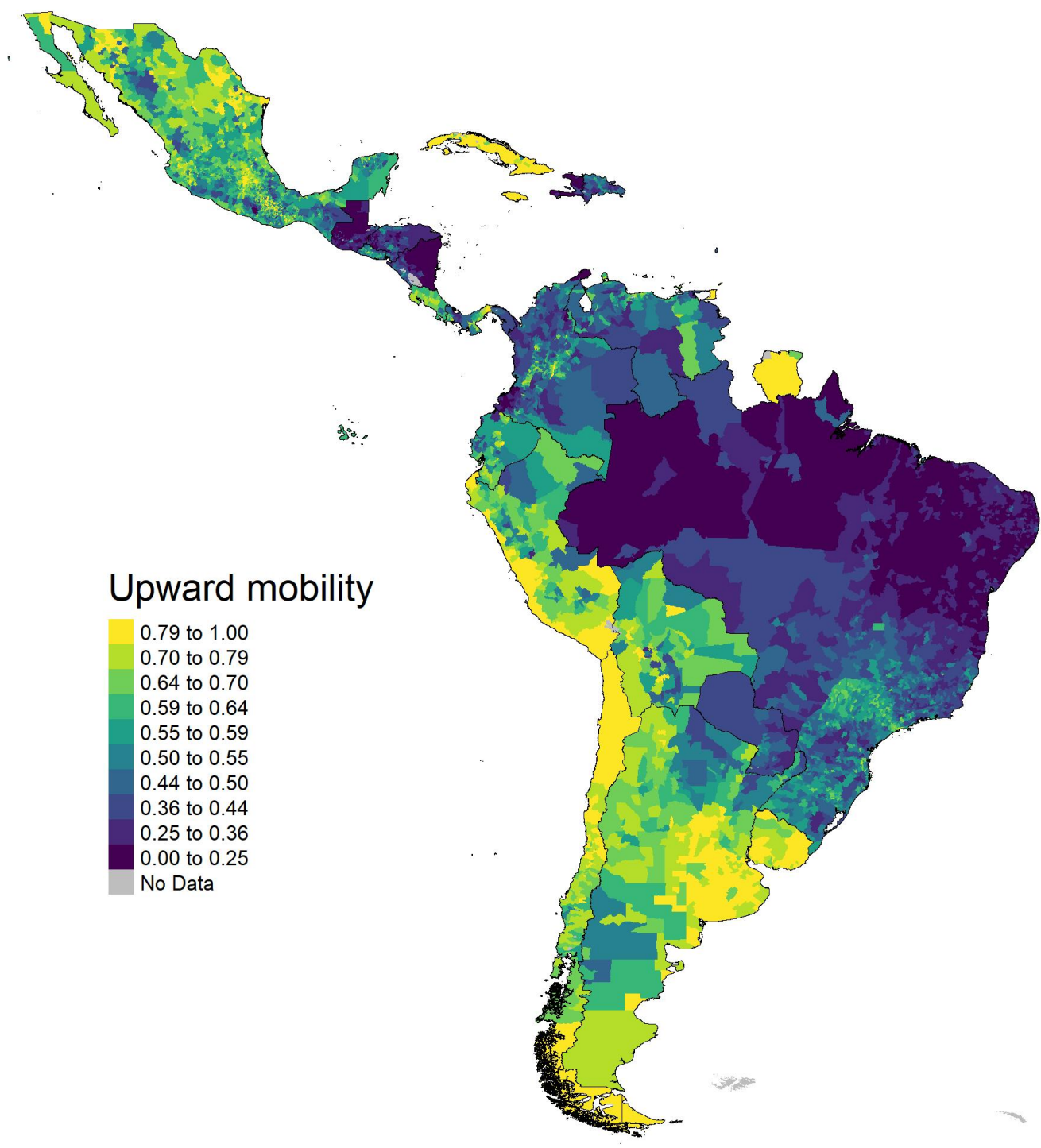

Notes: Upward mobility reflects the likelihood that children, aged 14-18, whose parents have not completed primary schooling will manage to complete at least primary education. This graph uses provinces for St. Lucia, Jamaica, Trinidad and Tobago and Suriname that do not have a finer administrative units in the data set. 
Figure A3: Downward Mobility in LAC

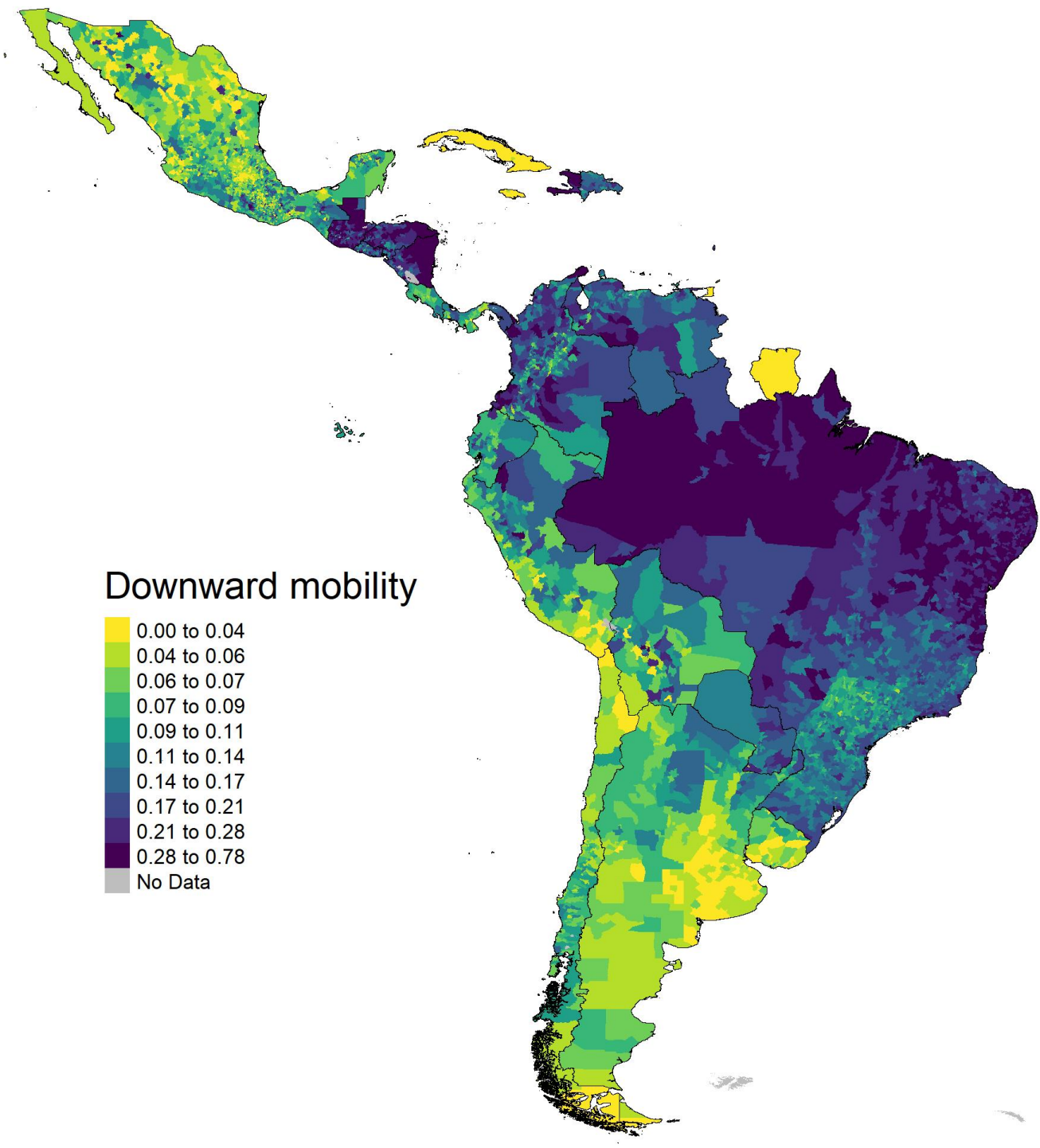

Notes: Downward mobility reflects the likelihood that children, aged 14-18, whose parents completed at least primary schooling will not manage to complete primary education. This graph uses provinces for St. Lucia, Jamaica, Trinidad and Tobago and Suriname that do not have a finer administrative units in the data set. 


\section{F District-level maps of mobility in secondary}

Figure A4: Upward Mobility in LAC

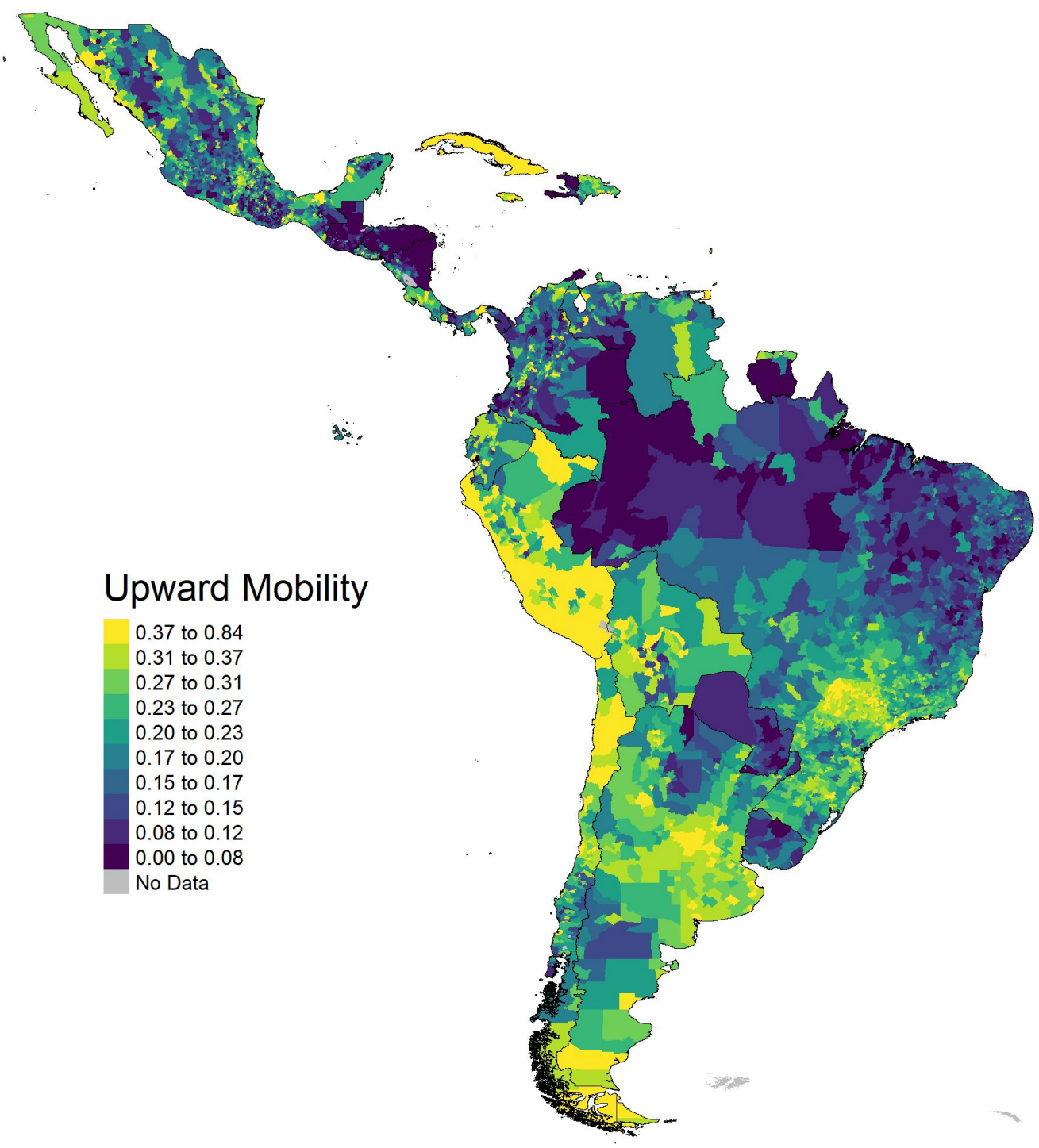

Notes: Upward mobility reflects the likelihood that children, aged 14-18, whose parents have not completed secondary schooling will manage to complete at least secondary education. This graph uses provinces for St. Lucia, Jamaica, Trinidad and Tobago and Suriname that do not have a finer administrative units in the data set. 
Figure A5: Downward Mobility in LAC

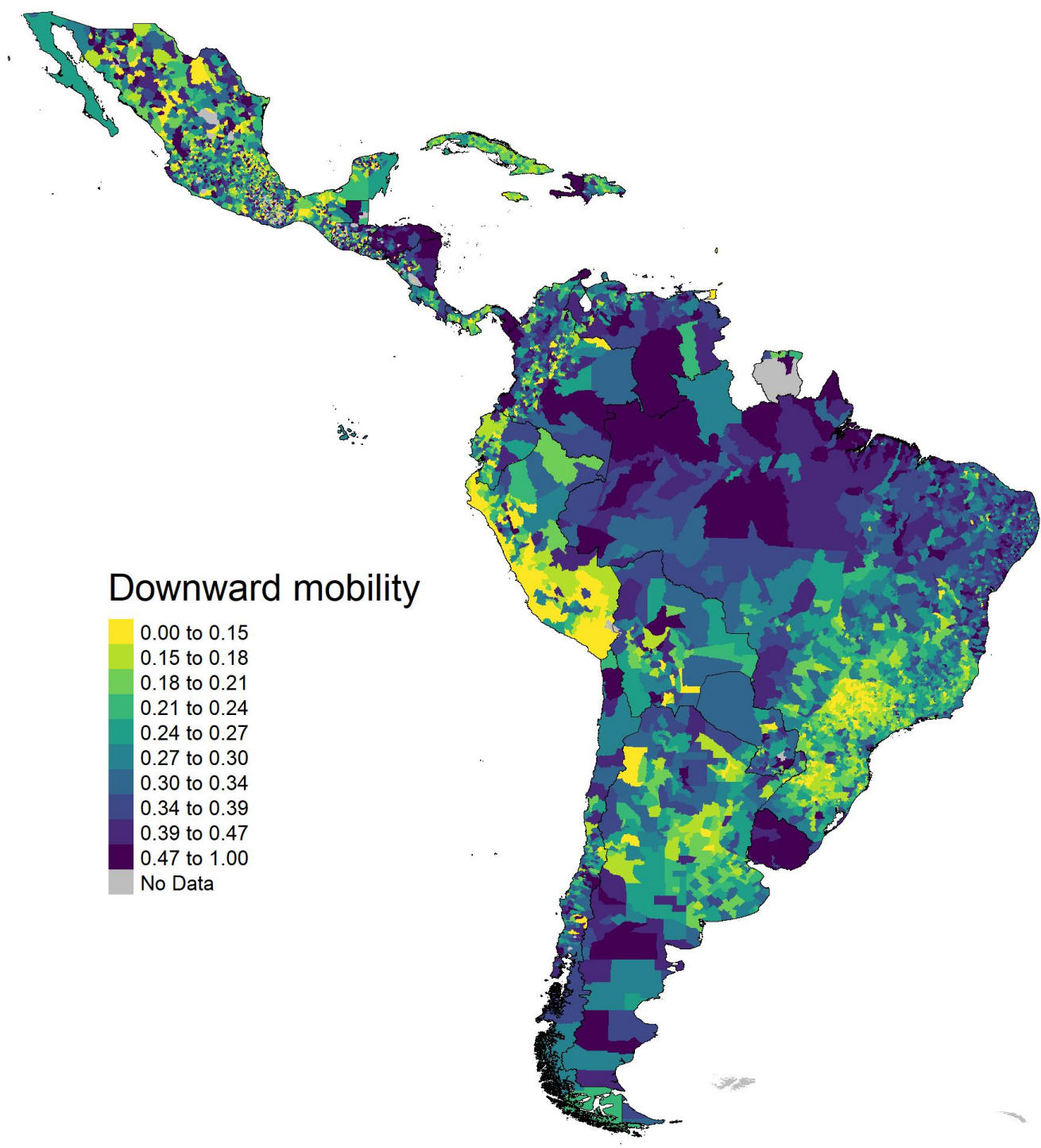

Notes: Downward mobility reflects the likelihood that children, aged 14-18, whose parents completed at least secondary schooling will not manage to complete secondary education. This graph uses provinces for St. Lucia, Jamaica, Trinidad and Tobago and Suriname that do not have a finer administrative units in the data set. 


\title{
G Estimates of IGM using secondary education
}

\author{
Table A7: Country-Level Estimates of Educational Intergenerational Mobility
}

\begin{tabular}{|c|c|c|c|c|c|c|c|}
\hline & & $(1)$ & $\overline{(2)}$ & $\overline{(3)}$ & $\overline{(4)}$ & $\overline{(5)}$ & $(6)$ \\
\hline mobility / N & census years & upward & upward & downward & downward & $\mathrm{N}$ & $\mathrm{N}$ \\
\hline age range & & $19-25$ & $20-25$ & $19-25$ & $20-25$ & $19-25$ & $20-25$ \\
\hline Trinidad and Tobago & $1970,1980,1990,2000,2011$ & .58 & .579 & .077 & .072 & 51,140 & 21,370 \\
\hline Peru & 1993,2007 & .493 & .504 & .059 & .049 & 348,429 & 220,485 \\
\hline Jamaica & $1982,1991,2001$ & .458 & .455 & .138 & .149 & 49,411 & 11,400 \\
\hline Saint Lucia & 1980,1991 & .42 & .408 & .084 & .139 & 2,694 & 168 \\
\hline Cuba & 2002,2012 & .362 & .381 & .221 & .205 & 84,252 & 123,515 \\
\hline Chile & $1970,1982,1992,2002$ & .358 & .369 & .164 & .148 & 431,534 & 129,491 \\
\hline Argentina & $1970,1980,1991,2001,2010$ & .344 & .358 & .213 & 198 & $1,276,838$ & 447,347 \\
\hline Panama & $1960,1970,1980,1990,2000,2010$ & .338 & .351 & .186 & .174 & 97,802 & 31,532 \\
\hline Bolivia & $1976,1992,2001,2012$ & .326 & .338 & .21 & .2 & 211,870 & 62,971 \\
\hline Venezuela & $1971,1981,1990,2001$ & .292 & .297 & .236 & .233 & 636,479 & 130,603 \\
\hline Ecuador & $1974,1982,1990,2001,2010$ & .289 & .3 & .194 & .176 & 429,008 & 105,824 \\
\hline Costa Rica & $1973,1984,2000,2011$ & .287 & .296 & .205 & .19 & 122,731 & 40,554 \\
\hline Dominican Republic & $1981,2002,2010$ & .257 & .278 & .243 & .216 & 197,241 & 54,451 \\
\hline Brazil & $1960,1970,1980,1991,2000,2010$ & .249 & .268 & .231 & .203 & $12,610,650$ & $1,718,702$ \\
\hline Colombia & $1973,1985,1993,2005$ & .242 & .255 & .2 & .171 & $1,152,288$ & 160,657 \\
\hline Mexico & $1970,1990,2000,2010$ & .24 & .252 & .226 & .202 & $3,392,481$ & 506,282 \\
\hline Uruguay & $1963,1975,1985,1996,2006,2011$ & .237 & .24 & .334 & .31 & 130,248 & 34,931 \\
\hline Paraguay & $1962,1972,1982,1992,2002$ & .206 & .218 & .143 & .12 & 146,601 & 15,782 \\
\hline El Salvador & 1992,2007 & .185 & .201 & .224 & .193 & 100,588 & 17,559 \\
\hline Haiti & $1971,1982,2003$ & .157 & .162 & .425 & .398 & 133,746 & 10,397 \\
\hline Guatemala & $1964,1973,1981,1994,2002$ & .122 & .131 & .195 & .169 & 278,412 & 19,341 \\
\hline Honduras & $1974,1988,2001$ & .093 & .096 & .383 & .371 & 121,155 & 11,281 \\
\hline Suriname & 2012 & .077 & .114 & .367 & .334 & 4,413 & 1,318 \\
\hline Nicaragua & $1971,1995,2005$ & .033 & .043 & .338 & .309 & 118,929 & 15,611 \\
\hline mean / total & & .277 & .287 & .221 & .205 & $22,128,940$ & $3,891,572$ \\
\hline
\end{tabular}

Notes: Columns (1) and (2) give upward-IGM estimates. They reflect the likelihood that children, aged 19-25 and 20-25, whose parents have not completed secondary schooling will manage to complete at least secondary education. Columns (3) and (4) give downward-IGM estimates. They reflect the likelihood that children, aged 19-25 and 20-25, whose parents have completed secondary schooling or higher will not manage to complete secondary education. Columns (5) and (6) give the number of observations used to estimate the country-specific IGM statistics (children whose parental education is reported in the censuses). Countries are sorted from the highest to the lowest level of upward IGM in the 19-25 sample (column (1)). "mean" gives the unweighted average of the 24 country-estimates. 
Table A8: Summary Statistics: Province-Level Estimates of Educational IGM

\begin{tabular}{|c|c|c|c|c|c|c|c|c|c|c|c|c|c|c|c|}
\hline \multirow[b]{2}{*}{ country } & \multirow[b]{2}{*}{ provinces } & \multicolumn{7}{|c|}{ upward } & \multicolumn{7}{|c|}{ downward } \\
\hline & & mean & median & stdev & $\min$ & $\max$ & Nmin & Nmean & mean & median & stdev & $\min$ & $\max$ & Nmin & Nmean \\
\hline Trinidad and Tobago & 4 & .62 & .619 & .121 & .494 & .746 & 835 & 7021 & .1 & .102 & .015 & .082 & .117 & 327 & 2941 \\
\hline Peru & 25 & .534 & .508 & .157 & .288 & .787 & 441 & 7603 & .114 & .1 & .049 & .043 & .249 & 291 & 4850 \\
\hline Cuba & 14 & .504 & .501 & .026 & .472 & .574 & 443 & 3264 & .2 & .199 & .021 & .171 & .247 & 611 & 4823 \\
\hline Jamaica & 14 & .394 & .398 & .055 & .322 & .505 & 741 & 1957 & .173 & .168 & .038 & .117 & .248 & 123 & 459 \\
\hline Bolivia & 9 & .364 & .366 & .081 & .256 & .485 & 707 & 12967 & .201 & .183 & .061 & .137 & .306 & 154 & 3841 \\
\hline Saint Lucia & 4 & .325 & .312 & .065 & .268 & .406 & 262 & 373 & .181 & .181 & & .181 & .181 & 62 & 62 \\
\hline Chile & 44 & .321 & .314 & .079 & .154 & .477 & 234 & 4438 & .283 & .28 & .059 & .175 & .42 & 68 & 1627 \\
\hline Argentina & 24 & .317 & .314 & .064 & .222 & .56 & 1136 & 29270 & .242 & .241 & .057 & .136 & .377 & 504 & 10278 \\
\hline Costa Rica & 7 & .297 & .296 & .061 & .222 & .391 & 4477 & 9661 & .263 & .227 & .073 & .193 & .371 & 864 & 3186 \\
\hline Dominican Republic & 23 & .281 & .29 & .057 & .136 & .394 & 733 & 2938 & .264 & .234 & .077 & .176 & .518 & 54 & 864 \\
\hline Mexico & 32 & .279 & .274 & .049 & .193 & .394 & 5016 & 58421 & .217 & .214 & .025 & .155 & .263 & 1130 & 8763 \\
\hline Panama & 7 & .277 & .297 & .101 & .087 & .409 & 673 & 7697 & .193 & .19 & .018 & .173 & .226 & 300 & 2912 \\
\hline Suriname & 7 & .273 & .305 & .124 & .04 & .392 & 62 & 344 & .282 & .282 & .019 & .269 & .296 & 170 & 316 \\
\hline Ecuador & 14 & .266 & .28 & .052 & .182 & .342 & 1339 & 16814 & .219 & .191 & .08 & .139 & .427 & 188 & 4181 \\
\hline Colombia & 22 & .257 & .236 & .075 & .148 & .435 & 645 & 28660 & .228 & .216 & .067 & .122 & .42 & 132 & 4020 \\
\hline Venezuela & 22 & .253 & .251 & .049 & .161 & .36 & 894 & 15945 & .291 & .281 & .07 & .183 & .487 & 153 & 3279 \\
\hline El Salvador & 14 & .208 & .216 & .066 & .124 & .385 & 1430 & 3963 & .308 & .298 & .067 & .207 & .497 & 69 & 742 \\
\hline Uruguay & 19 & .189 & .192 & .029 & .142 & .272 & 647 & 3783 & .492 & .505 & .053 & .357 & .574 & 109 & 1013 \\
\hline Brazil & 25 & .185 & .168 & .057 & .11 & .305 & 6098 & 280107 & .264 & .271 & .049 & .184 & .352 & 1744 & 38217 \\
\hline Nicaragua & 12 & .164 & .174 & .075 & .05 & .286 & 918 & 5457 & .298 & .3 & .048 & .219 & .391 & 70 & 782 \\
\hline Paraguay & 14 & .148 & .13 & .082 & .08 & .373 & 1844 & 6227 & .275 & .273 & .05 & .151 & .345 & 60 & 723 \\
\hline Guatemala & 22 & .083 & .076 & .04 & .03 & .214 & 1967 & 6973 & .305 & .284 & .064 & .214 & .426 & 51 & 486 \\
\hline Honduras & 18 & .074 & .064 & .04 & .02 & .176 & 297 & 3726 & .482 & .486 & .079 & .302 & .573 & 65 & 440 \\
\hline Haiti & 4 & .059 & .051 & .021 & .044 & .09 & 4577 & 18354 & .698 & .707 & .112 & .553 & .827 & 115 & 1426 \\
\hline total & 400 & .274 & .267 & .14 & .02 & .787 & 62 & 30464 & .268 & .247 & .112 & .043 & .827 & 51 & 5629 \\
\hline
\end{tabular}

Notes: This table shows summary statistics for province-level estimates of upward and downward IGM. Upward reflects the likelihood that children, aged 19-25, whose parents have not completed secondary schooling will manage to complete at least secondary education. Downward reflects the likelihood that children, aged 19-25, whose parents have completed secondary schooling or higher will not manage to complete secondary education. "Total" shows the unweighted summary statistics across all provinces. The columns "Nmin" and "Nmean" report respectively the smallest and average sample size across provinces. Provinces with less than 50 observations are omitted. 
Table A9: Summary Statistics: District-Level Estimates of Educational IGM

\begin{tabular}{|c|c|c|c|c|c|c|c|c|c|c|c|c|c|c|c|}
\hline \multirow[b]{2}{*}{ country } & \multirow[b]{2}{*}{ districts } & \multicolumn{7}{|c|}{ upward } & \multicolumn{7}{|c|}{ downward } \\
\hline & & mean & median & stdev & $\min$ & $\max$ & Nmin & Nmean & mean & median & stdev & $\min$ & $\max$ & Nmin & Nmean \\
\hline Cuba & 137 & .496 & .493 & .052 & .373 & .632 & 90 & 333 & .212 & .209 & .038 & .107 & .325 & 66 & 493 \\
\hline Peru & 168 & .437 & .416 & .176 & .104 & .84 & 156 & 1138 & .144 & .127 & .075 & .034 & .444 & 50 & 1024 \\
\hline Chile & 179 & .318 & .311 & .123 & .088 & .82 & 140 & 1091 & .273 & .27 & .087 & .045 & .533 & 50 & 513 \\
\hline Costa Rica & 55 & .316 & .317 & .071 & .155 & .488 & 288 & 1230 & .244 & .232 & .082 & .104 & .474 & 59 & 412 \\
\hline Argentina & 312 & .287 & .294 & .08 & .059 & .562 & 192 & 2252 & .25 & .243 & .067 & .106 & .532 & 50 & 868 \\
\hline Bolivia & 80 & .281 & .267 & .114 & .102 & .592 & 219 & 1459 & .258 & .25 & .08 & .124 & .479 & 52 & 784 \\
\hline Dominican Republic & 66 & .277 & .282 & .058 & .136 & .466 & 111 & 1040 & .26 & .241 & .073 & .158 & .518 & 51 & 427 \\
\hline Panama & 35 & .248 & .233 & .124 & .019 & .444 & 356 & 1539 & .214 & .198 & .063 & .075 & .344 & 52 & 689 \\
\hline Ecuador & 78 & .237 & .217 & .081 & .096 & .423 & 331 & 3057 & .238 & .228 & .076 & .127 & .465 & 53 & 952 \\
\hline Uruguay & 67 & .219 & .193 & .093 & .051 & .499 & 169 & 572 & .471 & .485 & .121 & .173 & .71 & 50 & 233 \\
\hline Venezuela & 157 & .216 & .211 & .07 & .067 & .404 & 289 & 2234 & .327 & .317 & .09 & .125 & .599 & 50 & 634 \\
\hline Brazil & 2,040 & .213 & .208 & .09 & -.007 & .528 & 365 & 2373 & .273 & .261 & .096 & .055 & .659 & 50 & 484 \\
\hline El Salvador & 103 & .212 & .188 & .106 & .03 & .516 & 160 & 539 & .279 & .277 & .073 & .117 & .464 & 51 & 293 \\
\hline Colombia & 434 & .21 & .189 & .098 & -.09 & .493 & 185 & 1453 & .261 & .249 & .092 & .077 & .629 & 50 & 348 \\
\hline Mexico & 2,331 & .19 & .181 & .097 & -.046 & .663 & 50 & 813 & .244 & .234 & .076 & .059 & .54 & 50 & 362 \\
\hline Nicaragua & 68 & .161 & .159 & .072 & .034 & .312 & 228 & 963 & .287 & .277 & .081 & .179 & .476 & 50 & 323 \\
\hline Paraguay & 64 & .15 & .132 & .084 & -.049 & .374 & 187 & 1326 & .264 & .259 & .064 & .151 & .406 & 53 & 377 \\
\hline Guatemala & 191 & .069 & .059 & .051 & -.006 & .268 & 199 & 803 & .302 & .282 & .075 & .162 & .441 & 55 & 324 \\
\hline Honduras & 96 & .059 & .052 & .042 & -.004 & .219 & 195 & 699 & .454 & .461 & .081 & .298 & .579 & 51 & 376 \\
\hline Haiti & 23 & .042 & .035 & .031 & .001 & .137 & 753 & 3192 & .708 & .717 & .09 & .52 & .83 & 59 & 451 \\
\hline total & 6,684 & .217 & .203 & .117 & -.09 & .84 & 50 & 1490 & .264 & .249 & .098 & .034 & .83 & 50 & 506 \\
\hline
\end{tabular}

Notes: This table shows summary statistics for district-level estimates of upward and downward IGM. Upward reflects the likelihood that children, aged 19-25, whose parents have not completed secondary schooling will manage to complete at least secondary education. Downward reflects the likelihood that children, aged 19-25, whose parents have completed secondary schooling or higher will not manage to complete secondary education. "Total" shows the unweighted summary statistics across all districts. The columns "Nmin" and "Nmean" report respectively the smallest and average sample size across districts. Districts with less than 50 observations are omitted. 


\section{H Estimates of upward IGM using primary-to-secondary education}

Table A10: Country-Level Estimates of Upward IGM using primary-to-secondary education

\begin{tabular}{|c|c|c|c|}
\hline & & (1) & $(2)$ \\
\hline mobility / N & census years & upward & $\mathrm{N}$ \\
\hline age range & & $19-25$ & $19-25$ \\
\hline Trinidad and Tobago & $1970,1980,1990,2000,2011$ & .466 & 8,506 \\
\hline Peru & 1993,2007 & .416 & 131,085 \\
\hline Saint Lucia & 1980,1991 & .388 & 1,452 \\
\hline Jamaica & $1982,1991,2001$ & .315 & 4,304 \\
\hline Bolivia & $1976,1992,2001,2012$ & .237 & 66,410 \\
\hline Chile & $1970,1982,1992,2002$ & .19 & 97,017 \\
\hline Brazil & $1960,1970,1980,1991,2000,2010$ & .187 & $6,142,101$ \\
\hline Cuba & 2002,2012 & .187 & 4,037 \\
\hline Uruguay & $1963,1975,1985,1996,2006,2011$ & .178 & 25,192 \\
\hline Argentina & $1970,1980,1991,2001,2010$ & .177 & 226,100 \\
\hline Dominican Republic & $1981,2002,2010$ & .161 & 64,387 \\
\hline Panama & $1960,1970,1980,1990,2000,2010$ & .161 & 23,221 \\
\hline Venezuela & $1971,1981,1990,2001$ & .148 & 185,993 \\
\hline Costa Rica & $1973,1984,2000,2011$ & .133 & 28,829 \\
\hline Ecuador & $1974,1982,1990,2001,2010$ & .128 & 121,410 \\
\hline Colombia & $1973,1985,1993,2005$ & .121 & 354,007 \\
\hline Mexico & $1970,1990,2000,2010$ & .107 & $1,008,707$ \\
\hline El Salvador & 1992,2007 & .092 & 37,462 \\
\hline Paraguay & $1962,1972,1982,1992,2002$ & .085 & 54,934 \\
\hline Haiti & $1971,1982,2003$ & .073 & 62,660 \\
\hline Guatemala & $1964,1973,1981,1994,2002$ & .042 & 125,087 \\
\hline Honduras & $1974,1988,2001$ & .036 & 52,754 \\
\hline Nicaragua & $1971,1995,2005$ & -.004 & 47,560 \\
\hline Suriname & 2012 & -.094 & 200 \\
\hline mean / total & & .164 & $8,873,415$ \\
\hline
\end{tabular}

Notes: Column (1) gives upward-IGM estimates. It reflects the likelihood that children, aged 19-25, whose parents have not completed primary schooling will manage to complete at least secondary education. Column (2) gives the number of observations used to estimate the country-specific IGM statistics (children whose parental education is reported in the censuses). Countries are sorted from the highest to the lowest level of upward IGM (column (1)). "mean" gives the unweighted average of the 24 country-estimates. 
Table A11: Province-Level estimates of upward IGM using primary-to-secondary education

\begin{tabular}{|c|c|c|c|c|c|c|c|c|}
\hline \multirow[b]{2}{*}{ country } & \multirow[b]{2}{*}{ provinces } & \multicolumn{7}{|c|}{ upward } \\
\hline & & mean & median & stdev & $\min$ & $\max$ & Nmin & Nmean \\
\hline Peru & 25 & .481 & .442 & .165 & .246 & .748 & 250 & 5243 \\
\hline Cuba & 14 & .323 & .342 & .049 & .231 & .384 & 155 & 309 \\
\hline Bolivia & 9 & .251 & .254 & .08 & .154 & .384 & 348 & 7379 \\
\hline Chile & 44 & .203 & .205 & .062 & .093 & .331 & 114 & 1694 \\
\hline Dominican Republic & 23 & .194 & .201 & .046 & .067 & .275 & 588 & 1795 \\
\hline Costa Rica & 7 & .166 & .167 & .042 & .12 & .244 & 2051 & 4118 \\
\hline Argentina & 24 & .155 & .15 & .048 & .089 & .322 & 219 & 9421 \\
\hline Mexico & 32 & .155 & .149 & .039 & .096 & .244 & 2143 & 31522 \\
\hline Colombia & 22 & .149 & .136 & .047 & .092 & .254 & 141 & 16091 \\
\hline El Salvador & 14 & .148 & .145 & .044 & .097 & .27 & 1209 & 2676 \\
\hline Venezuela & 22 & .147 & .147 & .029 & .082 & .214 & 643 & 8454 \\
\hline Uruguay & 19 & .144 & .139 & .027 & .094 & .191 & 264 & 1326 \\
\hline Brazil & 25 & .14 & .128 & .05 & .074 & .249 & 4716 & 245684 \\
\hline Ecuador & 14 & .136 & .134 & .031 & .098 & .204 & 840 & 8672 \\
\hline Panama & 7 & .131 & .127 & .054 & .055 & .224 & 457 & 3317 \\
\hline Nicaragua & 12 & .107 & .114 & .051 & .04 & .19 & 807 & 3963 \\
\hline Paraguay & 14 & .076 & .067 & .048 & .032 & .211 & 1312 & 4225 \\
\hline Guatemala & 22 & .049 & .047 & .021 & .012 & .106 & 1614 & 5686 \\
\hline Haiti & 4 & .046 & .041 & .011 & .039 & .063 & 4211 & 15665 \\
\hline Honduras & 18 & .045 & .036 & .024 & .01 & .105 & 152 & 2931 \\
\hline total & 371 & .173 & .149 & .118 & .01 & .748 & 114 & 23884 \\
\hline
\end{tabular}

Notes: This table shows summary statistics for province-level estimates of upward IGM. Upward reflects the likelihood that children, aged 19-25, whose parents have not completed primary schooling will manage to complete at least secondary education. "Total" shows the unweighted summary statistics across all provinces. The columns "Nmin" and "Nmean" report respectively the smallest and average sample size across provinces. Provinces with less than 50 observations are omitted. 
Table A12: District-Level Estimates of Upward IGM using primary-to-secondary education

\begin{tabular}{llccccccc}
\hline & & \multicolumn{9}{c}{ upward } \\
\cline { 3 - 8 } country & districts & mean & median & stdev & min & max & Nmin & Nmean \\
\hline Peru & 168 & .395 & .365 & .175 & .084 & .807 & 105 & 785 \\
Cuba & 137 & .338 & .354 & .091 & .149 & .479 & 52 & 81 \\
Bolivia & 80 & .202 & .194 & .095 & .064 & .473 & 150 & 830 \\
Chile & 179 & .2 & .192 & .082 & .04 & .478 & 81 & 421 \\
Dominican Republic & 66 & .193 & .187 & .056 & .067 & .433 & 65 & 635 \\
Costa Rica & 55 & .179 & .181 & .06 & .057 & .304 & 117 & 524 \\
Brazil & 2,040 & .174 & .168 & .079 & -.018 & .471 & 278 & 1990 \\
El Salvador & 103 & .155 & .139 & .076 & .023 & .381 & 87 & 364 \\
Uruguay & 67 & .15 & .144 & .065 & .024 & .355 & 51 & 156 \\
Argentina & 312 & .139 & .14 & .053 & .012 & .325 & 54 & 727 \\
Colombia & 434 & .131 & .115 & .066 & -.097 & .321 & 82 & 816 \\
Venezuela & 157 & .128 & .123 & .046 & .028 & .257 & 190 & 1185 \\
Ecuador & 78 & .126 & .115 & .049 & .026 & .241 & 142 & 1577 \\
Panama & 35 & .123 & .098 & .075 & .011 & .276 & 176 & 663 \\
Nicaragua & 68 & .11 & .101 & .054 & .017 & .232 & 192 & 699 \\
Mexico & 2,331 & .109 & .098 & .068 & -.041 & .635 & 50 & 452 \\
Paraguay & 63 & .077 & .07 & .051 & -.067 & .211 & 153 & 900 \\
Guatemala & 191 & .043 & .039 & .03 & -.005 & .156 & 172 & 655 \\
Honduras & 96 & .037 & .032 & .028 & -.006 & .141 & 152 & 550 \\
Haiti & 23 & .034 & .033 & .024 & -.003 & .103 & 664 & 2724 \\
total & 6,683 & .144 & .127 & .093 & -.097 & .807 & 50 & 1042 \\
\hline
\end{tabular}

Notes: This table shows summary statistics for district-level estimates of upward IGM. Upward reflects the likelihood that children, aged 19-25, whose parents have not completed primary schooling will manage to complete at least secondary education. "Total" shows the unweighted summary statistics across all districts. The columns "Nmin" and "Nmean" report respectively the smallest and average sample size across districts. Districts with less than 50 observations are omitted. 


\section{Transition matrix by country}

Figure A6: Transition matrix by country

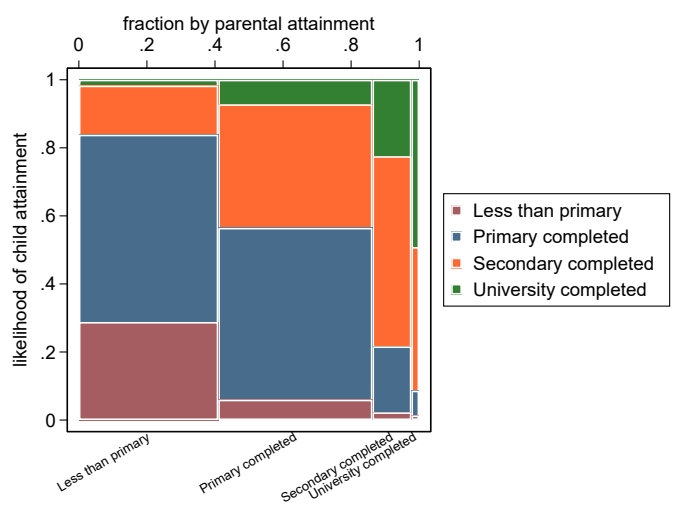

(a) Argentina

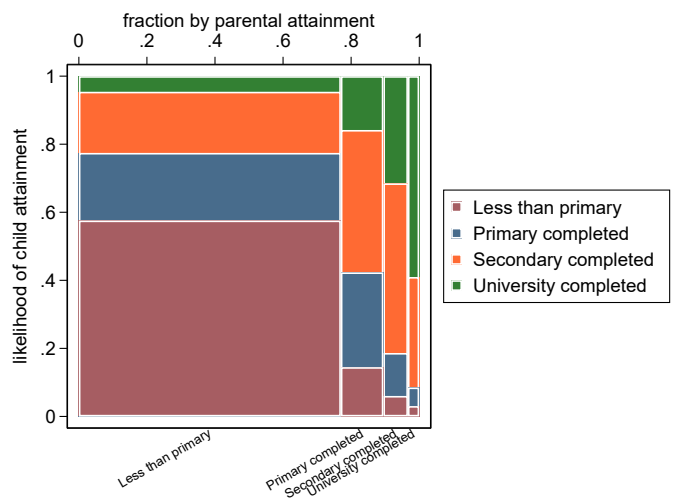

(c) Brazil

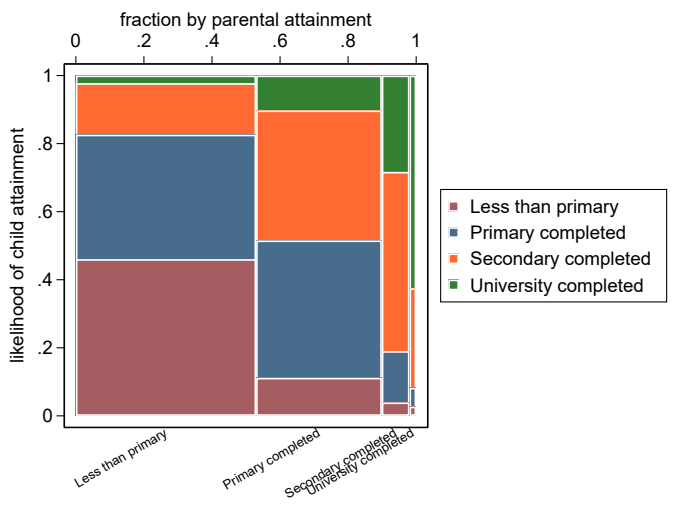

(e) Colombia

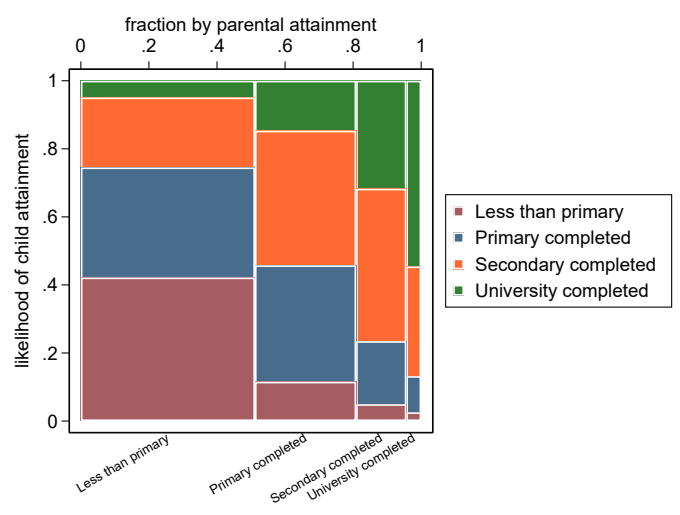

(b) Bolivia

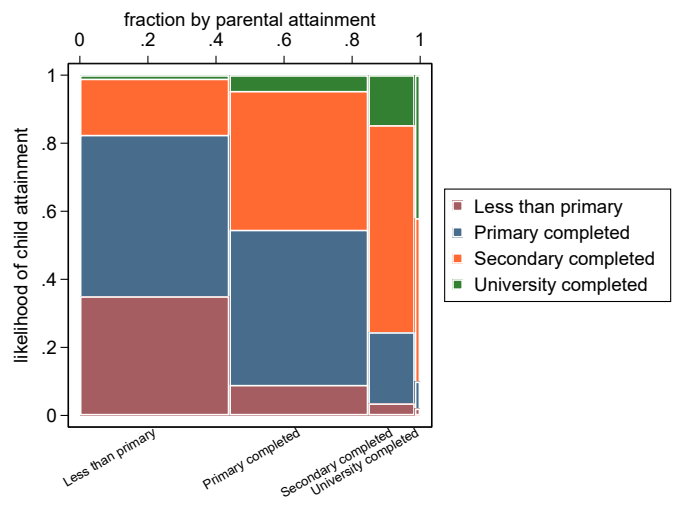

(d) Chile

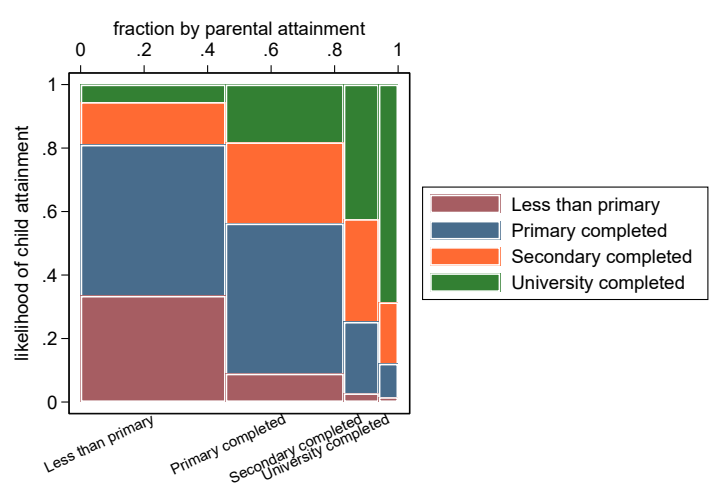

(f) Costa Rica 
Figure A7: Transition matrix by country

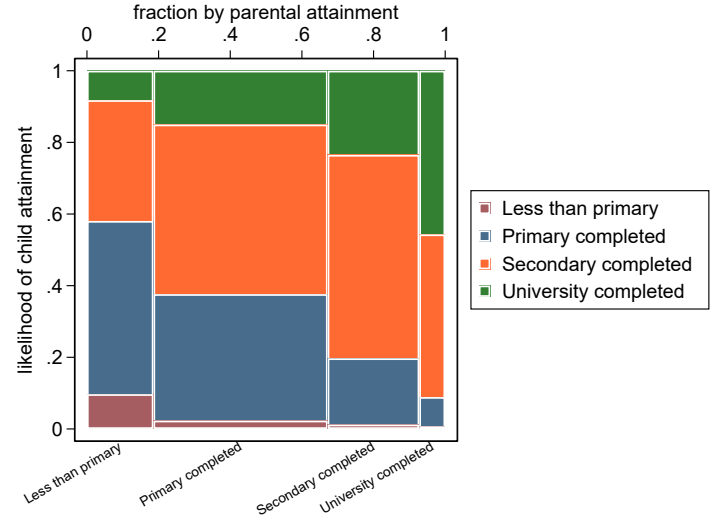

(a) Cuba

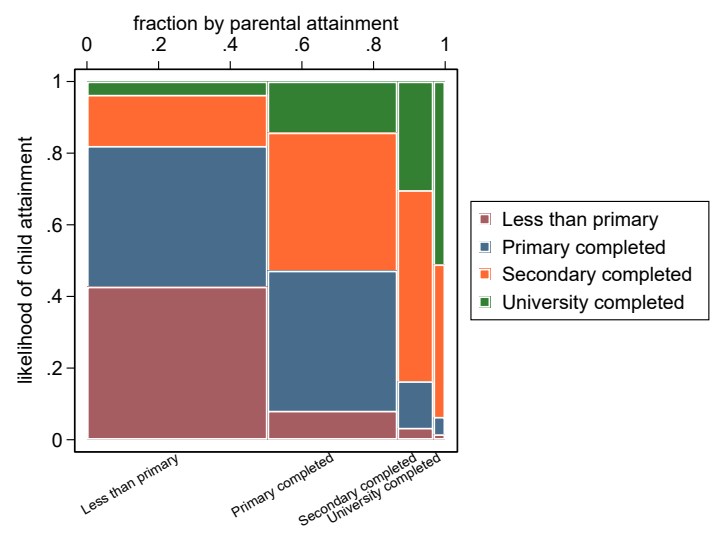

(c) Ecuador

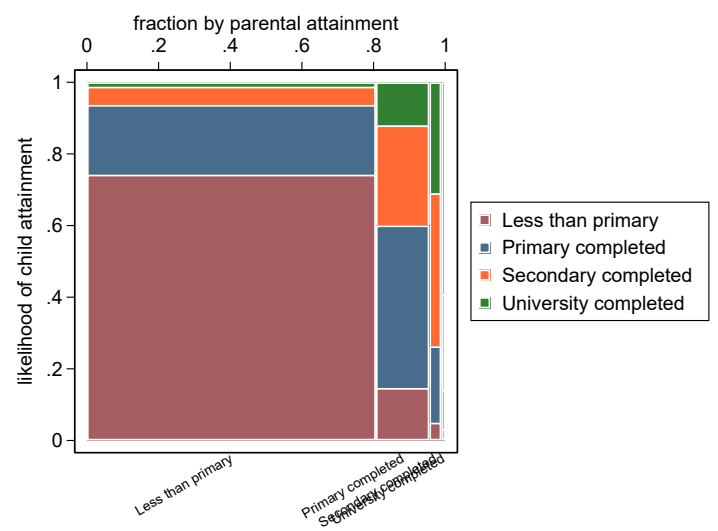

(e) Guatemala

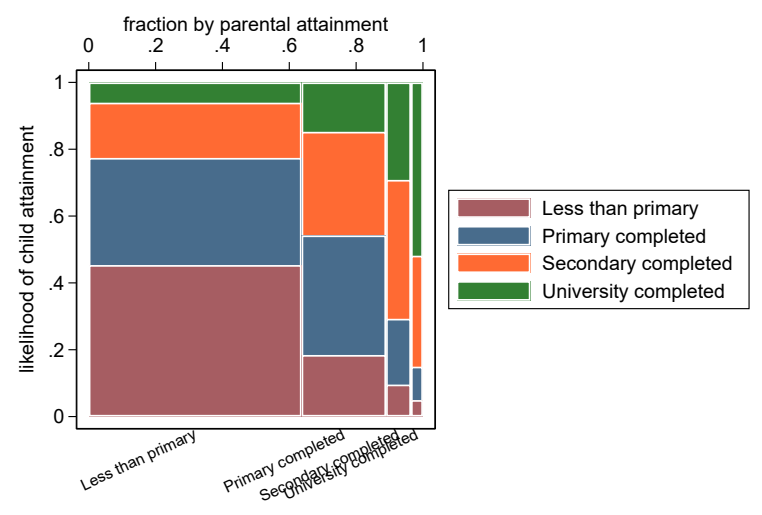

(b) Dominican Republic

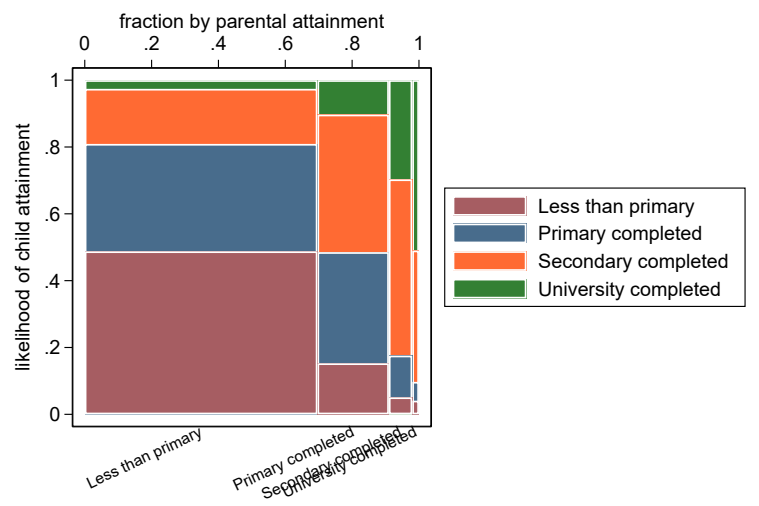

(d) El Salvador

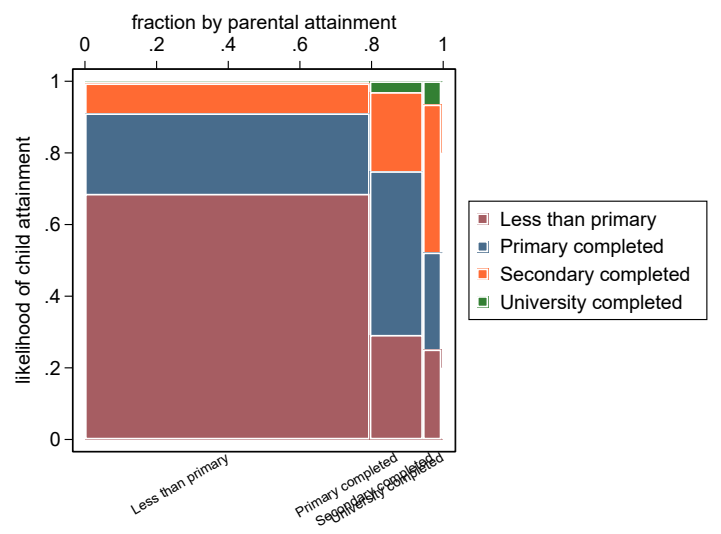

(f) Haiti 
Figure A8: Transition matrix by country

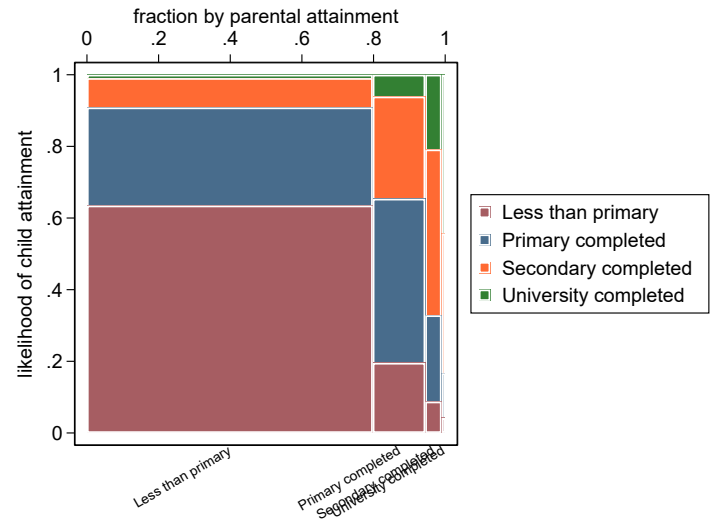

(a) Honduras

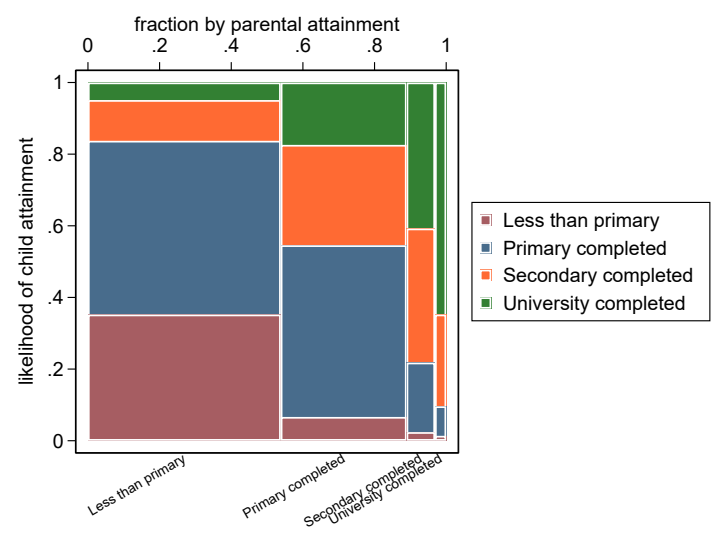

(c) Mexico

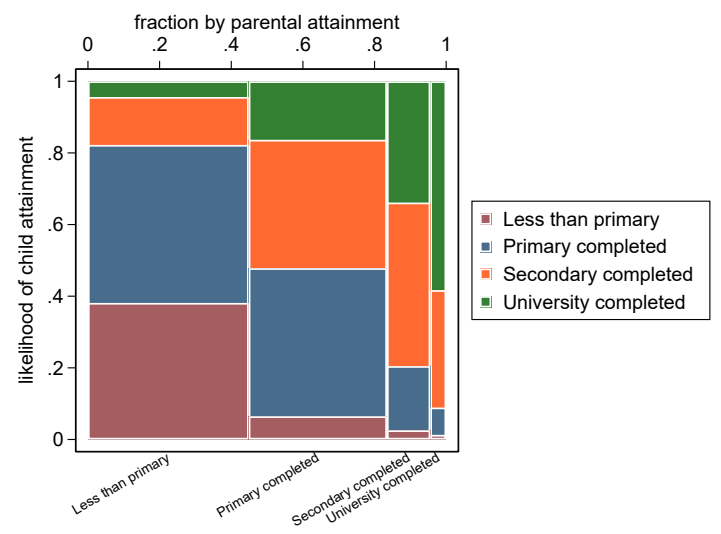

(e) Panama

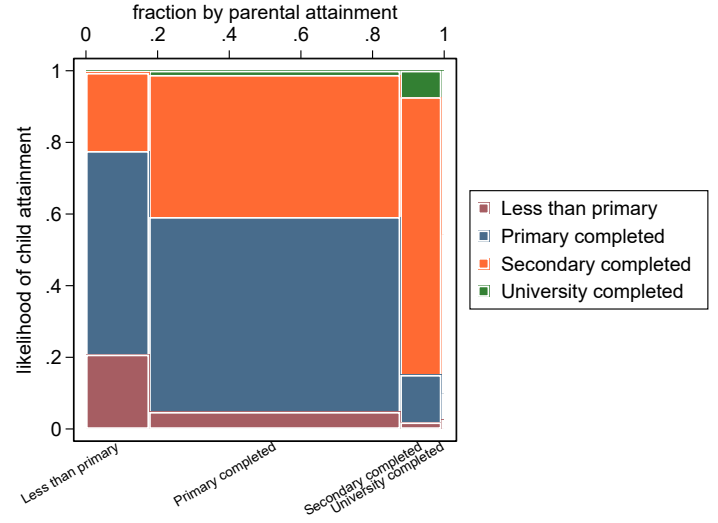

(b) Jamaica

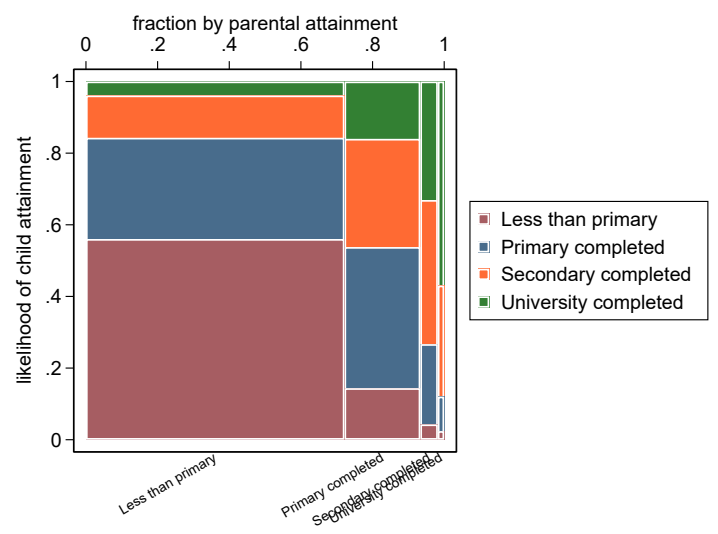

(d) Nicaragua

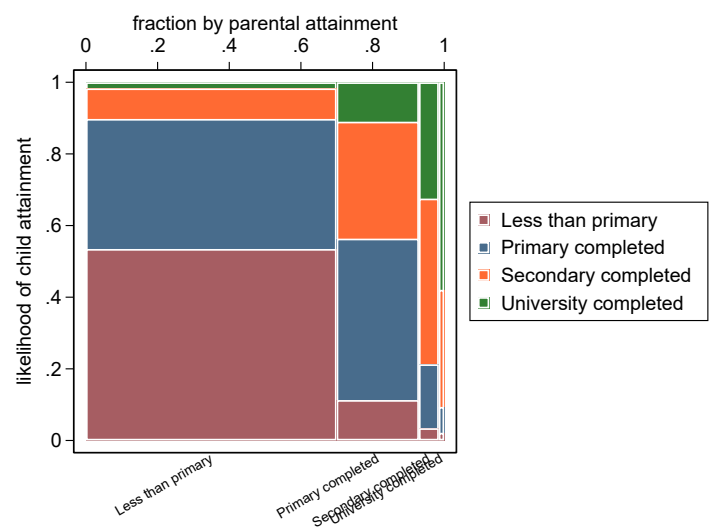

(f) Paraguay 
Figure A9: Transition matrix by country

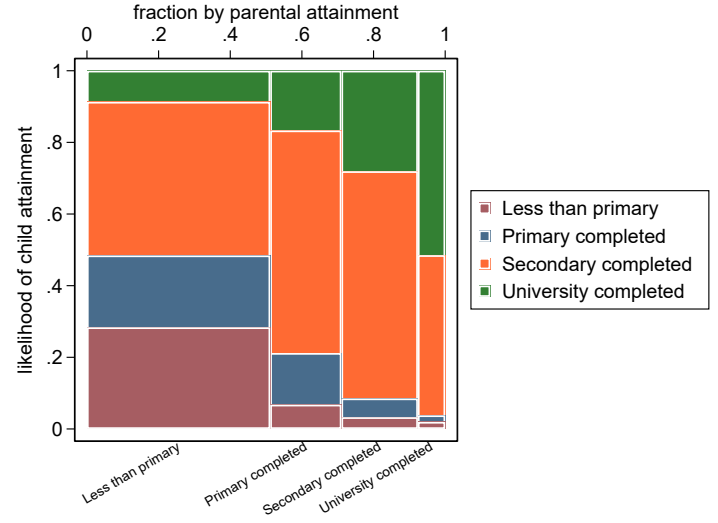

(a) Peru

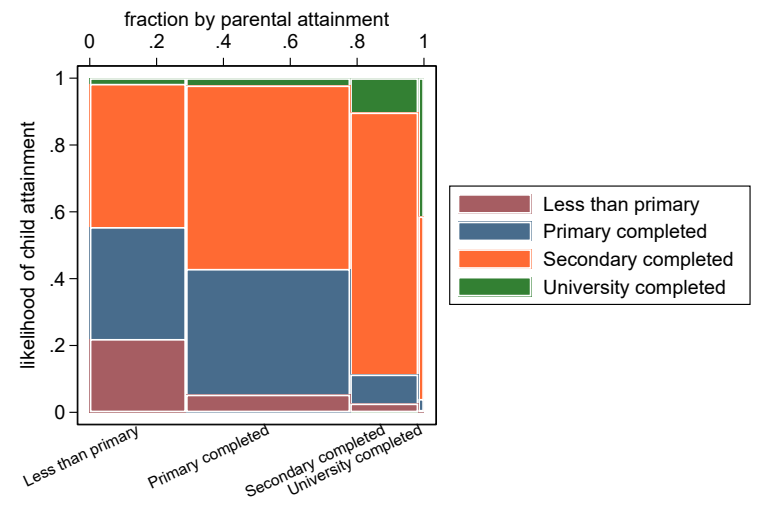

(c) Trinidad and Tobago

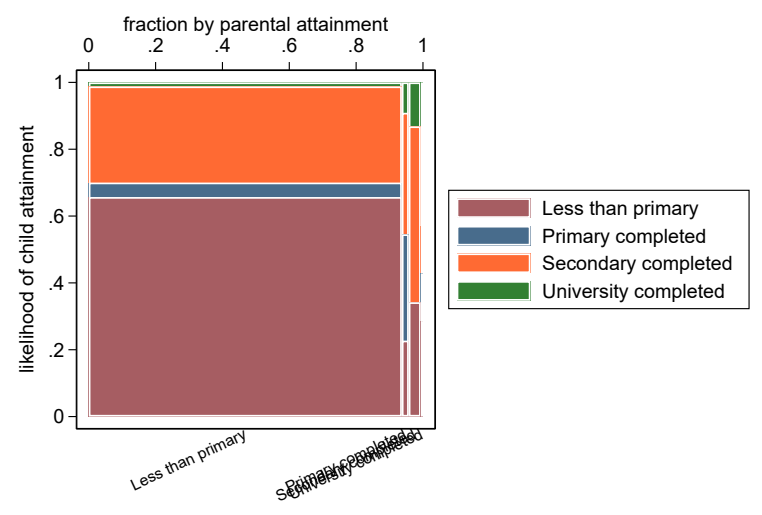

(b) Saint Lucia

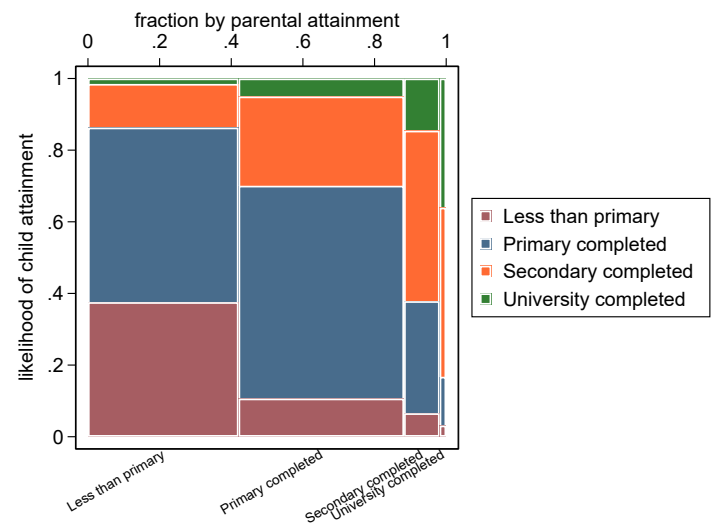

(d) Uruguay

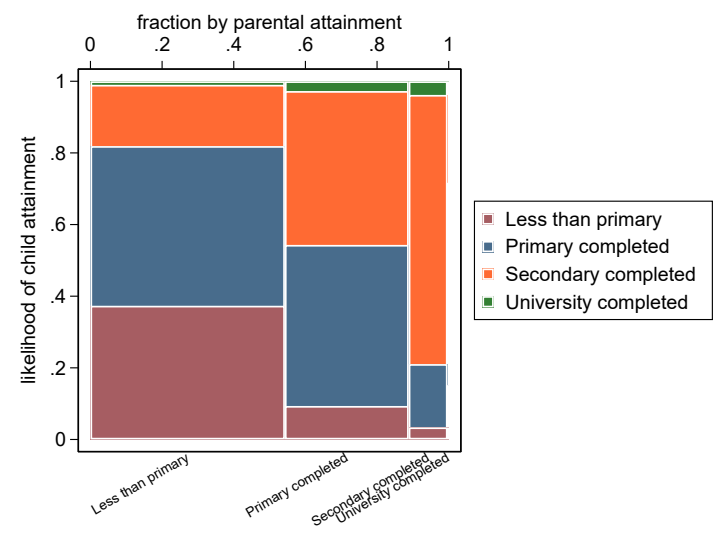

(e) Panama 
Figure A10: Upward and downward mobility are highly negatively correlated

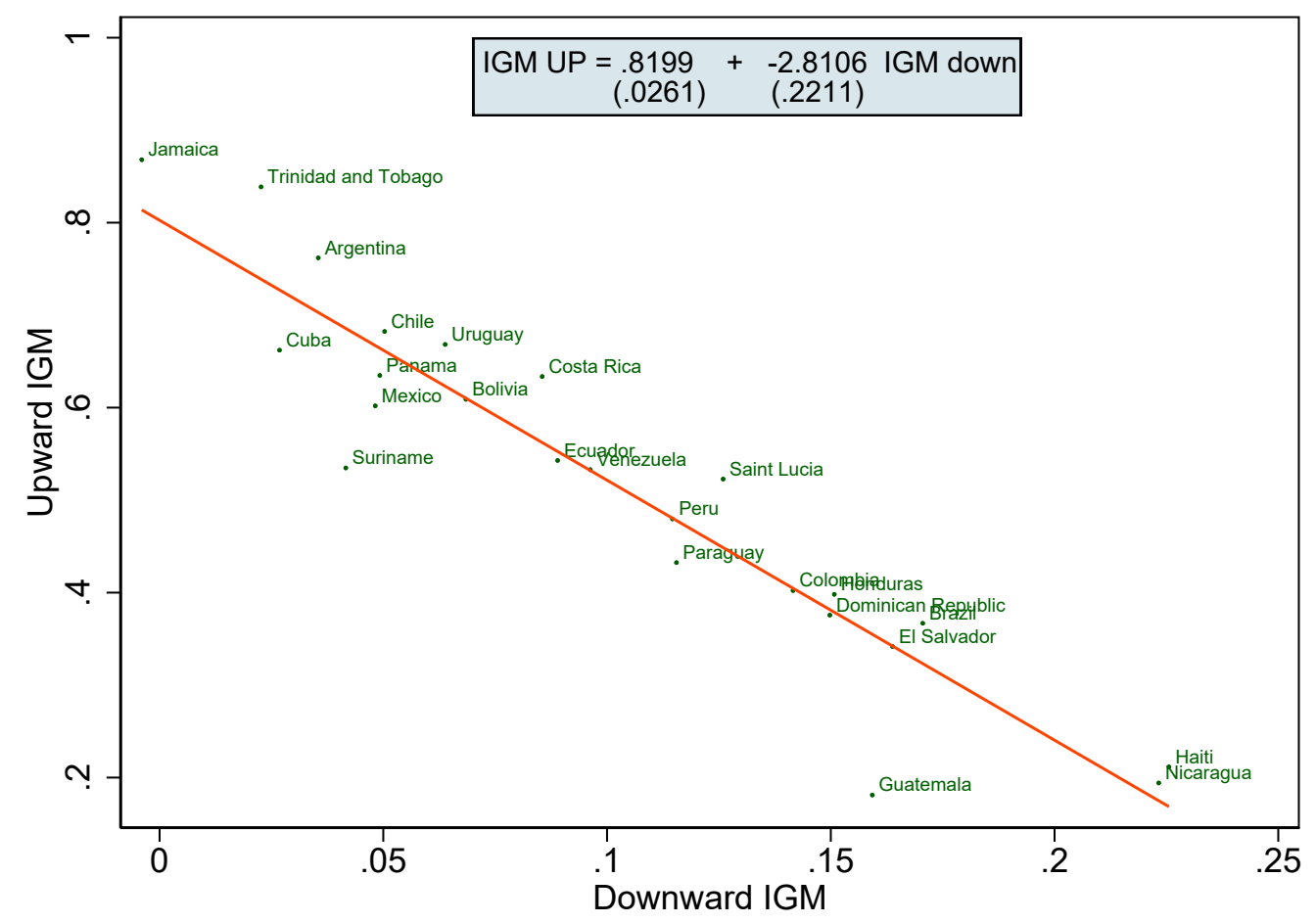

Figure A11: Intergenerational Mobility and Literacy of the Old Generation

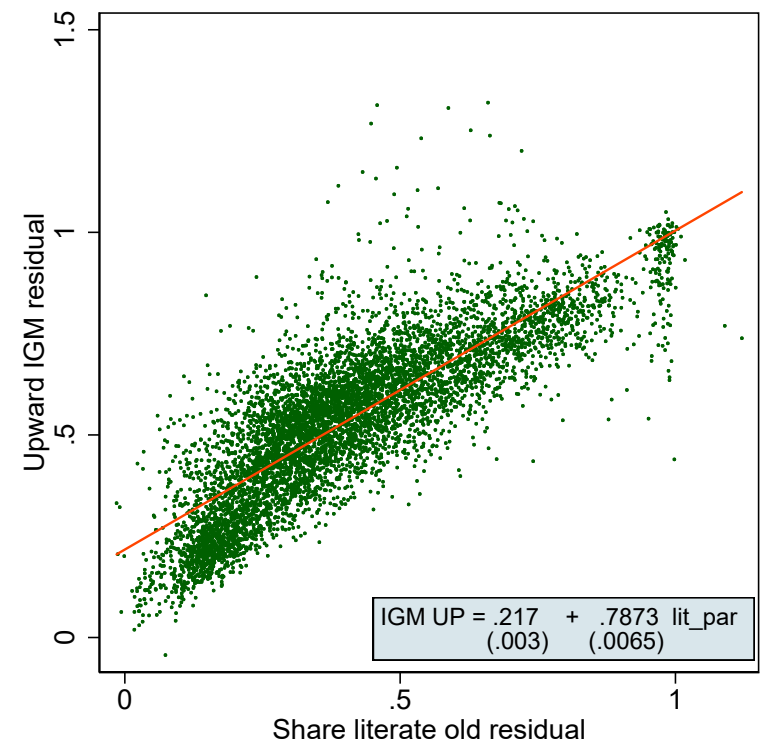

(a) Upward mobility

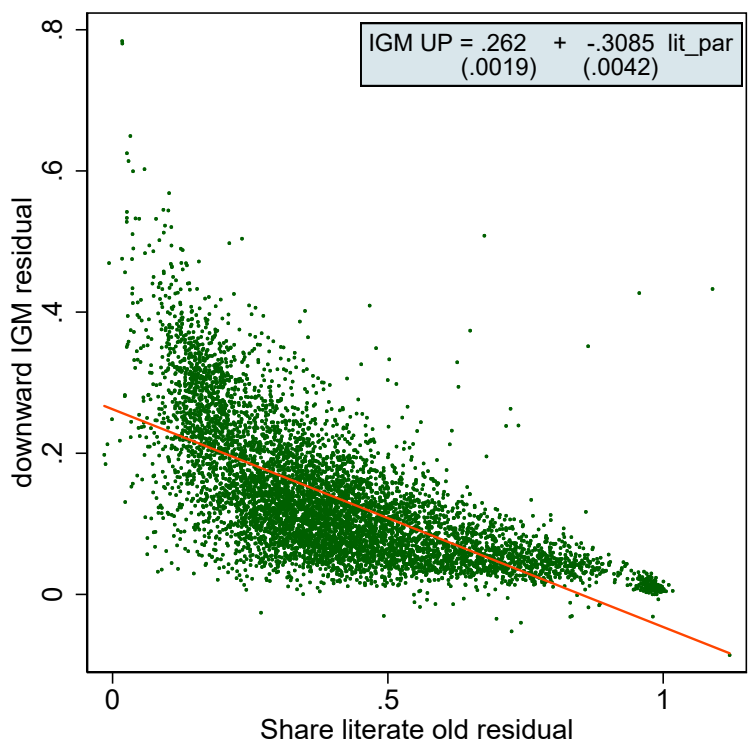

(b) Downward mobility

Notes: This graph uses data at the district-level netting out country fixed effects. 